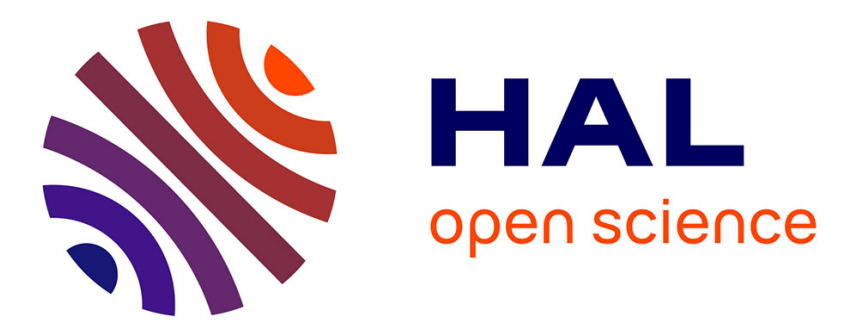

\title{
Les manuscrits rubriqués du "Pèlerinage de vie humaine" de Guillaume de Digulleville (première rédaction), ou comment mettre en chapitres à défaut de mettre en prose
}

Géraldine Veysseyre

\section{To cite this version:}

Géraldine Veysseyre. Les manuscrits rubriqués du "Pèlerinage de vie humaine" de Guillaume de Digulleville (première rédaction), ou comment mettre en chapitres à défaut de mettre en prose. Bibliotheque- Ecole des Chartes, 2016, 170, pp.473-557. hal-01417934

\author{
HAL Id: hal-01417934 \\ https://hal.science/hal-01417934
}

Submitted on 16 Dec 2016

HAL is a multi-disciplinary open access archive for the deposit and dissemination of scientific research documents, whether they are published or not. The documents may come from teaching and research institutions in France or abroad, or from public or private research centers.
L'archive ouverte pluridisciplinaire HAL, est destinée au dépôt et à la diffusion de documents scientifiques de niveau recherche, publiés ou non, émanant des établissements d'enseignement et de recherche français ou étrangers, des laboratoires publics ou privés. 


\title{
LES MANUSCRITS RUBRIQUÉS DU PÈLERINAGE DE VIE HUMAINE DE GUILLAUME DE DIGULLEVILLE (PREMIÈRE RÉDACTION)

\author{
OU COMMENT METTRE EN CHAPITRES
} À DÉFAUT DE METTRE EN PROSE
}

\author{
par
}

Géraldine VEYSSEYRE

Réalisé entre 1460 et 1468 pour Claude de Montaigu et son épouse Louise de La Tour, le manuscrit Londres, British Library, Add. 22937 contient les trois Pèlerinages composés par Guillaume de Digulleville ${ }^{1}$ : aux fol. 1a-74vb le Pèlerinage de vie humaine ${ }^{2}$ (première rédaction, 1330-1331), aux fol. 75a-132a le Pèlerinage de l'âme (v. 1355-1358), enfin aux fol. 132va191b le Pèlerinage de Jésus-Christ (1358) ${ }^{3}$. Les circonstances de sa confection

1. Cet article a été rédigé sous les auspices du Conseil européen de la recherche (European Research Council, ERC), dans le cadre du projet de recherche « Old Pious Vernacular Successes »(OPVS), financé de novembre 2010 à avril 2016 (voir le site internet du projet : www.opvs.fr). Je remercie Marc Smith pour ses suggestions de fond et de forme, qui ont permis d'enrichir cet article et de rendre plus lisibles en particulier les annexes. Les manuscrits les plus fréquemment cités sont les suivants, accompagnés des sigles que nous leur avons attribués dans le cadre de ce projet et qui serviront fréquemment à les désigner dans la présente étude : Bruxelles, Bibliothèque royale de Belgique [désormais : KBR], 10197-10198 : Brux 3; - Londres, British Library [désormais : BL], Additional 22937 : Lond 1; - Paris, Bibliothèque nationale de France [désormais : BnF], fr. 824 : BnF 4; - fr. 1577 : BnF 13; fr. $12462:$ BnF 22.

2. C'est cette œuvre qui sera désignée ci-après sous le titre Pèlerinage.

3. Pour une étude des circonstances dans lesquelles a été produit ce manuscrit, voir G. Veysseyre, « Une trilogie des Pèlerinages à la cour de Bourgogne au milieu du Xv siècle : le manuscrit Londres, British Library, Additional 22937 », dans Mittelalterliche Textualität als Retextualisierung. Das «Pèlerinage »-Corpus des Guillaume de Déguileville im europäischen Mittelalter, dir. Andreas Kablitz et Ursula Peters, collab. Mathias Bode, Sabine Lange, Florian Meyer et Sebastian Riedel, Heidelberg, 2014 (Neues Forum für allgemeine und vergleichende Literaturwissenschaft), p. 312-320.

Géraldine Veysseyre, chargée de recherches à l'Institut de recherche et d'histoire des textes (IRHT, CNRS), 40 avenue d'Iéna, 75116 Paris. <gveyssey@gmail.com> 
d'une part, son contenu d'autre part, placent cette trilogie de Pèlerinages à la croisée de deux traditions présentant par ailleurs peu de points d'intersection : celle des Pèlerinages allégoriques ${ }^{4}$ et celle du genre narratif tel qu'il s'illustra sous forme de proses à la cour de Bourgogne ${ }^{5}$. En effet, cette copie combine des caractéristiques liées à chacune de ces deux familles de textes et de manuscrits, sans être entièrement réductible à aucune : en tant que représentant du genre allégorique, le poème y conserve sa forme versifiée puisque, contrairement à la cour angevine qui commanda une mise en prose du texte, le milieu bourguignon reçut sans adaptation formelle le premier Pèlerinage en octosyllabes ${ }^{6}$. Toutefois, dans la copie de Claude de Montaigu, une concession est faite au goût du public bourguignon du $\mathrm{Xv}^{\mathrm{e}}$ siècle, amateur de proses narratives, romanesques, historiques ou épiques pour la plupart : l'aménagement d'une subdivision en chapitres, unités textuelles matérialisées par des rubriques saillantes et conséquentes.

En effet, la plupart des textes rédigés, compilés ou dérimés en milieu bourguignon ont été structurés en chapitres délimités par des titres intermédiaires. Le procédé prévaut lors de la composition d'œuvres nouvelles aussi bien que lors du dérimage de textes antérieurs ${ }^{7}$. Les rubriques requises en pareil cas ont sans doute été composées par les auteurs eux-mêmes de ces deux types de proses, compositions originales et remaniements. Tel semble bien avoir été le cas pour plusieurs des textes rédigés par Jean Wauquelin, et notamment pour son dérimage de La Manekine de Philippe de Beaumanoir (le père de l'auteur des Coutumes de Beauvaisis) : dans ce cas, Wauquelin est au moins l'auteur de la structuration en chapitres, et sans doute aussi des rubriques elles-mêmes, à moins que la rédaction de ces dernières n'ait été confiée à « une autre personne de [son] atelier montois ${ }^{8}$. Il en va de même

4. Sur le pèlerinage allégorique comme genre littéraire caractéristique du Moyen Âge tardif, voir notamment Siegfried Wenzel, Elucidations. Medieval poetry and its religious backgrounds, Louvain, 2010, p. 39-59, chap. 3 : « The Pilgrimage of Life as a late medieval genre ».

5. Dans son effort pour discerner les caractéristiques générales du genre narratif bourguignon au sein d'un manuel, Michel Zink évoque une « résolution des différents genres littéraires et des modes d'utilisation variés qui leur sont liés en une forme unique, celle de la narration en prose divisée en chapitres » : M. Zink, Introduction à la littérature française du Moyen Âge, Paris, 1993 (Le Livre de poche, 500), à la p. 149, cité par exemple dans Claude Roussel, «Les rubriques de la Belle Hélène de Constantinople », dans Jean Wauquelin, de Mons à la cour de Bourgogne, éd. Marie-Claude de Crécy, avec l'aide de Sandrine Hériché-Pradeau et de Gabriella Parussa, Turnhout, 2006 (Burgundica, 11), p. 201-212, à la p. 201.

6. Voir G. Veysseyre, «Une trilogie... », p. 299-302.

7. Cet usage a été observé et analysé de longue date. En témoigne notamment Georges Doutrepont, Les mises en prose des épopées et des romans chevaleresques du XIVe au XVIe siècle, Bruxelles, 1939, p. 469-475.

8. Maria Colombo Timelli, « La rhétorique épistolaire dans deux mises en prose de Jean Wauquelin : la Manekine et La Belle Hélène de Constantinople », dans Jean Wauquelin, de Mons..., p. 69-88, à la p. 81; recherches approfondies dans Jean Wauquelin, La Manequine, éd. M. Colombo Timelli, Paris, 2010 (Textes littéraires du Moyen Âge. Série Mises en prose, 13), p. 38-44, où l'éditrice commente les titres intermédiaires de la Manekine dérimée par 
dans sa traduction de l'Historia regum Britannie de Geoffroy de Monmouth. Dans ce cas, la concordance - position et teneur - des titres présents dans les deux témoins manuscrits connus de cette «translacion » plaide en faveur du caractère originel de la rubrication ${ }^{9}$. Le dérimage, par Jean Wauquelin, de La Belle Hélène de Constantinople offre un exemple complémentaire : dans la Belle Hélène de Wauquelin, l'analogie de style qui unit corps du texte et rubriques plaide pour un concepteur unique ${ }^{10}$. Au total, les méthodes de composition qui ont prévalu pour ces trois proses semblent caractéristiques de l'ensemble des œuvres du même auteur ${ }^{11}$; et sans doute de la majorité de ses homologues. Il semble bien qu'en milieu bourguignon au moins, les rubriques intermédiaires et le corps d'un dérimage doivent être attribuées à un même auteur, à défaut de preuves du contraire. Ainsi en va-t-il même pour les proses dont il ne reste qu'un témoin, comme le Roman du chastelain de Coucy et de la dame de Fayel, conservé dans le seul manuscrit Lille, fonds Godefroy, $50^{12}$. Un argument de type génétique pèse dans son cas : le roman en vers qui est la source de ce dérimage est connu par deux copies réalisées au XIII ${ }^{\mathrm{e}}$ siècle et dépourvues, l'une comme l'autre, de toute rubrique intermédiaire ${ }^{13}$.

\section{Rubriques ET Mise EN CHAPITRES DANS LA TRADITION des Pèlerinages de Guillaume de Digulleville.}

1. Une structuration originelle ou seconde? - Une telle unanimité de copies continues ne prévaut pas dans la tradition manuscrite du Pèlerinage en vers. Il est vrai que celle-ci compte presque soixante-dix témoins ${ }^{14}$, dont la

Wauquelin en supposant que celui-ci en était l'auteur sans exclure absolument qu'il faille « attribuer la responsabilité des rubriques à une autre personne de l'atelier de Wauquelin ou au copiste du manuscrit de Turin » (ibid., p. 79).

9. Il s'agit, pour cette traduction intitulée Roman de Brut, des manuscrits BL, Lansdowne 214, et KBR, 10415-10416 (G. Veysseyre, « Translater » Geoffroy de Monmouth : trois traductions en prose française de l' « Historia regum Britanniae », thèse de doctorat, Univ. Paris-IV Paris-Sorbonne, 2002, 5 vol., t. IV, p. 2-6).

10. La concordance de plusieurs copies ne joue pas ici, le ms. KBR, 9967, étant la seule copie subsistante de cette prose : Jean Wauquelin, La Belle Hélène de Constantinople, mise en prose d'une chanson de geste, éd. Marie-Claude de Crécy, Genève, 2002 (Textes littéraires français, 547), p. I.

11. «Sans qu'on puisse le prouver de manière indubitable, il nous paraît très vraisemblable que Wauquelin est bien l'auteur, ou le concepteur, des rubriques introduites dans ses œuvres » (C. Roussel, « Les rubriques... », p. 212, n. 34).

12. Danielle Quéruel, «La naissance des titres : rubriques, enluminures et chapitres dans les mises en prose du $\mathrm{xv}^{\mathrm{e}}$ siècle », dans $A$ plus d'un titre. Les titres des oeuvres dans la littérature française du Moyen Âge. Actes du colloque (18 et 19 mai 2000), éd. Claude Lachet, Lyon, 2000 (CEDIC, 17), p. 49-60, aux p. 50-53.

13. Il s'agit des manuscrits $A(\mathrm{BnF}$, fr. 15098) et $B$ (BnF, fr. 7514), décrits ibid., p. 50 .

14. Au total, on connaît à ce jour 69 copies du Pèlerinage de vie humaine tel qu'il a été composé vers 1330-1331. Voir G. Veysseyre, collab. Julia Drobinsky et Émilie Fréger, « Liste 
confection s'échelonne sur plus d'un siècle ${ }^{15}$. L'absence de toute rubrication domine parmi les témoins précoces en vers. Une telle continuité textuelle s'observe notamment dans les manuscrits $\mathrm{BnF}$, fr. $1818^{16}$, fr. $1819^{17}$, et nouvelles acquisitions françaises $10551^{18}$, tous trois antérieurs à 1400 , et parmi lesquels le fr. 1818 au moins consigne un texte particulièrement fiable ${ }^{19}$. Une telle présentation d'octosyllabes copiés en continu demeure possible bien après 1400 , comme le montre la configuration du manuscrit $\mathrm{BnF}$, fr. 1649 , copié entre 1440 et $1490^{20}$. Avec ces quatre manuscrits, la liste des copies continues est assurément incomplète. Reste que ces copies dépourvues de toute rubrication, et dont la plupart sont précoces, sont assez rares et largement minoritaires à l'échelle de la tradition manuscrite du Pèlerinage de 1330-1331. En dépit de leur petit nombre, leur précocité

des manuscrits des trois Pèlerinages », dans Guillaume de Digulleville. Les « Pèlerinages » allégoriques. Actes du colloque de Cerisy, septembre 2007, éd. Frédéric Duval et Fabienne Pomel, Rennes, 2008 (Interférences), p. 425-453, données complétées depuis et maintenues à jour dans G. Veysseyre, « Guillaume de Digulleville, Pèlerinage de vie humaine, $1^{\text {re }}$ rédaction (notice) », dans la base Jonas. Répertoire des textes et des manuscrits médiévaux d'oc et d'oül (IRHT/CNRS), en ligne : http://jonas.irht.cnrs.fr/oeuvre/3955, consulté 19 mars 2015.

15. Dans l'état actuel de nos connaissances, le ms. Munich, Bayerische Staatsbibl., gall. 30, confectionné vers 1348, apparaît comme l'un des deux témoins les plus précoces du Pèlerinage de vie humaine (datation proposée dans Michael Camille, The illustrated manuscripts of Guillaume de Deguileville's « Pèlerinages », 1330-1426, thèse de Ph. D., Univ. de Cambridge, 1985, p. 303), avec le ms. New York, Morgan Library and Museum, 772, daté quant à lui de 1348 (voir ci-après, note 47); ces deux copies sont suivies de près par les mss. BnF, fr. 1577 et fr. 1645, tous deux copiés vers 1350 (ibid., p. 332 et 334). À l'autre extrémité de la chaîne de diffusion, on trouve par exemple les manuscrits $\mathrm{BnF}$, fr. 19186, daté de 1455 par son colophon (G. Veysseyre, Notice du ms. BnF, fr. 19186, dans Jonas, http://jonas.irht. cnrs.fr/manuscrit/73655, consulté 3 avril 2014) ou fr. 1649 (copié entre 1445 et 1485 d'après ses filigranes : G. Veysseyre, Notice du ms. BnF, fr. 1649, dans Jonas, http://jonas.irht.cnrs.fr/ manuscrit/73633, consulté 3 avril 2014).

16. G. Veysseyre, Notice du ms. BnF, fr. 1818, dans Jonas, http://jonas.irht.cnrs.fr/ manuscrit/73635, consulté 3 avril 2014.

17. G. Veysseyre, Notice du ms. BnF, fr. 1819, dans Jonas, http://jonas.irht.cnrs.fr/ manuscrit/73636, consulté 3 avril 2014.

18. G. Veysseyre, Notice du ms. BnF, nouv. acq. fr. 10551, dans Jonas, http://jonas.irht. cnrs.fr/manuscrit/73659, consulté 3 avril 2014.

19. L'édition de 1893 (Guillaume de Digulleville, Le Pèlerinage de vie humaine, éd. Johann Jakob Stürzinger, Londres, 1893 [désormais PVH1]) n'est plus à même de satisfaire pleinement la communauté scientifique. Elle continue toutefois à rendre des services, notamment parce qu'elle se fonde - moyennant les libertés que prend parfois Stürzinger, dont Béatrice Stumpf a présenté la typologie dans « Présentation d'une nouvelle transcription du Pèlerinage de vie humaine (BnF, fr. 1818) et de quelques aspects de la langue des Pèlerinages de Guillaume de Digulleville », communication inédite au colloque organisé à l'université de Lausanne par Stephanie A. Viereck Gibbs Kamath et Marco Nievergelt, The Allegory of Guillaume de Digulleville in Europe, 21-23 juillet 2011 - sur le ms. BnF, fr. 1818, dont la fiabilité est remarquable. Nos collations, pour l'instant partielles, suggèrent qu'aucun autre témoin du Pèlerinage n'est moins fautif.

20. G. Veysseyre, Notice du ms. BnF, fr. 1649, dans Jonas, http://jonas.irht.cnrs.fr/ manuscrit/73633, consulté 3 avril 2014. 
suggère-t-elle que le poème allégorique, très vraisemblablement composé par Guillaume en quatre livres, fut dès l'origine subdivisé plus finement par le moine de Chaalis ${ }^{21}$ ? On pourrait d'abord le croire, notamment sur la foi des manuscrits $\mathrm{BnF}$, fr. 1577 (désigné dorénavant par le sigle BnF 13) et fr. 12462 (sigle : BnF 22), où un apparat régulier de rubriques a été soigneusement écrit de la même main que le reste du texte ${ }^{22}$. Tous deux ont été produits peu après la composition du premier Pèlerinage de Guillaume de Digulleville : $\mathrm{BnF} 13$ date du milieu du $\mathrm{xIV}^{\mathrm{e}}$ siècle ${ }^{23}$. Quant à $\mathrm{BnF} 22$, ses vingt-trois miniatures permettent d'en situer la réalisation dans les années 1340-1350, l'illustration ayant été exécutée à Paris, dans l'atelier de Richard de Montbaston ${ }^{24}$. Rien ne permet de déterminer d'emblée si ces deux témoins sont postérieurs aux trois copies continues mentionnées ci-dessus pour le XIV siècle, ni a fortiori quelles sont leurs positions respectives dans le stemma du poème allégorique ${ }^{25}$. Tout au plus est-on forcé de constater que les titres rubriqués des manuscrits fr. 1577 et fr. 12462 concordent presque en tout point; sans que la conformité structurelle de ces deux manuscrits suffise à faire pressentir en Guillaume de Digulleville un précurseur des méthodes de composition qui prévaudront ultérieurement dans les proses bourguignonnes. De fait ces deux copies, assurément précoces, sont isolées dans la tradition manuscrite du premier Pèlerinage. Or, si Guillaume était

21. La division du récit en « quatre journées de lecture » est matérialisée dans le texte : « suspendant sa narration, et faisant une "pause" [ou "pausee", v. 9046 et 11406], [Guillaume de Digulleville] renvoyait chaque fois ses auditeurs à une autre séance pour entendre la suite » (Edmond Faral, « Guillaume de Digulleville, moine de Chaalis », dans Histoire littéraire de la France, t. 39, 1962, p. 1-132, à la p. 3). Aussi trouve-t-on systématiquement des formules de transition entre chacun des quatre livres, voir PVH1, p. 157, v. 5055-5066; p. 280-281, v. 9043-9054; enfin p. 356, v. 11404-11406. La plupart des copistes du premier Pèlerinage se sont efforcés de faire apparaître cette articulation du texte en quatre parties, notamment en séparant celles-ci par des titres où elles sont souvent désignées par les termes livres ou libri. Il arrive toutefois, notamment dans plusieurs des manuscrits les plus anciens, que les articulations entre les différents livres n'aient donné lieu à aucun effort de mise en texte de la part des copistes, et qu'il faille lire le poème pour les percevoir. Tel est notamment le cas dans le ms. BnF, fr. 1818 : la délimitation entre les différents livres n'y est matérialisée que par des signes qui, loin d'être réservés à ces articulations de premier plan, sont aussi employés à des charnières moins cruciales : tantôt une miniature inscrite au sein de la colonne entre les livres I et II (fol. 45b), tantôt des majuscules ornées, entre les livres II et III (fol. 79vb), puis III et IV (fol. 99vb, après une unité de réglure de blanc). Pour plus de détails, voir G. Veysseyre, Notice du ms. BnF, fr. 1818, dans Jonas.

22. Pour une description et une édition critique de ces rubriques à l'échelle des quelque 7000 premiers vers du Pèlerinage, voir Annexe II, p. 538-555.

23. M. Camille, The illustrated manuscripts..., p. 332.

24. Marguerite Debae, La bibliothèque de Marguerite d'Autriche. Essai de reconstitution d'après l'inventaire de 1523-1524, Louvain, 1995, p. 181-183, notice no 109, où l'auteur invoque l'expertise de François Avril.

25. Le stemma du premier Pèlerinage est en cours d'élaboration, en préliminaire à l'édition du poème aux Classiques français du Moyen Âge (Paris, Champion) par Béatrice Stumpf, avec ma collaboration pour le stemma seulement. 
l'auteur des rubriques qui les scandent, on s'attendrait à ce que cet apparat ait eu une diffusion plus générale.

En effet, si les rubriques peuvent se multiplier au fil des copies successives d'un texte qui en était d'abord dépourvu, le phénomène inverse que constituerait leur suppression, ou même leur allégement, est difficilement concevable : dès lors qu'un texte est innervé de rubriques dans un de ses témoins, ces titres intermédiaires font partie intégrante du matériau à copier. Les différentes générations de manuscrits des Décades de Tite-Live traduites par Pierre Bersuire, dont la circulation est bien documentée, offrent un exemple révélateur quant au statut des rubriques et à leur diffusion : seules les deux copies les plus anciennes, réalisées sous le règne de Jean le Bon, sont dépourvues de rubriques. C'est a posteriori, sous Charles V, que seront conçus pour cette traduction des titres intermédiaires. Or ceux-ci seront repris, et éventuellement adaptés, dans l'ensemble de la tradition postérieure ${ }^{26}$. Les Décades ne furent donc pas subdivisées par Bersuire en chapitres délimités par des titres; les copies présentant le texte en continu, minoritaires, reflètent la traduction française telle qu'elle fut composée au XIV ${ }^{\mathrm{e}}$ siècle.

Les exemples concordants abondent dans le domaine vernaculaire, tous types de textes narratifs confondus. Ainsi des proses arthuriennes: les copies du vaste cycle du Lancelot-Graal sont dès l'origine articulées en

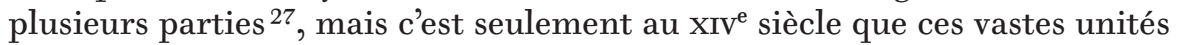
seront subdivisées en quatre-vingt-dix chapitres. L'initiative reste isolée au $\mathrm{XIV}^{\mathrm{e}}$ siècle puisque, parmi les nombreux témoins conservés à Paris, seule la copie en deux volumes $\mathrm{BnF}$, fr. 122 et 123 en porte le témoignage ${ }^{28}$. En revanche, au siècle suivant, cette distribution de la matière arthurienne en chapitres deviendra la norme, non seulement pour le Lancelot-Graal, mais aussi pour des recueils plus larges et composites, comme les manuscrits $\mathrm{BnF}$, fr. 111 et fr. $112^{29}$. Dans ce cas comme dans d'autres, le but recherché serait « la mise en place de procédés permettant à la fois une plus grande lisibi-

26. Marie-Hélène Tesnière, « Les Décades de Tite-Live traduites par Pierre Bersuire et la politique éditoriale de Charles V », dans Quand la peinture était dans les livres. Mélanges en l'honneur de François Avril, éd. Mara Hofmann et Caroline Zöhl, Turnhout, 2007 (Ars nova,15), p. 344-351.

27. Emmanuèle Baumgartner, « Espace du texte, espace du manuscrit : les manuscrits du Lancelot-Graal », dans Écritures II, éd. Anne-Marie Christin et al., Paris, 1985, p. 95-116, aux p. 100-104.

28. Ibid., p. 105.

29. Parmi les témoins tardifs du cycle du Lancelot-Graal, Emmanuèle Baumgartner attire l'attention sur le $\mathrm{ms}$. BnF, fr. 111, en raison de « ses procédés très élaborés de découpage du texte ». De fait, celui-ci isole chaque chapitre par une enluminure et une rubrique (ibid., p. 108 pour la citation), comme dans le manuscrit des Pèlerinages qui nous occupe. Pour l'analyse d'autres manuscrits arthuriens $d u x^{e}$ siècle et des modalités de mise en chapitres des textes qu'ils consignent, voir Cedric Edward Pickford, L'évolution du roman arthurien en prose vers la fin du Moyen Âge d'après le manuscrit 112 du fonds français de la Bibliothèque nationale, Paris, 1959, p. 156-175. 
lité et une plus grande maniabilité du livre manuscrit ${ }^{30}$. Aussi le même phénomène, mû par les mêmes intentions, se laisse-t-il observer au sein d'une tradition manuscrite plus resserrée comme celle de La Belle Hélène de Constantinople anonyme en prose : trois manuscrits en sont conservés, dont la copie $\mathrm{BnF}$, fr. 1489 (P1) « transmet la version la plus ancienne du texte ${ }^{31}$. Or cette dernière est dénuée de titres de chapitre, ce qui permet « de faire remonter l'absence de titres à la forme originelle de la prose ${ }^{32}$. Plus proche du Pèlerinage par sa forme, par son recours au cryptage allégorique, enfin parce qu'il est une source d'inspiration revendiquée par Digulleville $^{33}$, le Roman de la Rose a lui aussi circulé d'abord sans rubriques internes : l'insertion de tels titres intermédiaires ne faisait pas encore partie des habitudes des artisans du livre vernaculaire au XIII ${ }^{\mathrm{e}}$ siècle ${ }^{34}$. De ce caractère adventice découlent, dans les manuscrits postérieurs du Roman de la Rose, des variations importantes quant à la place et au contenu des rubriques ${ }^{35}$. En effet, tout comme pour le Pèlerinage, les copies rubriquées du modèle avoué de Digulleville deviendront rapidement majoritaires ${ }^{36}$.

Parmi les copies du Pèlerinage qui sont antérieures à 1400, trois comportent des systèmes développés de rubriques : $\mathrm{BnF} 13$ et $\mathrm{BnF} 22$, déjà cités, et le ms. Bruxelles, Bibliothèque royale de Belgique, 10197-10198 (dernier

30. E. Baumgartner, « Espace du texte... », p. 113.

31. M. Colombo Timelli, «Pour une "défense et illustration" des titres de chapitres : analyse d'un corpus de romans mis en prose au Xve siècle », dans Du roman courtois au roman baroque : actes du colloque des 2-5 juillet 2002 à l'université de Versailles-Saint-Quentin-enYvelines, éd. Emmanuel Bury et Francine Mora, Paris, 2004, p. 209-232, aux p. 220-221 citant, pour l'étude de la tradition manuscrite de cette prose, un travail alors en gestation, qui a été publié ensuite : Barbara Ferrari, « La Belle Hélène de Constantinople anonyme en prose. La tradition manuscrite », dans L'écrit et le manuscrit à la fin du Moyen Âge, éd. Tania Van Hemelryck, Cécile Van Hoorebeeck, Olivier Delsaux et Marie Jennequin, Turnhout, 2006 (Texte, codex et contexte, 1), p. 121-132.

32. M. Colombo Timelli, « Pour une "défense et illustration"... », p. 221.

33. La référence au Roman de la Rose intervient dans PVH1, p. 1, v. 9-11; elle a souvent été commentée, notamment dans Pierre-Yves Badel, Le «Roman de la Rose » au XIVe siècle: étude de la réception de l'œuvre, Genève, 1980 (Publications romanes et françaises, 153), p. 362-376.

34. Si les rubriques attribuant des discours directs et balisant des dialogues se trouvent, dès le XIII $^{\text {e }}$ siècle, dans des dialogues philosophiques ainsi que dans des traités ou des sommes savantes en latin - notamment dans plusieurs témoins manuscrits du Speculum majus de Vincent de Beauvais -, elles sont beaucoup plus rares, et de toute façon postérieures au Roman de la Rose, en domaine roman (Sylvia Huot, " "Ci parle l'aucteur". The rubrication of voice and authorship in Roman de la Rose manuscripts », dans Sub-stance, t. 17, 1988, p. 42-48, à la p. 44). D'où l'hypothèse émise par $\mathrm{S}$. Huot que ce soit aux copies de ce roman que remonte le recours à ces rubriques brèves, qui se généralisera progressivement dans les romans français (ibid.).

35. Ibid., p. 46, où est soulignée la richesse de telles variations en tant que matériau d'analyse.

36. Ibid., p. 42 : « The Rose was usually provided with an extraordinarily thorough program of rubrication » (je souligne). 
quart du XIV siècle). Ces témoins relativement précoces ont eu peu d'émules parmi les copies du siècle suivant, parmi lesquelles deux sont abondamment rubriquées : les manuscrits $\mathrm{BnF}$, fr. 824 (daté de 144437) et BL, Add. 22937 (vers 1460-1468). La comparaison des chapitres et des rubriques de ces cinq témoins permet d'emblée de mettre au jour des différences d'emplacement et de libellé des titres. On en repère dès les vers 95-168 du Pèlerinage; mais aussi aux v. 202-478; et plus encore entre les vers 2005 et $3358^{38}$. A côté de ces sections où les divergences sont saillantes, nombreux sont les passages où les cinq copies présentent des rubriques relativement homogènes. Néanmoins, si la structuration du Pèlerinage et le libellé des titres intermédiaires avaient été conçus en même temps que le poème allégorique lui-même, les cinq copies rubriquées seraient plus proches encore les unes des autres; et surtout, elles ne seraient pas aussi exceptionnelles dans la tradition manuscrite du Pèlerinage. Or, sans que cette liste de cinq manuscrits dotés de rubriques développées soit encore définitive, elle ne saurait guère être étoffée qu'à la marge. Aussi l'architecte de BnF 13, qui a soigneusement fait coïncider les vignettes et les rubriques articulant l'ensemble du poème, doit-il être considéré comme une exception, au même titre que ceux qui ont confectionné les manuscrits arthuriens BnF, fr. 122 et 123 - à la différence près que $\mathrm{BnF} 13$, ou l'un de ses proches parents, a été imité une fois au moins : dans BnF $22^{39}$.

Pas plus que bien d'autres textes contemporains, les Pèlerinages n'ont été munis, lors de leur rédaction, de titres intermédiaires venant les subdiviser en autant de chapitres. Sont responsables de cette structuration interne les artisans du livre qui ont diffusé le poème du moine de Chaalis : copistes ou rubricateurs, sans doute en concertation avec les miniaturistes et avec leurs commanditaires.

2. Distribuer la parole : la nécessité précoce de structurer les discours directs. - Même si cinq témoins seulement du premier Pèlerinage ont été subdivisés en chapitres délimités par des rubriques développées, nombreuses sont les copies du poème où des rubriques brèves distribuent la parole aux personnages prononçant des discours directs. La matière même du poème appelait un tel apparat : tout comme le Roman de la Rose, son modèle avoué, le Pèlerinage regorge de discours directs, tantôt brefs, tantôt particulièrement développés ${ }^{40}$. Le poème allégorique de Guillaume de Digul-

37. Sur la datation de ce manuscrit, voir ci-après note 61 .

38. On trouvera une édition synoptique des rubriques de quatre de ces cinq manuscrits dans l'Annexe II.

39. Sur les liens de filiation qui se laissent discerner entre BnF 13 et BnF 22, voir ci-dessus p. 5, et ci-dessous, Annexe II, col. 1.

40. Le Testament de Jésus, lu par Charité au sein du livre I, comporte plus de 100 vers (PVH1, p. 77-81, v. 2459-2588); encore est-il particulier en ce qu'il est lu à partir d'un support écrit. À ce titre, Fabienne Pomel l'a classé parmi les « écrits seconds, morceaux détachables 
leville a suscité, dans les copies qui en ont été réalisées, le même arsenal de rubriques brèves que celui de Guillaume de Lorris continué par Jean de Meung ${ }^{41}$. L'édition par Johann Jakob Stürzinger du Pèlerinage intègre cet apparat : sa marge gauche est jalonnée de mentions spécifiant l'identité des locuteurs amenés à prendre la parole au fil du récit, au premier rang desquels « le pelerin » ou « l'acteur », et « Grace Dieu » ${ }^{42}$. Le fait mérite d'être signalé, sachant que ces mentions ne proviennent nullement de la copie que l'éditeur a élue comme témoin de base de son édition : le manuscrit $\mathrm{BnF}$, fr. 1818 est l'un des rares témoins du premier Pèlerinage de Digulleville qui soit dépourvu de toute rubrique, de quelque amplitude que ce soit. Quoique l'éditeur ne précise pas d'où il a tiré ses indications marginales, leur forme et leur contenu incitent à penser qu'elles proviennent de l'une des copies de contrôle mentionnées dans son introduction ${ }^{43}$. Leur adjonction à l'édition $\mathrm{du} \mathrm{XIX}^{\mathrm{e}}$ siècle relève d'une logique comparable à celle qui sous-tendit la réalisation de la majorité des copies médiévales du Pèlerinage : il s'agit de faciliter la lecture du texte allégorique en le dotant d'apparats qui n'étaient pas encore requis par son premier public. De fait, certaines habitudes de lecture se sont sensiblement modifiées entre les premiers témoins du Pèlerinage et les copies du $\mathrm{Xv}^{\mathrm{e}}$ siècle. Les lecteurs du $\mathrm{XIV}^{\mathrm{e}}$ siècle, à l'instar de ceux

et autonomes, caractérisés par des ruptures formelles et un autre art d'écrire que celui de la narration allégorique » dont plusieurs sont insérés dans les divers Pèlerinages (F. Pomel, «Les écrits pérégrins ou les voies de l'autorité chez Guillaume de Digulleville : le modèle épistolaire et juridique », dans The « Pèlerinage » allegories of Guillaume de Deguileville. Tradition, authority and influence, éd. M. Nievergelt et S. A. Viereck Gibbs Kamath, Cambridge, 2013 (Gallica, 32), p. 91-111, à la p. 92 pour la citation, passim pour l'étude de cet « écrit pérégrin »). Ailleurs, des discours directs qui nourrissent la narration allégorique plutôt que de la suspendre peuvent égaler en volume le testament du Christ, et même le dépasser. Ainsi les enseignements de Raison au Pèlerin sur la dichotomie du corps et de l'âme se développent-ils en plusieurs longues séries de vers, régulièrement entrecoupées par les questions du Pèlerin (PVH1, p. 179, v. 5743-5790; p. 181-182, v. 5807-5842; p. 182-183, v. 5847-5874; p. 185-188, v. 5935-6022; p. 189-191, v. 6055-6114; etc.). De même, presque à la fin de son parcours, lorsque le Pèlerin a progressé dans sa capacité à entendre les enseignements et acquis l'aptitude d'écouter longuement sans poser de questions, Grâce de Dieu lui adresse un très long discours sur la mer du monde (ibid., p. 363-368, v. 11607-11781), auquel elle mettra fin en mentionnant précisément le risque de lasser son auditeur : « De li [Satan] te garde, m'en passe | Briefment, que trop ne t'en lasse ». C'est toutefois à Orgueil que semble revenir la palme du plus long discours direct : si Avarice l'emporte par la somme de ses allocutions successives (ibid., p. 285-317, v. 9156-9190, 9202-9276, 9289-9542, 9684 9812, 9817-9898, v. 9905-9978, enfin v. 10117-10218), elle ne parvient pas, comme lui, à assener au Pèlerin 682 vers d'affilée (ibid., p. 231-252, v. 7423-8094).

41. Dans le cas du Roman de la Rose, ce dispositif est étudié dans S. Huot, « Ci parle l'aucteur... », passim.

42. L’expression « l'Acteur » est d'abord privilégiée pour désigner le narrateur, puis le narrateur-Pèlerin (PVH1, p. 1-210); elle cède ensuite la place à la formule « le Pèlerin » qui prévaudra jusqu'à la fin du poème.

43. Voir la liste des huit manuscrits de contrôle que J. J. Stürzinger dit avoir collationnés dans PVH1, p. vi. 
des $\mathrm{XII}^{\mathrm{e}}$ et $\mathrm{XIII}^{\mathrm{e}}$ siècles, étaient accoutumés à fréquenter des textes copiés en continu, au sein desquels les discours rapportés étaient matérialisés par des moyens purement linguistiques, et les articulations par des éléments discursifs. Des lettrines pouvaient venir à l'appui, parfois sous forme de lettres ornées ${ }^{44}$. Cet apparat était plus ou moins mobile, d'un manuscrit à l'autre, selon les textes copiés ${ }^{45}$. D'ailleurs, les lettrines constituaient à elles seules des éléments d'articulation assez saillants pour que leur réaménagement infléchisse le sens du texte et module l'interprétation favorisée par chaque témoin. La démonstration qui en a été faite à partir des différents manuscrits de la Châtelaine de Vergy en fournit un exemple particulièrement éclairant ${ }^{46}$. Quoique l'usage des miniatures et des lettrines ait perduré jusqu'à la fin de l'ère du manuscrit, en particulier dans les copies du Pèlerinage en vers, elles se sont rapidement vu adjoindre des rubriques venant signaler les limites des discours directs, ou en matérialiser la continuité lorsqu'ils sont très développés.

De tels titres rubriqués se sont développés très tôt dans la tradition du Pèlerinage, au point de coloniser presque l'intégralité de ses copies. Leur mise en œuvre est d'autant plus facile que la solution adoptée par J. J. Stürzinger, qui consiste à les imprimer en marge, était déjà loisible à la fin du Moyen Âge pour les artisans du livre : l'introduction de rubriques brèves sous la forme de simples noms de personnages ne supposait pas de concertation préalable entre le rubricateur et le copiste, ni d'attention particulière de la part de ce dernier pour ménager régulièrement les espaces nécessaires à leur réalisation ultérieure. Un tel apparat est présent dès la copie la plus ancienne du Pèlerinage de 1330, le manuscrit New York, Morgan Library

44. Sur la précocité des lettrines, rapidement usitées pour « guider la lecture du texte en mettant en évidence ses principales articulations grâce à l'aspect particulier donné à chaque initiale de section significative », voir Hélène Toubert, « Illustration et mise en page », dans Mise en page et mise en texte du livre manuscrit, dir. Henri-Jean Martin et Jean Vezin, Paris, 1990, p. 355-420, à la p. 379. À titre d'exemple, sur l'usage de la lettrine dans deux célèbres manuscrits du Roman de Troie en vers au XIII ${ }^{\mathrm{e}}$ siècle (mss. BnF, fr. 783, et Paris, Bibl. de l'Arsenal, 3340), voir Geneviève Hasenohr, « Traductions et littérature en langue vulgaire », ibid., p. 231-352, à la p. 251.

45. Faute d'étude synthétique sur le sujet, deux exemples contradictoires montrent les contrastes opposant différentes traditions manuscrites. Mobiles parmi les copies de la Châtelaine de Vergi (Jean-Pierre Bordier, François Maquere et Michel Martin, « Disposition de la lettrine et interprétation des œuvres : l'exemple de La Chastelaine de Vergi », dans Le Moyen Âge, t. 79, 1973, p. 231-250), les lettrines sont au contraire stables dans la tradition manuscrite du roman Cleriadus et Meliadice (M. Colombo Timelli, « Titres, enluminures, lettrines : l'organisation du texte dans quelques témoins de Cleriadus et Meliadice », dans Tra Italia e Francia. Entre France et Italie. In honorem Elina Suomela-Härmä, éd. Enrico Garavelli, Mervi Helkkula et Olli Välikangas, Helsinki, 2006, p. 99-118, à la p. 100). Une telle stabilité permettrait, dans ce cas, de déceler un respect de l'intention auctoriale dans l'aménagement des subdivisions (ibid.).

46. J.-P. Bordier, F. Maquere et M. Martin, « Disposition... ». 
and Museum, 772, daté d'après son colophon de $1348^{47}$ : outre les capitales de couleurs qui y articulent le texte, les discours directs y sont introduits par des rubriques courtes, ces deux types d'apparat étant totalement indépendants des cent dix miniatures en grisaille que l'on a placées, quant à elles, au plus près des vers qu'elles venaient illustrer ${ }^{48}$. Des rubriques analogues sont très répandues dans la tradition manuscrite du premier Pèlerinage sans y être absolument systématiques ${ }^{49}$. Ces « marques de la distribution des voix $\gg^{50}$ deviendront encore plus fréquentes dans les manuscrits du Pèlerinage en prose composé en $1465^{51}$.

La présence d'un tel apparat ne s'observe que dans certains des manuscrits dotés par ailleurs de rubriques plus amples délimitant des chapitres. Ainsi les deux manuscrits les plus précoces (BnF 13 et BnF 22) sont-ils dénués de ces rubriques brèves destinées à faciliter le repérage des discours directs. Par contraste, les trois autres copies abondamment rubriquées en sont pourvues, selon des modalités différentes en matière de mise en page : soit les deux niveaux de rubriques ont une présentation uniforme et ne peuvent être distingués que par leur contenu ${ }^{52}$, soit au contraire une hiérarchie est clairement établie entre eux par la mise en page. Tel est le cas dans le manuscrit de Claude de Montaigu et Louise de La Tour (Lond 1) : les rubriques distribuant les discours directs y sont lapidaires, insérées dans l'espace justifié, mais aux marges du poème, sans qu'aucune réserve ait été ménagée au moment de la copie. À l'inverse, les rubriques structurant le texte en chapitres disposent de réserves généreuses - qui n'ont pourtant pas

47. Colophon édité dans G. Veysseyre, Notice du ms. New York, Morgan Library and Museum, 772, dans Jonas, http://jonas.irht.cnrs.fr/manuscrit/73609, consulté 3 avril 2014.

48. Richard K. Emmerson, « Translating images : image and poetic reception in French, English, and Latin versions of Guillaume de Deguileville's Trois Pèlerinages », dans Poetry, place, and gender. Studies in medieval culture in honor of Helen Damico, éd. Catherine E. Karkov, Kalamazoo, 2009, p. 275-301, à la p. 285.

49. Parmi les quelque 50 copies examinées à ce jour (sur 69), 8 en sont dépourvues : BL, Harley 4399; BnF, fr. 1649 ; fr. 1818; fr. 1819; fr. 19186 ; fr. 24303 ; fr. 24304; Pont-à-Mousson, Bibl. mun. 6.

50. Philippe Maupeu, Pèlerins de vie humaine. Autobiographie et allégorique narrative, de Guillaume de Digulleville à Octovien de Saint-Gelais, Paris, 2009 (Nouvelle bibliothèque du Moyen Âge, 90), p. 299.

51. Ibid., deux manuscrits sont invoqués comme exemples de cette rubrication de la prose : BnF, fr. 12461 et fr. 1137. Pour une description complète, voir G. Veysseyre, Notice du ms. BnF, fr. 12461, dans Jonas, http://jonas.irht.cnrs.fr/manuscrit/73988; et Notice du ms. BnF, fr. 1137, ibid., http://jonas.irht.cnrs.fr/manuscrit/73989, consulté le 3 avril 2014. D’autres copies du Pèlerinage en prose sont pourvues du même apparat, notamment les mss. Bibl. de Genève, fr. 181 et fr. 182; Paris, Bibl. de l'École nat. sup. des beaux-arts, Masson 80; BnF, fr. 1646 (voir G. Veysseyre, Notice du ms. BnF, fr. 1646, dans Jonas, http://jonas.irht.cnrs. fr/manuscrit/73990, consulté 3 avril 2014); Paris, Bibl. Sainte-Geneviève, 294; ou encore Soissons, Bibl. mun. 208 (194).

52. Tel est le cas par exemple dans BnF 13 (voir Annexe II, p. 538). 
toujours suffi - et sont systématiquement associées à une enluminure, ou à une réserve demeurée blanche puisque le manuscrit est resté inachevé ${ }^{53}$.

\section{Chapitres ET RUBRIQUES DANS LE MANUSCRIT BL, AdD. 22937.}

1. Aucun modèle direct. - Parmi les cinq manuscrits dotés de rubriques délimitant des chapitres au sein du Pèlerinage de 1330-1331, trois familles se distinguent ${ }^{54}$ : la première comprend BnF 13 et BnF 22. C'est la plus cohérente quant au contenu et la plus resserrée quant aux dates : entre les rubriques de ces deux manuscrits, les écarts sont très rares. En effet la position des titres intermédiaires coïncide presque toujours - à une seule exception près sur les 7000 premiers vers ${ }^{55}$-, de même que leur formulation ${ }^{56}$. Les fautes qui, dans ces rubriques, sont propres à l'un des deux manuscrits, sont toutes bénignes et aisées à amender ex ingenio ou à l'aide du poème, de telle sorte qu'elles ne permettent pas de préciser la nature des relations de filiation qui unissent les apparats des deux témoins. Toutefois le contenu de la rubrique introduisant le chapitre 16 est plus satisfaisant dans $\mathrm{BnF} 13^{57}$. Sans doute tronqué dans $\mathrm{BnF} 22$ à défaut d'une réserve suffisante, ce titre invite à penser que $\mathrm{BnF} 13$ se situe plus haut que $\mathrm{BnF} 22$ dans le stemma de ces rubriques. La dimension respective des réserves ménagées dans les deux témoins tend à confirmer l'hypothèse. Mieux : l'apparat de BnF 13, joignant une enluminure à chaque rubrique ou presque, invite à y voir un modèle de l'apparat à peine différent, mais beaucoup moins régulier, de $\mathrm{BnF} 22$; à moins que leurs deux apparats ne découlent d'un ancêtre commun.

Par comparaison avec ces deux manuscrits, frères et proches dans le temps, le groupe formé par les manuscrits KBR, 10197-10198 (sigle : Brux 3) et $\mathrm{BnF}$, fr. 824, (sigle : BnF 4) est plus lâche ${ }^{58}$. Plus d'un demi-siècle les

53. Voir annexe II. Seuls deux cas intermédiaires, légèrement problématiques, se distinguent dans l'ensemble du premier Pèlerinage (voir Annexe II, n. 24). Sur la mise en page des rubriques dans Brux 3, voir Annexe II, p. 539.

54. Ce développement gagnera à être lu en parallèle avec l'Annexe II.

55. Jusqu'au v. 6992, fin de l'échantillon, un unique décalage s'observe aux v. 503-796, scindés entre les v. 532 et 533 dans BnF 22 et entre les v. 570 et 571 dans BnF 13. Sur 42 chapitres, c'est un détail.

56. La convergence textuelle des deux séries de rubriques est plus saisissante encore que l'uniformité de leur répartition : même le titre présent dans les v. 503 à 796, dont la position diverge entre ces deux manuscrits, y a un contenu identique - « Comment Raison parle a l'official, qui est prestre de Dieu » (Annexe II, p. 542). Par ailleurs, les rubriques ne divergent que sur des détails, variantes ténues ou fautes bénignes (voir Annexe II, notes 77, 78 et 79, etc.).

57. Titre intermédiaire dans BnF 13 (et Bnf 22) : «Comment Nature fu esbahie de ce mengier que Moÿsés avoit donné »| « Comment Nature fu esbahie de ce mengier »; sans doute écourté faute de place dans BnF 22. Voir aussi Annexe II, p. 544 et n. 96.

58. Voir Gaëlle Cadoret, Étude comparative de la mise en chapitres et des rubriques dans le premier livre de deux manuscrits du « Pèlerinage de vie humaine » de Guillaume de Digulle- 
sépare. Brux 3 est le plus ancien : sans doute du dernier quart du XIV ${ }^{\mathrm{e}}$ siècle, il est à coup sûr antérieur à $1400^{59}$. Son premier possesseur connu fut le duc de Bourgogne Philippe le Hardi ${ }^{60}$. Quant à BnF 4, son colophon permet de le dater précisément de 144,61. Contrairement à ce que ces dates pourraient laisser imaginer, les rubriques de Brux 3 sont plus nombreuses et plus complètes que celles de $\mathrm{BnF} 4$. Pourtant les rubriques des deux manuscrits attestent leur appartenance à une même famille, qui se distingue du couple constitué par BnF 13 et $\mathrm{BnF} 22$ dès le vers 125. Par la suite, la position des rubriques dans les deux paires de manuscrits continuera de converger occasionnellement ${ }^{62}$; mais entre ces points de recoupement, leurs titres intermédiaires ont été disposés différemment ${ }^{63}$. Distincts de ceux de BnF 13 et $\mathrm{BnF} 22$, les chapitres et les rubriques de Brux 3 et BnF 4 sont presque identiques entre eux jusqu'au vers 1502, qui marque le début du débat opposant Nature et Grâce de Dieu sur la question de la transsubstantiation ${ }^{64}$. Par la suite, alors que l'ensemble de ce débat occupe un seul chapitre dans BnF 4, il est subdivisé en cinq sections dans le manuscrit de Bruxelles. De surcroît, alors que $\mathrm{BnF} 4$ ne sépare pas ce débat des développements narratifs qui le suivent, eux aussi entrecoupés de dialogues, Brux 3 annonce explicitement l'évocation du dîner de Moïse par « Ci parole l'aucteur comment Penitance et Charité vindrent au disner Moÿsés... » ${ }^{65}$. Lors du débat ultérieur entre Sapience et Aristote (v. 2921-3301), le même contraste s'observe entre le rubricateur de $\mathrm{BnF}$ 4, qui réunit en un seul chapitre les vers 2987 à 3432, et celui de Brux 3, qui articule le débat scolastique en quatre mouvements ${ }^{66}$.

ville : manuscrit de Bruxelles, KBR 10197-10198; manuscrit de Paris, BnF, fr. 824, mémoire de master 1, Univ. Paris-IV Paris-Sorbonne, 2008.

59. L'iconographie de ce manuscrit a amené les spécialistes à proposer plusieurs fourchettes de dates. La plus récente et la plus large englobe tout le dernier quart du XIV siècle (Dominique Vanwijnsberghe, « Manuscrit 10197-98 », dans La librairie des ducs de Bourgogne. Manuscrits conservés à la Bibliothèque royale de Belgique, t. I : Textes liturgiques, ascétiques, théologiques, philosophiques et moraux, éd. Bernard Bousmanne et Cécile Van Hoorebeeck, Turnhout, 2000, p. 205-207, à la p. 206). Des fenêtres plus étroites avaient été proposées par Michael Camille ou par Camille Gaspar et Frédéric Lyna. Voir la synthèse de leurs conclusions et de leurs arguments dans G. Veysseyre, « Liste des manuscrits... », p. 440, notice $n^{\circ} 24$.

60. Voir par exemple D. Vanwijnsberghe, « Manuscrit 10197-98... ».

61. Ce colophon, où le copiste se nomme, est le suivant : « Galterus Leporis scripsit, anno Domini 1444 » (fol. 265vb, à l'encre bleue, de la même main que le corps du Pèlerinage).

62. Aux v. 168, 502, 796, 830, 932, 1430, 1464, etc.

63. Voir Annexe II.

64. En amont du v. 1502, on ne recense que deux divergences : aux v. 1261-1430, groupés dans BnF 4. alors qu'ils forment deux blocs distincts dans Brux 3 (respectivement v. 12611302 et 1303-1430). À l'inverse, Brux 3 réunit en un même chapitre les v. 1465-1502 alors que $\mathrm{BnF} 4$ les scinde en deux sections très inégales, la coupure intervenant après quatre vers seulement (v. 1464-1467; voir Annexe II).

65. Voir la suite de cette rubrique, Annexe II, p. 546.

66. Sur la structure de ce débat, voir S. A. Viereck Gibbs Kamath, « Rewriting ancient Auctores in the Pèlerinage de la vie humaine », dans Mittelalterliche Textualität..., p. 326-330 (je remercie l'auteur de m'avoir donné à lire son étude avant publication). Dans le manuscrit 
Au total, le premier livre est subdivisé en soixante-quatre chapitres dans le manuscrit de Philippe le Hardi, contre quarante-huit seulement dans $\mathrm{BnF} 4^{67}$. Dans le détail, à chaque fois que la position de ces rubriques coïncide, leur teneur est assez proche pour attester leur parenté ${ }^{68}$. Sachant d'une part qu'il est rarissime que le système des rubriques connaisse des allégements au fil des copies successives, d'autre part que Brux 3 a été réalisé avant $\mathrm{BnF} 4$, on est amené à supposer, en amont de ces deux manuscrits, un modèle antérieur à 1400, dont les titres intermédiaires auraient été développés dans Brux 3 davantage que dans $\mathrm{BnF} 4$.

Les rubriques articulant le manuscrit Add. 22937 de la British Library (sigle : Lond 1) se démarquent des deux familles discernées jusqu'ici, et ce d'abord par leur ampleur. Rien que pour les 7000 premiers vers du poème, elles comptent presque 1500 mots, soit deux fois et demie plus que le couple $\mathrm{BnF} 13$ et BnF 22 (environ 560); sensiblement plus que BnF 4. (près de 1300); presque autant enfin que Brux 3 (un peu plus de 1700).

Encore ces valeurs absolues doivent-elles être rapportées à la fréquence inégale des rubriques : les rubriques du manuscrit ayant appartenu à Philippe le Hardi (Brux 3), bien moins disertes que celles du manuscrit de Claude de Montaigu (Lond 1), sont en revanche plus fréquentes. En effet, le même segment du Pèlerinage est subdivisé en soixante-dix chapitres dans Brux 3 contre cinquante-trois dans $\mathrm{BnF} 4$, et quarante-trois seulement dans Lond 1. Ainsi, plutôt que des manuscrits isolés, ce sont trois familles de rubriques qui se distinguent par leur volume moyen, avec treize mots en moyenne par titre intermédiaire dans $\mathrm{BnF} 13$ et $\mathrm{BnF} 22$ (désormais : famille $\mathrm{R} \mathrm{I}$ ); vingt-cinq dans Brux 3 et BnF 4 (désormais : famille R II); enfin trente-six dans Lond 1 (seul représentant de la famille qui sera nommée par commodité R III). De tels chiffres étayent et précisent l'impression que procure d'emblée une lecture simultanée des trois apparats : Brux 3 et BnF 4. (R II) contiennent des titres deux fois plus développés que ceux de BnF 13 et BnF 22 (R I); le manuscrit de Claude de Montaigu (Lond 1, R III) présentant, quant à lui, le volume moyen le plus important.

La position et le libellé de ces titres intermédiaires permettent-ils de

qui nous occupe, sont détachés les v. 2987 à 3252, v. 3253 à 3306, v. 3307 à 3358, enfin v. 3359 à 3432, ce dernier ensemble servant de transition et introduisant l'une des nombreuses discussions entre le Pèlerin et Grâce de Dieu.

67. À l'échelle des v. 1 à 6500, on compte 70 chapitres dans Brux 3 contre 53 dans BnF 4 .

68. Les rubriques liminaires des 16 premiers chapitres de Brux 3 et BnF 4 coïncident presque mot pour mot, tout en s'opposant nettement aux deux autres séries de rubriques éditées en Annexe II, notamment par la présence systématique, devant l'interrogatif « comme(nt) », d'un support syntaxique : « Ci devise... », « Ci parole... ». Par la suite, bien que les rubriques de Brux 3 et BnF 4 ne soient plus strictement superposables, elles demeurent apparentées. Voir notamment les fol. 11va et $12 \mathrm{a}$, où la seconde est une version enrichie de la première. Le même rapport entre les deux manuscrits s'observe à l'orée du débat entre Nature et Grâce de Dieu, respectivement aux fol. 11va (Brux 3) et 12a (Bnf 4). L'édition synoptique de ces deux séries de rubriques permet de mettre au jour leur proximité, attestant leur parenté. 
confirmer le regroupement précédemment opéré en familles de rubriques? Assurément. Il semble d'abord que ce soit avec la famille R II que Lond 1 présente des affinités. La rubrique liminaire invoquant le modèle du Roman de la Rose, qui tendrait à rapprocher ce dernier des deux manuscrits rubriqués les plus précoces (famille R I), n'est pas déterminante : cette allusion faisant directement écho au vers $11 \mathrm{du}$ Pèlerinage, elle est largement répandue dans la tradition manuscrite du premier poème allégorique de Guillaume, surtout dans les titres initiaux ou finaux ${ }^{69}$, sans impliquer de liens de filiation entre les copies concernées. Les rapprochements qui se font jour par la suite entre le manuscrit de Claude de Montaigu (Lond 1), d'une part, et le couple Brux 3 et BnF 4 (famille R II), d'autre part, sont beaucoup plus significatifs. Ainsi en va-t-il d'abord de deux mentions renvoyant aux enluminures, que l'on trouve, moyennant quelques variantes lexicales, dans les trois manuscrits : « Hystoire comment il songe en dormant en son lit » et «L'istoire est seulement du cherubin qui deffend l'entree ou l'espee » ${ }^{70}$. Nous aurons l'occasion de revenir sur l'incongruité que revêt, dans deux de ces trois copies, cette mention absente des deux manuscrits rubriqués réalisés au milieu du XIV siècle (famille R I). Comme elle est indépendante du texte du poème, sa présence parallèle dans la famille $\mathrm{R}$ III et dans les deux représentants de la famille $\mathrm{R}$ II met au jour la parenté qui unit Brux 3, BnF 4 et Lond 1. Cette parenté, qui se construit par opposition à $\mathrm{BnF} 13$ et $\mathrm{BnF} 22$, est régulièrement confirmée jusqu'à la hauteur du vers 1278. Jusque-là, les analogies qui unissent R II et R III sont récurrentes : « Cy est comment les docteurs sont aux carneaulx, qui enseignent les gens a faire ailles... » ${ }^{71}$, «Cy aprés est comment le pelerin queroit escherpe et bourdon, et en ce querant il rencontra Grace Dieu... » ${ }^{2}$, « Cy est comme le pelerin estoit en la maison de Grace Dieu... » ${ }^{73}$, « Comment l'official emporta les oingnemens et comment il conjoint ung homme et une femme ensemble... » ${ }^{74}$, « Cy dit

69. La mention du Roman de la Rose figure notamment dans les titres initiaux des mss. KBR, II 7844 ( « Cy commance le Romans de l'umain voyage de vie humaine qui est exposé sus le Romans de la Rose »); BnF, fr. 376 (« Cy commence le Pelerinage de humain voyage de vie humainne qui est exposé sus le Romans de la Rose »); fr. 24302 (« Ci commence le Rommans de l'humain lignage, voiage du viel moinne, qui est exposé et pris sur le Romans de la Rose. L'acteur parle »); ou encore dans l'explicit versifié du ms. Paris, Bibl. de l'Arsenal, 5071, fol. 85b : « Cy fine le Roumant du moigne | du pelerinage de vie humaine, | qui est fait pour bon pelerin | qui en ce monde tel chemin | veult tenir que voise a bon port | et qu'il ait du ciel le deport, | pris sur le Romans de la Rose, | ou l'art d'amours est toute enclose. Explicit. »

70. Lond 1; variantes proches dans Brux 3 et BnF 4, éditées dans l'Annexe II, p. 540-541.

71. Lond 1 , entre les v. 94 et 95 , à rapprocher de Brux 3 et BnF 4 par opposition aux deux manuscrits plus précoces (Annexe II, p. 540-541).

72. Lond 1, entre les v. 226 et 227, à rapprocher de Brux 3 et $\mathrm{BnF} 4$ par opposition aux deux manuscrits plus précoces (Annexe II, p. 540-541).

73. Lond 1, entre les v. 502 et 503, à rapprocher de Brux 3 et BnF 4 par opposition aux deux manuscrits plus précoces (Annexe II, p. 542-543).

74. Lond 1, entre les v. 796 et 797, à rapprocher de Brux 3 et BnF 4 par opposition aux deux manuscrits plus précoces (Annexe II, p. 542-543). 
l'acteur comme il vit Raison sermonner au prone en commun et declaire la signifiance du glaive et des clefz, et comment il en doivent user chascun en son office... » ${ }^{75}$. Cette liste, aisée à étoffer à l'échelle de ces quelque 1300 vers du poème, ne peut pas en revanche être prolongée vers l'aval. De fait, après quelque vers d'indécision, c'est à la famille la plus précoce (R I) que le manuscrit de Claude de Montaigu se rallie. Le premier indice de ce rapprochement, signalant l'écart par rapport à la famille R II, intervient dans la rubrique qui sépare les vers 1980 et 1981 : absente de la famille R II, cette rubrique voit sa première partie - « Comment Nature, qui est a genouz, cria merci a Grace Dieu... » ${ }^{76}$ - libellée de manière identique dans les trois autres copies rubriquées ${ }^{77}$. Cet écho, s'il était isolé, pourrait être trompeur, tant cette rubrique est proche du poème lui-même ${ }^{78}$; mais il est suivi, en aval, par d'autres similitudes, comme celle qui unit les rubriques insérées dans les trois manuscrits entre les vers 4344 et 4345 du poème de Guillaume : « Le fourrel de l'espee signifie Humilité, la renge a nom Perseverence et la targe a nom Prudence ${ }^{79}$. Cette rubrique, comme la plupart de celles qui l'entourent, procède par collage d'éléments tirés du poème ${ }^{80}$; mais ceux-ci y sont assez épars, et les formulations assez proches les unes des autres dans les trois copies concernées, pour attester qu'il y a là davantage qu'une coïncidence. De surcroît, à partir du vers 1981, ce ne sont pas seulement les libellés des rubriques qui coïncident bien souvent entre les représentants des familles $\mathrm{R}$ I et $\mathrm{R}$ III : le poème est subdivisé presque constamment aux mêmes niveaux dans Lond 1 et dans la paire $\mathrm{BnF} 13-\mathrm{BnF} 22$, les deux autres copies se singularisant par contraste. L'opposition, en matière de mise en chapitres, entre les deux ensembles de manuscrits est particulièrement frappante à compter du vers 3359 : par la suite, sur plus de trois mille vers, les chapitres ont toujours les mêmes frontières dans Lond 1 et dans les deux copies rubriquées du milieu du XIv siècle.

Le copiste qui a œuvré pour Claude de Montaigu et Louise de La Tour a-t-il eu recours successivement, pour ce premier livre, à deux modèles respectivement apparentés aux deux familles de copies rubriquées qui se distinguaient d'abord? Il semble plus probable que les rubriques aient connu une circulation plus capricieuse encore que le corps des textes qu'elles accompagnent; et que chaque binôme associant un copiste et un rubricateur ait travaillé à infléchir, en fonction d'une commande particulière, des modèles antérieurs. Le fonds commun de cette mise en chapitres et des titres intermédiaires qui

75. Lond 1, entre les v. 796 et 797, à rapprocher surtout de BnF 4 (Annexe II, p. 542-543).

76. Lond 1, fol. $12 \mathrm{vb}$.

77. Voir l'opposition entre Lond 1, BnF 13 (fol. 14a) et BnF 22 (fol. 16a), d'une part, et Brux 3 et BnF 4, d'autre part, Annexe II, p. 544-547.

78. Voir PVH1, p. 63, v. 1984 et 1986.

79. Lond 1 (fol. 23vb), à rapprocher de Brux 3 et BnF 4 par opposition aux deux manuscrits plus précoces, $\mathrm{BnF} 13$ (fol. 29b) et BnF 22 (fol. 34a); voir l'Annexe II, p. 550-551.

80. Voir le détail de ces emprunts dans l’Annexe I, p. 528-537. 
la matérialisent, se laisse entrevoir, dans l'édition synoptique présentée en annexe, à chaque fois que l'ensemble des cinq copies rubriquées convergent dans leurs choix. Ce cas de figure est fréquent lors des premières stations du pèlerinage, jusqu'à l'entrée en scène de Grâce de Dieu ${ }^{81}$. Moins systématique ensuite, une telle unanimité se retrouve occasionnellement, mais va se raréfiant au fur et à mesure que l'on avance dans le Pèlerinage ${ }^{82}$. Ces points de concordances occasionnels, jalonnant le texte de loin en loin, laissent affleurer le socle commun à partir duquel ont travaillé les enlumineurs et les rubricateurs. Chacun a enrichi ce canevas initial, peut-être lié à un programme iconographique minimal. Si l'on voulait situer dans une arborescence stemmatique les séries de rubriques dont on dispose, voici le schéma approximatif auquel on parviendrait ${ }^{83}$ :

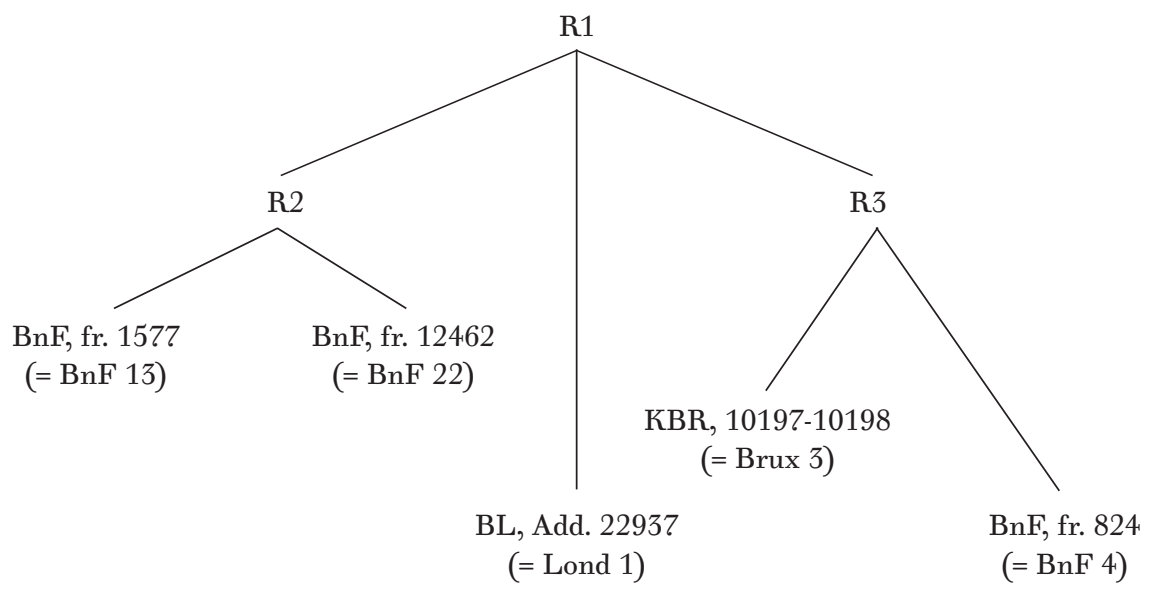

Fig. 1. Familles de rubriques développées du « Pèlerinage».

Le manuscrit Lond 1 n'a donc pas de parent direct parmi les témoins rubriqués qui nous sont conservés. Comme les autres manuscrits articulés en chapitres, il porte la trace de modèles antérieurs qui n'y ont pas été repris littéralement, mais infléchis en fonction d'un projet individualisé.

La place de Lond 1 dans le stemma du texte reste à préciser. En dépit de sa date assez tardive, mes sondages permettent de le classer parmi les nombreuses copies convenables, réalisées par des copistes qui, pour la plupart, se montrent peu interventionnistes. La seule originalité notable consiste à avoir inséré entre les vers 11372 et 11373 deux octosyllabes approximatifs,

81. PVH1, p. 8 , v. 227.

82. L'échantillon montre cette unanimité aux v. 502, 797, 932, 1430, 1464, 3812 et 3908 ; plus jamais par la suite jusqu'au v. 7000, terme de mes comparaisons exhaustives.

83. Les mentions R1, R2 et R3, qui servent à schématiser un ou plusieurs manuscrits perdus, représentent des modèles de rubriques antérieurs ayant disparu. 
qui ne se trouvent à notre connaissance dans aucun autre témoin du premier Pèlerinage ${ }^{84}$. À défaut de liens génétiques, les quatre autres manuscrits rubriqués ont avec Lond 1 des accointances de différentes natures. C'est surtout le cas de la famille R II, découlant du modèle R3. Ainsi Brux 3, qui précède d'un demi-siècle la copie réalisée pour Claude de Montaigu et son épouse (Lond 1), a circulé comme cette dernière en milieu bourguignon, puisqu'il a été possédé par le duc Philippe le Hardi. BnF 4, dont ni le milieu de production ni les possesseurs anciens ne sont connus, se rapproche de Lond 1 par sa date de production et par l'ampleur de son programme iconographique : ces deux témoins du Pèlerinage ont été réalisés au milieu du $\mathrm{XV}^{\mathrm{e}}$ siècle et comportent d'abondantes miniatures, respectivement 93 dans BnF 4 - dont 87 dans le Pèlerinage - et 40 dans Lond 1, suivies là de 43 réserves dans le seul Pèlerinage de vie humaine. Par contraste, le manuscrit des ducs de Bourgogne (Brux 3) n'est orné que de dix miniatures, parmi lesquelles une seule illustre le premier Pèlerinage: son frontispice ${ }^{85}$.

Les liens de cousinage qui unissent les rubriques de ces cinq manuscrits ressortissant à trois familles suggèrent d'emblée que chaque copiste ou rubricateur a composé ces titres intermédiaires en s'inspirant de modèles dont la prégnance a pu traverser plusieurs décennies d'une tradition manuscrite particulièrement dynamique. Dans le détail, la combinaison des ressemblances et des contrastes qu'offrent les diverses réalisations de cet apparat pose plus de questions qu'elle n'en résout. Aussi est-ce dans sa singularité qu'il faut à présent analyser Lond 1 : sa mise en chapitres et ses rubriques n'ayant pas de modèle direct dans la tradition manuscrite du Pèlerinage, tentons de mesurer la marge de liberté dont a bénéficié leur conception, en relation avec les enluminures auxquelles les titres intermédiaires sont constamment associés.

2. La division en chapitres : mise en texte et mise en images. - Dans Lond 1, les 13540 vers du Pèlerinage sont distribués en 82 chapitres par des rubriques assorties d'abord de miniatures effectivement réalisées, puis seulement de réserves ${ }^{86}: 40$ dans le livre I, qui compte 5066 vers $^{87} ; 16$ dans le

84. PVH1, p. 355. Pour une analyse de cette adjonction, riche d'enseignements sur les destinataires du volume, voir Réjane Gay-Canton et G. Veysseyre, « Books exclusively for the laity? The manuscript copies of Guillaume de Digulleville's Pèlerinage de vie humaine (French redaction in verse and German translations) 》, à paraître dans The Mediaeval Journal.

85. G. Veysseyre, « Liste des manuscrits... », p. 427, notice $\mathrm{n}^{\circ}$ 8. Cette rareté des images est concertée : le manuscrit a été achevé, puisque aucune réserve n’a été ménagée dans le texte qui soit restée vierge.

86. À titre d'échantillon, on trouvera dans l'Annexe I la répartition précise des vers dans le premier livre et au début du deuxième livre, et ce jusqu'au v. 6198 (fol. 32vb), où les vignettes cèdent définitivement le pas aux réserves.

87. Le décompte précis du nombre de chapitres suscite quelque hésitation au chap. 14 du livre I, seul à comporter trois rubriques intermédiaires. Nous les avons considérées comme internes, et non pas comme limites entre deux chapitres, bien qu'elles occupent une unité 
livre II, plus bref avec ses 3988 vers; neuf dans les 2352 vers du livre III; enfin 17 dans le quatrième et dernier livre, le plus court avec 2134 vers $^{88}$. À l'échelle de l'œuvre, les chapitres ont donc une longueur moyenne de 170 vers environ.

Ce chiffre est le plus élevé parmi les cinq manuscrits dotés de rubriques développées. Ainsi la longueur moyenne des chapitres est-elle de 96 vers dans Brux 3; d'environ 109 vers dans $\mathrm{BnF} 4$; enfin de 151 vers dans $\mathrm{BnF} 13^{89}$. Reste que ces chiffres moyens tendent à faire oublier un trait commun à toutes ces copies : l'irrégularité des chapitres.

Dans Lond 1, les écarts de gabarit sont spectaculaires, non seulement d'un livre à l'autre, mais dans un même livre. Il est vrai que cette copie ne détient pas l'exclusivité de tels écarts : la longueur des chapitres a souvent été décrite comme irrégulière dans des manuscrits de la fin du Moyen Âge qui transmettent d'autres textes. Tout est question d'échelle. Ainsi dans

de réglure spécifiquement ménagée dans la justification. Certaines caractéristiques invitent à les assimiler aux rubriques brèves copiées ailleurs à côté des vers, à défaut d'occuper une ligne de justification (sur ce second niveau de rubrication, voir ci-après, p. 496). D'abord leur contenu, puisqu'elles annoncent deux discours directs : celui du vicaire à Raison, v. 625-634, introduit au fol. 5b par le titre «Comment le vicaire respond a Raison »; puis la réponse de Raison, objet de deux rubriques insérées avant les v. 635 et 703 : « Cy respont Raison au vicaire » (fol. $5 \mathrm{~b})$ et « Raison respond a l'acteur » (fol. 5vb). La seconde rubrique est d'ailleurs en porte-à-faux, puisque la fin de l'allocution de Raison s'adresse, comme les vers précédents, à Moïse (v. 702-796). Quoi qu'il en soit, ces trois titres sont hybrides : leur contenu et leur fonction les rapprochent des rubriques copiées ailleurs dans les marges et destinées à distribuer les nombreux discours, mais l'espace ménagé dans la justification, ainsi que leur brièveté toute relative, les rapproche des titres de premier plan. Tel est le cas pour la première, qui s'ouvre sur l'interrogatif « comment », amorce habituelle des titres de chapitre (voir ci-après, p. 505-506). De surcroît, la construction d'une véritable phrase autour du noyau verbal respondre oppose ces trois titres intermédiaires des rubriques internes aux autres chapitres et copiées dans les marges, qui se limitent généralement à un nom de personnage; deux seulement sont constituées d'un énoncé verbal ayant pour noyau le verbe dire (voir ci-après, p. 506). Plus encore que ces caractéristiques ambiguës, c'est l'association systématique d'une rubrique de premier plan avec une enluminure - réalisée ou du moins prévue - qui est déterminante. En effet les trois titres copiés aux fol. $5 \mathrm{~b}$ et $5 \mathrm{vb}$ sont enserrés entre deux vers, sans espace pour une miniature. Cet isolement au sein du texte incite à les considérer comme de simples marqueurs des discours directs.

88. Lond 1 propose un texte suffisamment proche de celui du ms. BnF, fr. 1818 pour que le chiffre correspondant à l'édition de J. J. Stürzinger puisse servir de repère. Car, en dépit des nombreuses fantaisies recensées par B. Stumpf dans PVH1, on n'y déplore guère de lacunes, d'ajouts ou d'autres erreurs pouvant fausser la numérotation des vers. Voir B. Stumpf, Lexicographie et lexicologie historique du français, thèse de doctorat, sciences du langage, Univ. Nancy-II, 2009 (en ligne, http://www.cnrtl.fr/corpus/digulleville/documentation.pdf, consulté 4 avril 2014), t. I, p. 3-21; sur l'exactitude de la numérotation des vers dans PVH1, voir ead., « Présentation d'une nouvelle transcription... ».

89. Mes calculs se limitent, dans ce cas, à la première partie du texte (v. 1-6500), soit les chapitres dont l'Annexe II édite en parallèle les rubriques. À cette échelle, Lond 1 présente des chapitres à peine plus longs que pour l'ensemble du Pèlerinage : 168 vers au lieu de 166. $\mathrm{BnF} 22$ a été laissé de côté, sa mise en texte étant presque identique à celle de BnF 13. 
Gérard de Nevers, transposition en prose du Roman de la Violette de Gerbert de Montreuil, les chapitres, « de taille variable », oscillent entre un peu plus d'un feuillet et quatre feuillets et demi, pour une moyenne comprise entre trois et quatre feuillets ${ }^{90}$. Un exemple comparable est fourni par le témoin unique de La Belle Hélène de Constantinople mise en prose par Jean Wauquelin, où les écarts entre le chapitre le plus court, qui compte 32 lignes de prose, et le plus long, de 121 lignes, va également du simple au quadruple ${ }^{91}$. Qui plus est, dans ce dernier manuscrit, les « amplitudes extrêmes sont relativement rares : la moyenne s'établit à environ soixante-six lignes, et près de la moitié des chapitres se situent dans une fourchette allant de cinquante-six à soixante-seize lignes ${ }^{92}$. L'Erec en prose offre un exemple analogue, avec des chiffres compris entre 16 lignes pour son chapitre le plus court et 82 lignes pour le plus long ${ }^{93}$ — écart « sensible » à l'aune de la tradition bourguignonne ${ }^{94}$. On en trouve de plus amples encore dans la mise en prose du Roman du chastelain de Coucy et de la dame de Fayel, conservée par le seul manuscrit BnF, fr. $7514^{95}$ : s'y opposent une majorité de chapitres « très brefs (moins d'une page du manuscrit) 》 et deux chapitres particulièrement longs, comptant respectivement 10 pages environ et 14 pages et demie $^{96}$.

Même dans ce dernier cas, la différence entre le chapitre le plus court et le plus développé est sans commune mesure avec l'irrégularité qui caractérise Lond 1. Dans le Pèlerinage copié pour Claude de Montaigu et Louise de La Tour, l'amplitude exceptionnelle des écarts peut être montrée par plusieurs chiffres, et d'abord par la proportion de presque 1 à 100 qui oppose les deux chapitres les plus brefs, comportant respectivement 12 et 13 vers, au plus développé, qui en compte $1066^{97}$. Les unités brèves sont beaucoup

90. Matthieu Marchal, « Mise en chapitres, rubriques et miniatures dans Gérard de Nevers », dans Mettre en prose aux XIV e $X V I^{e}$ siècles, éd. M. Colombo Timelli, Barbara Ferrari et Anne Schoysman, Turnhout, 2010, p. 187-195, à la p. 188, n. 6.

91. C. Roussel, « Les rubriques... », p. 204.

92. Ibid. D'où l'hypothèse formulée par Claude Roussel que «Wauquelin tente d'équilibrer ses chapitres et de procéder à un découpage homogène du texte en séquences relativement courtes » (ibid.).

93. Les références précises de ces chapitres sont fournies dans M. Colombo Timelli, « Syntaxe et technique narrative : titres et attaques de chapitre dans l'Erec bourguignon », dans Fifteenth-century studies, t. 24, 1998, p. 208-230, à la p. 209.

94. M. Colombo Timelli parle en effet de chapitres « de longueur sensiblement différente » (ibid.).

95. D. Quéruel, « La naissance des titres... », p. 53.

96. François Suard, « Le Chastellain de Coucy: du vers à la prose », dans Richesses médiévales du Nord et du Hainaut, éd. Jean-Charles Herlin, Valenciennes, 2002, p. 25-36, aux p. $26-27$.

97. Le chapitre le plus court est le chap. IV-15 (v. 13262 à 13274, soit 13 vers), dont la rubrique liminaire résume parfaitement le contenu - « Comment les vieillez Enfermeté et Vieillesse assaillirent le pelerin et l'abbatirent et midrent au lit » (fol. 73b) - ; le chap. I-39 (v. 4969 à 4982) est à peine plus long, avec ses 14 vers, et son titre est presque aussi développé 
plus fréquentes que les chapitres de très grande amplitude, de telle sorte que c'est ce chapitre de plus de 1000 vers qui fait figure d'exception. On dénombre en effet jusqu'à 20 chapitres comportant moins de 40 vers, parmi lesquels 16 se trouvent dans la première partie ${ }^{98}$. À l'autre extrémité, on ne compte que 6 chapitres excédant 500 vers ${ }^{99}$; encore cette amplitude demeure-t-elle deux fois inférieure à celle du chapitre le plus long, seul à dépasser 1000 vers.

Par un tel écart de 1 à 100, Lond 1 se distingue nettement des copies de mises en prose qui ont été étudiées à ce jour. En effet les chapitres d'amplitude extrême y abondent, sans aucune sorte d'évolution linéaire : les brusques ruptures de proportions y sont constantes. Le phénomène est flagrant au premier livre ${ }^{100}$; les livres II et IV présentant eux aussi, à une échelle plus modeste, des variations sensibles ${ }^{101}$. Même le livre III, qui ne compte que 9 chapitres, n'échappe pas à la tendance : un premier chapitre de taille moyenne, avec 114 vers, y est suivi des 1066 vers du chapitre le plus long.

Un dernier chiffre enfin illustre cette irrégularité dans Lond 1 : l'écart,

que son contenu même (voir Annexe I, p. 536). À l'autre extrémité, le chapitre le plus long est le chap. III-2 (v. 9169 à 10234, soit 1066 vers), qui appelle un titre fort développé : « Comment Avarice fist monter le pelerin sur une montaigne et li fist regarder une place plainne, la ou il y avoit ung beau moustier et ung eschiquier et pions, sotz, rocz, chevaliers et rois qui veullent abatre l'esclise, et comment elle devise de ses mains et moignons » (fol. 51b).

98. Quatre chapitres comptent 20 vers ou moins : chap. IV-15, I-39 (voir la note précédente), I-5 (v. 125-142 : 18) et IV-1 (v. 11483-11502 : 20). Huit chapitres comptent de 21 à 30 vers (par ordre croissant) : I-2 (v. 35 à $58: 24)$, I-11 (v. 479 à $502: 24)$, I-24 (v. 1981 à 2004 : 24), I-30 (v. 3813 à 3836 : 24), I-6 (v. 143 à 168 : 26), II-1 (v. 5067 à 5092 : 26), I-4 (v. 95 à 124 : 30) et I-36 (v. 4747 à $4776: 30)$. Huit chapitres comptent de 31 à 40 vers : I-12 (v. 503 à 536 : 34), I-13 (v. 537 à $570: 34)$, I-15 (v. 797 à 830 : 34), I-21 (v. 1431 à 1464 : 34), I-1 (v. 1 à 34 : 34), I-3 (v. 59 à 94: 36), II-11 (v. 7257 à $7292: 36)$ et I-37 (v. 4777 à $4814: 38)$.

99. Il s'agit des unités textuelles suivantes : II-5 (v. 5633 à 6198 : 566; la rubrique qui les introduit est éditée en Annexe I, p. 537); II-14 (v. 8191 à 8796 : 606), introduite par «Comment le pelerin, en parlant a Flaterie, vit III aultres vieilles, desquelles l'une, seiche et deffaitte, qui aloit a quatre piez et avoit deux lances en ses deux yeux, nommee Envie, sus son dos portoit II aultres vieilles. L’une avoit afulé ung faulz visaige et tenoit ung glaive et l'auctre tenoit en sa bouche ung os tout sanglant; Traïson et Detraction se nomment » (fol. 46b; titre amendé pour le sens puisque l'on trouve sur le manuscrit «Envie et sus », soit une faute de syntaxe); I-25 (v. 2005 à 2638 : 634; rubrique en Annexe I, p. 534); I-26 (v. 2639 à 3358 : 720; rubrique en Annexe I, p. 534); II-13 (v. 7349 à 8190 : 842), introduite par « Comment le pelerin qui aloit devant Paresse en une hideuse valee vit deux vieilles. L'une appellee estoit Flaterie, qui tenoit ung miroir et portoit l'autre, qui estoit grosse a merveille, qui tenoit a son col ung baston. Ou fronc une corne, en la main un cornet, au costé ung soufflet avoit. Orgueil ditte est 》 (fol. 43a); et III-2, seul chapitre à excéder 1000 vers (voir ci-dessus, note 97).

100. Du chap. I-13 au chap. I-14 puis au chap. I-15, on passe de 34 à 226 vers pour revenir ensuite à 34 vers. De même le contraste est grand entre les chap. I-22 et I-24, d'une part, comptant respectivement 54 et 24 vers, et le chap. I-23 qu'ils encadrent, d'autre part, de 461 vers.

101. Ainsi aux 56 vers du chap. II-12 succède le chap. II-13 avec 842 vers. Au sein du livre IV, la rupture la plus sensible s'observe entre les chap. IV-12, de 48 vers, et IV-13, de 319 vers. 


\begin{tabular}{|l|r|r|r|c|c|}
\cline { 2 - 6 } \multicolumn{1}{c|}{} & PVH1 & Livre I & Livre II & Livre III & Livre IV \\
\hline Moyenne vers/chap. & 166 & 128 & 259 & 269 & 123 \\
\hline Médiane vers/chap. & 89 & 66 & 164 & 114 & 97 \\
\hline Écart type absolu & 199 & 160 & 246 & 329 & 89 \\
\hline Écart type relatif & 1 & 1,25 & 0,95 & 1,23 & 0,72 \\
\hline
\end{tabular}

ТАВ. 1. Longueur des chapitres: Lond 1, livre par livre (valeurs arrondies à l'unité).

à l'échelle du recueil, mais aussi au sein de chaque livre, entre le nombre moyen de vers par chapitre et la médiane correspondante (tab.1).

Â l'échelle du Pèlerinage, l'écart entre médiane et moyenne s'élève presque du simple au double. Il est révélateur de la répartition entre chapitres brefs et chapitres longs : la moyenne est trompeusement gonflée par une poignée de chapitres très volumineux - notamment les six chapitres supérieurs à 500 vers énumérés ci-dessus (note 99) -, alors que plus de la moitié des chapitres restent en-deçà de 89 vers. Cette répartition caractérise surtout les livres I et III, où le rapport entre la médiane et la moyenne est du simple au double, excédant même cette proportion pour le livre III ${ }^{102}$. Aux livres II et IV, les inégalités sont moindres : l'écart type relatif passe dans les deux cas au-dessous de 1 , et le rapport entre moyenne et médiane décroît, jusqu'à 1,58 et 1,27 respectivement. Il n'en reste pas moins que, sur l'ensemble du Pèlerinage, l'irrégularité volumétrique des chapitres demeure le trait dominant.

Poussé à l'extrême dans Lond 1, ce trait caractérise dans une moindre mesure toutes les copies subdivisées en chapitres. Les chiffres portant sur leurs quelque 6500 premiers vers sont significatifs à cet égard ${ }^{103}$ (tab. 2). Dans tous les cas, des chapitres extrêmement brefs ont pu être ménagés. En la matière, Brux 3 et BnF 4 offrent un plancher plus bas encore que Lond $1^{104}$. À l'autre extrémité, des chapitres excédant 500 vers se rencon-

102. Le rapport entre la moyenne et la médiane s'élève pour ce livre à 2,4 .

103. Les chiffres qui caractérisent les 6500 premiers vers du Pèlerinage, subdivisés en 47 chapitres dans Lond 1 , ne se vérifient pas tous lorsqu'on élargit les relevés à l'ensemble du poème. Aussi la comparaison ébauchée entre les quatre copies manuscrites rubriquées gagnerait-elle à être étendue à la totalité de l'œuvre. Un chiffre se maintient, entre l'échantillon retenu de 6500 vers et l'ensemble du Pèlerinage : celui qui mesure la longueur moyenne des chapitres. En effet cette moyenne demeure stable, même si en valeur absolue les disparités sont plus frappantes à l'échelle des 4.7 premiers chapitres que dans la totalité du Pèlerinage. De ce fait, la longueur médiane des chapitres, 67 vers pour les chap. 1 à 47 , passe à 89 si l'on prend en considération l'ensemble du poème. À l'échelle des deux ensembles, l'écart entre moyenne et médiane, dont la valeur absolue varie, demeure important quel que soit le périmètre retenu.

104. Les chapitres les plus brefs de $\mathrm{BnF} 13$ sont comparables à ceux de Lond 1. En effet, leur volume est identique quoiqu'ils ne se situent pas dans le même segment du Pèlerinage : 


\begin{tabular}{|l|c|c|c|c|}
\cline { 2 - 5 } \multicolumn{1}{c|}{} & BnF 13 & Brux 3 & BnF 4 & Lond 1 \\
\hline Nombre de chapitres & 43 & 68 & 60 & 47 \\
\hline Moyenne vers/chapitre & 151 & 96 & 109 & 168 \\
\hline Médiane vers/chapitre & 72 & 56 & 60 & 67 \\
\hline Chap. le plus court (vers) & 14 & 6 & 3 & 13 \\
\hline Chap. le plus long (vers) & 630 & 544 & 844 & 719 \\
\hline Écart type moy./médiane & 56 & 28 & 35 & 71 \\
\hline
\end{tabular}

ТАВ. 2. Longueur des chapitres : les autres mss. subdivisés (v. 1-6502).

trent aussi dans tous ces manuscrits. Leur fréquence est la même, au sein de la première série de chapitres, dans trois des copies : $\mathrm{BnF} 4, \mathrm{BnF} 13$ et Lond 1 en comportent trois chacun sur les 6502 premiers vers ${ }^{105}$. En revanche on en recense un seul dans Brux 3, où la subdivision est plus fine. Et surtout un écart tangible sépare, dans tous les cas, moyenne et médiane : la médiane est largement au-dessous de la moyenne, les chapitres inférieurs à 72 vers étant les plus nombreux et la moyenne étant tirée vers le haut par quelques chapitres particulièrement développés. Toutefois l'écart, qui n'excède pas le rapport du simple au double dans BnF 4, BnF 13 et Brux 3, est plus spectaculaire dans Lond 1 , où il s'élève presque du simple au triple.

$\mathrm{Si}$, au-delà des comparaisons transversales sur le premier tiers du Pèlerinage, on s'intéresse à l'intégralité du poème dans le seul Lond 1, on mesure à quel point les écarts entre les différents livres sont significatifs : que l'on observe le calibre moyen des chapitres ou la médiane qui les caractérise, ces chiffres mettent en lumière un contraste persistant entre les livres I et IV d'une part, constitués d'unités relativement brèves (respectivement 127 et 122 vers en moyenne), et les livres II et III d'autre part, aux chapitres près de deux fois plus longs (respectivement 248 et jusqu'à 267 vers).

Ces écarts trouvent plusieurs explications, la première résidant de toute évidence dans la composition même du Pèlerinage. En effet, la première et la dernière partie panachent de manière assez équilibrée les segments textuels narratifs et les segments discursifs : c'est à l'orée et à l'issue de son parcours

c'est le chapitre formé des v. 4969 à 4982 qui est le plus bref dans BnF 13. On a vu qu'il en va autrement dans Lond 1.

105. Leur situation dans le Pèlerinage coïncide partiellement dans les trois copies. Ainsi, au chapitre composé des v. 2005 à 2630 de BnF 13 répond en partie le chap. I-25 de Lond 1 (v. 2005-2638); et de plus loin le chapitre encore plus vaste de BnF 4. (v. 1503-2346). D'ailleurs, les v. 2005-2346 ne sont jamais dissociés, puisque Brux 3 offre ici un chapitre de 450 vers environ qui les englobe (v. 2005-2458). Ainsi le segment qui met en scène Pénitence offre-t-il une unité intrinsèque qui semble avoir freiné les subdivisions. De telles correspondances, souples mais tangibles, confirment les liens entrevus entre les manuscrits rubriqués. La même convergence s'observe lors du dialogue entre le Pèlerin et Raison qui suit la victoire de cette dernière sur Rude Entendement (v. 5621 et suiv.). 
que le Pèlerin intervient le plus souvent et le plus longuement comme narrateur, pour raconter son pèlerinage et décrire ce qu'il perçoit en chemin. Aux livres II et III, où le Pèlerin est aux prises avec Rude Entendement puis avec les figures allégoriques des sept vices, les dialogues occupent une place prépondérante, le Pèlerin prenant alors beaucoup moins la parole que ses adversaires; et plutôt comme Pèlerin, pour leur répondre, que comme narrateur. La longueur des chapitres de Lond 1 est donc proportionnelle, dans chaque livre, à la part qu'occupent les discours directs : dans les livres les plus riches en amples dialogues (livres II et III) se trouvent les chapitres les plus développés, et dans les livres où le Pèlerin est plus volontiers narrateur et les répliques plus circonscrites, l'encadrement du texte par les rubriques est plus serré. C'est que, dans les parties où les longs débats conflictuels entre le Pèlerin et ses adversaires se succèdent - et où ceux-ci tendent à monopoliser la parole -, le second niveau des rubriques internes, qui distribuent les discours directs, vient compenser l'inconfort qui pourrait résulter d'un espacement excessif des rubriques et, le cas échéant, des miniatures.

Ces rubriques de second niveau, réduites pour la plupart à un nom de personnage, sont présentes dans les marges de 47 des 80 chapitres du poème, soit un peu plus de la moitié. Néanmoins leur répartition n'est pas uniforme : leur fréquence est inversement proportionnelle à la densité des titres plus développés. Dans les livres I et IV, dont les chapitres sont majoritairement brefs, ce sont respectivement 22 chapitres sur 40 et 9 chapitres sur 17 qui sont dénués de rubriques intermédiaires ${ }^{106}$; et même lorsqu'ils en comportent, celles-ci sont très peu nombreuses ${ }^{107}$. À l'inverse, dans les livres II et III, les chapitres dénués de tout titre de second niveau sont rares, entre $10 \%$ et $20 \%$ seulement $^{108}$. Dans les autres, l'articulation peut être extrêmement dense, jusqu'à plus de 15 rubriques intermédiaires par chapitre $^{109}$. Ce cas de figure n'est pas tout à fait exclusif aux deux livres centraux. Absent de la quatrième partie ${ }^{110}$, il s'en trouve du moins une occurrence au livre I, dans le chapitre qui met en scène le long débat entre

106. Les chapitres sans titre intermédiaire représentent $55 \%$ de ceux du livre I et $53 \%$ de ceux du livre IV.

107. Ainsi compte-t-on, dans le livre I et dans le dernier livre, 5 chapitres dotés d'une seule rubrique interne. Le premier livre comporte en outre 3 chapitres dotés de 2 rubriques internes, et un chapitre doté de 3 rubriques internes. Le dernier livre, quant à lui, compte un seul chapitre doté de 2 rubriques internes et 2 chapitres dotés de 3 rubriques internes. Les chapitres comprenant moins de 3 rubriques internes représentent $70 \%$ des chapitres de chacun de ces deux livres ( 28 sur 40 pour le livre I, 12 sur 17 pour le livre IV).

108. Sur les 16 chapitres du livre II, 3 seulement sont dépourvus de rubrique interne, soit $19 \%$; sur les 9 chapitres du livre III, un seul.

109. Un tel développement est rare dans le poème : on compte 16 rubriques internes dans les chap. II-5 (v. 5633 à 6198) et III-3 (v. 10245 à 10686); 20 dans les chap. I-26 (v. 2639 à 3358) et II-8 (v. 6503 à 6904); enfin les chap. II-13 (v. 7349 à 8190) et II-14 (v. 8191 à 8796) en recèlent jusqu'à 26 chacun.

110. Ses deux chapitres les plus riches en rubriques internes sont les chap. IV-6 (v. 11979 à 12244) et IV-14 (v. 13043 à 13261). Or chacun ne compte que 3 rubriques intermédiaires. 
Sapience et Aristote ${ }^{111}$, rapporté par Grâce de Dieu au cours de l'un de ses enseignements les plus prolixes. Dans cette allocution ininterrompue, le risque de monotonie, contraire à l'efficacité didactique, est pallié par l'insertion d'un second niveau de discours rapporté. Grâce de Dieu prête ainsi sa voix tour à tour à Aristote et à Sapience, dont elle commente pour finir la dispute ${ }^{112}$. Avant même qu'elle ne reprenne la parole en son nom propre, la construction des discours rapportés aura atteint à deux reprises un troisième niveau d'enchâssement : d'abord lorsque Sapience rappelle à Aristote l'exemple «du champion qui son savoir | a un povre homme avoit apris | et qui du sien rien n'avoit pris » ${ }^{113}$, ce qui l'amène à citer elle-même les propos du maître et de son apprenti; puis lorsqu'elle s'adresse à lui en tant que « merciere », pour lui faire présent d'une bourse de florins ${ }^{114}$. Guillaume dote ainsi Grâce de Dieu des moyens rhétoriques auxquels il a recours luimême pour capter l'attention des lecteurs, le narrateur tout comme la figure allégorique de la grâce affichant explicitement leur intention didactique et déployant toutes les ressources de la pédagogie. Leurs procédés communs consistent notamment à échafauder des discours rapportés, savamment enchâssés, qui permettent aux personnages prenant longuement la parole de moduler leurs propos. Les deux veillent aussi à varier le rythme des dialogues composés d'un seul niveau de discours rapporté. Le dialogue entre Sapience et Aristote illustre notamment cette recherche : s'ouvrant sur des répliques d'une assez grande amplitude ${ }^{115}$, l'échange s'approche ensuite, au cœur de la joute, d'une stichomythie ${ }^{116}$. Le rubricateur, même sans distribuer toutes ces répliques particulièrement rapprochées, a néanmoins été entraîné, plus qu'ailleurs, à multiplier en marge les mentions de locuteurs. La physionomie de ce chapitre et de son apparat dans Lond 1 atteste l'attention que le rubricateur a portée à la structure du poème et à son contenu : loin de viser à une régularité métronomique lorsqu'il dispose ses rubriques

111. PVH1, v. 2921 à 3306.

112. Sur cet enchâssement, voir S. A. Viereck Gibbs Kamath, « Rewriting ancient Auctores... ». Tout au long du pèlerinage, il faut que Grâce de Dieu déploie toutes les ressources de son art d'enseigner, tant son élève est réticent. Ainsi le poème met-il plusieurs fois en scène, non sans humour, un Pèlerin distrait, obtus ou inapte (un exemple dans F. Pomel, « "Je est un autre" : représentation et connaissance de soi dans le Pèlerinage de vie humaine de Guillaume de Digulleville ou le prisme du "je" allégorique », dans La France latine, t. 132, p. 2001, p. 108-128, à la p. 114). Toutefois, comparé à l'obstination doublée de mauvaise volonté dont Rude Entendement est doté, le Pèlerin parvient à faire bonne figure, lui qui sait lire et accepte de servir Raison (PVH1, p. 162, v. 5201-5256, vers analysés dans R. Gay-Canton et G. Veysseyre, « Books exclusively for the laity?... »). Ailleurs, le Pèlerin est assez souvent rétif aux enseignements délivrés par les personnages qui lui montrent la voie du salut.

113. PVH1, v. 3044 à 3046 .

114. PVH1, v. 3079 à 3087.

115. Voir notamment les propos attribués à Aristote aux v. 2924 à 2986, puis à Sapience aux v. 2989 à 3090.

116. Voir notamment les v. 3130 à 3186 , où une seule réplique excède 10 vers, la majorité des discours rapportés n'occupant qu'un ou deux couplets d'octosyllabes. 
marginales, il module l'apparat en fonction des écarts de rythme savamment ménagés par Guillaume dans les dialogues ${ }^{117}$.

Le copiste a été attentif, lui aussi, à la structure du Pèlerinage et notamment au rythme de la narration, comme le montrent les écarts de répartition entre les chapitres des deux livres médians, d'une part, et ceux des premier et dernier livres, d'autre part. De fait, en ménageant les réserves, il manifeste sa sensibilité à la composition du récit. Alors qu'au début de son parcours le Pèlerin passe rapidement d'un lieu à un autre, d'une rencontre à une autre, le récit progressant par brèves saynètes ${ }^{118}$, les rencontres ultérieures avec chacun des sept vices qui tentent de l'écarter du salut sont beaucoup plus développées ${ }^{119}$. Une fois le Pèlerin arrivé en vue de la nef de religion, au début du livre IV, on retrouve dans la dernière partie du récit un rythme plus rapide et des unités narratives plus brèves entre deux changements de lieu ou d'interlocuteur ${ }^{120}$.

L'écart de longueur entre les chapitres des différents livres et les contrastes nombreux, au sein de chaque livre, entre chapitres contigus, sont ainsi révélateurs de la démarche adoptée par le copiste pour décomposer le poème. L'idée d'offrir au lecteur des jalons réguliers est tout à fait étrangère à son cahier des charges tel qu'il l'a conçu, de son propre chef ou sous l'influence du commanditaire. Privilégiant la cohérence de chaque unité textuelle, il ménage un parcours dont les pauses et les bilans intermédiaires arrivent à une fréquence aussi imprévisible que les apparitions de Grâce de Dieu auprès du Pèlerin. Évitant ainsi toute monotonie, mais aussi tout nivellement des modulations rythmiques voulues par Guillaume, il a placé ses repères selon la construction même du texte. Ce faisant, il s'est abstenu de faire entrer de force le poème dans le moule des mises en prose contemporaines, où la régularité de calibre, au moins relative, était la norme.

Le copiste était aussi tenu de prendre en compte les miniatures qui seraient placées après les rubriques. La mise en page de Lond 1 prévoit la réalisation d'une miniature à la suite de chaque rubrique de premier plan. L'associa-

117. Dans la mesure où les rubriques distribuant les discours directs sont systématiquement consignées dans les marges, c'est bien le rubricateur qui est responsable de leur disposition; à moins qu'il n'ait disposé de consignes du copiste, ensuite rognées, ou qu'il ne se soit inspiré d'une copie précédente où ces rubriques auraient été prévues au sein de la justification. Ce cas de figure est notamment attesté par BnF 4 (voir l'introduction à l'Annexe II).

118. Le calibre des premiers chapitres dans Brux 3, BnF 4 et Lond 1 - qui concordent presque toujours jusqu'à la rencontre du Pèlerin avec Grâce de Dieu, peu après le v. 200 souligne ce rythme des premières stations.

119. Les rencontres du Pèlerin avec les vices qui le guettent sur son chemin occupent un minimum de 257 vers (conversation et combat avec Ire, v. 8797-9054) et un maximum de 1179 vers (entrevue avec Avarice, v. 9055-10234), pour une moyenne de 630 vers environ.

120. La rencontre du Pèlerin avec la mer du monde, avec Satan et avec Hérésie occupe 169 vers (v. 11407-11575); celle avec Jeunesse, 189 vers (v. 11782-11970). Le rythme s'accélère encore lorsque le dénouement du récit approche et que se succèdent Obédience, Vieillesse, Infirmité, Miséricorde, puis la Mort. 
tion, pour articuler le texte, d'une rubrique et d'une illustration est courante $\mathrm{au} \mathrm{Xv}^{\mathrm{e}}$ siècle, que ce soit dans les manuscrits ou dans les incunables. Des exemples en sont notamment fournis par deux témoins du roman Cleriadus et Meliadice - le manuscrit Turin, Biblioteca nazionale universitaria, 1628 (L.II.02) et l'imprimé réalisé en 1495 par Antoine Vérard ${ }^{121}$ - et par le seul témoin du Roman du chastelain de Coucy et de la dame de Fayel en prose où, « dans 40 cas sur 76 la rubrique est accompagnée par une enluminure » ${ }^{122}$. Comme dans le cas présent, la rubrique y précède presque toujours la vignette $^{123}$. On pourrait aisément multiplier les exemples analogues, particulièrement en milieu bourguignon où rubriques et miniatures « marquent visuellement les coupures du récit ${ }^{124}$. Dans Lond 1 , comme dans d'autres Pèlerinages rubriqués et illustrés, la fonction de la rubrique est de ce fait double : « rubrics provided a kind of titulus for the picture as well as the following text $\gg 125$.

Une telle conjonction n'est guère problématique dans le Pèlerinage, divisé en autant de stations du Pèlerin. Une nouvelle unité textuelle est le plus souvent suscitée par un déplacement de ce dernier, par l'entrée en scène d'un nouveau personnage ou par le dévoilement d'une nouvelle figure allégorique, qui fournissent aussi bien le motif d'une nouvelle enluminure. C'est particulièrement vrai des premières stations du Pèlerin, lorsqu'il découvre de quelles manières astucieuses deux des quatre docteurs précédemment évoqués font entrer dans Jérusalem les fidèles dont ils ont la charge ${ }^{126}$. Par la suite, il arrive que deux rubriques consécutives aient un contenu assez semblable pour rendre plus délicate la besogne de l'enlumineur. Ainsi des chapitres I-8 et I-9, respectivement annoncés par les rubriques suivantes : «Cy aprés est comment le pelerin queroit escherpe et bourdon, et en ce querant il rencontra Grace Dieu et parla a elle » (fol. 2vb, en tête des v. 227-294) et « Cy aprés s'ensuit comment Grace Dieu, qui estoit si belle, si paree et aornee d'escharboucles, d'estoilles et ceintte du tissu verd se fait cognoistre au pelerin et si devise qui elle est » (fol. 3b, en tête des v. 295-378). C'est l'un des rares cas où le rubricateur a mêlé, dans deux rubriques successives, le contenu de deux chapitres. Ainsi les attributs de Grâce de Dieu mis en valeur dans la seconde rubrique sont-ils énumérés, logiquement, dès le titre du chapitre précédent qui marque son apparition ${ }^{127}$. Les deux enluminures correspondantes ont

121. M. Colombo Timelli, « Titres, enluminures, lettrines... », p. 100-101.

122. D. Quéruel, « La naissance des titres... », p. 53.

123. F. Suard, « Le Chastellain de Coucy... », p. 27.

124. M. Marchal, « Mise en chapitres... », p. 187. Dans Gérard de Nevers tel qu'il est conservé dans le ms. KBR, 9631 (l'un des deux témoins de cette prose), « rubriques et miniatures participent de la même volonté de clarifier et d'aérer la source : elles sont étroitement associées au texte et sont censées donner un avant-goût du contenu des différents chapitres » (ibid.).

125. M. Camille, The illustrated manuscripts..., p. 36, à propos de $\mathrm{BnF} 13$ et $\mathrm{BnF} 22$.

126. PVH1, p. 5-6, v. 125-142 et 143-168, où la structuration de trois des cinq manuscrits rubriqués coïncide étroitement (Brux 3, BnF 4 et Lond 1).

127. Quoiqu'un un tel phénomène soit assez marginal, il n'est pas tout à fait cantonné à 
un contenu tout aussi similaire : les deux mêmes personnages y conversent au premier plan, devant un paysage dont seuls quelques détails divergent.

Il n'a donc guère été difficile à cet enlumineur de marcher dans les pas du rubricateur. En effet, lorsque deux chapitres consécutifs étaient introduits par des rubriques proches, le peintre pouvait à son tour réaliser deux miniatures similaires. Et dans le cas inverse, lorsque titre et image pouvaient difficilement condenser le contenu d'un chapitre très développé, il suffisait aux deux artisans de renoncer à l'exhaustivité et d'élire, dans l'unité textuelle en question, les éléments les plus essentiels ou les plus propices à la représentation.

\section{LE RUBRICATEUR : UN PASSEUR.}

Dans un article consacré à une mise en prose de Philippe de Vigneulles, Pierre Demarolle nous ramène aux relations entre les rubriques et le texte en rappelant deux des principales fonctions remplies par les rubriques réalisées dans les manuscrits narratifs de la fin du Moyen Âge : « d'une part le titre est supposé rendre compte de la totalité du contenu sémantique du texte en tête duquel il est placé; d'autre part, privilégiant l'essentiel d'un processus (souvent son résultat), il établit une hiérarchie des signifiés, suivant l'importance relative des faits et des circonstances ${ }^{128}$. En composant des titres, l'auteur des rubriques assure en outre une fonction de médiation entre le texte et son auteur, d'une part, et ses destinataires, d'autre part. Ce rôle l'amène inévitablement à proposer une lecture du texte, à en fournir une interprétation. Aussi Sylvia Huot souligne-t-elle d'emblée l'analogie entre les rubricateurs qui sont intervenus dans de nombreux manuscrits du Roman de la Rose et les glossateurs, tous ayant adjoint leur voix et leurs commentaires au poème originel ${ }^{129}$. Au-delà, elle compare l'intervention du rubricateur à celle des acteurs, qui interprétaient les textes non seulement en les mettant en voix, mais en profitant de l'occasion pour les commenter, de manière plus ou moins explicite, devant leur auditoire. Or, de même que les interventions de l'acteur sont indissociablement unies au poème lors d'une performance orale, de même les séquences composées par le rubricateur -

ces deux rubriques. Ainsi la rubrique introduisant le chap. I-17 (v. 933-1000) - « Comment le pelerin demanda a l'evesque Moÿse le glaive et comme Moÿse lui baille sus condicion. L'acteur dit » (fol. 7a) - annonce un segment situé loin en aval dans le poème : c'est seulement aux v. 1273-1278 que le Pèlerin présentera à Moïse sa requête.

128. Pierre Demarolle, « De la narratologie à la syntaxe : les titres des chapitres de la mise en prose de Garin le Lorrain par Philippe de Vigneulles », dans Rhétorique et mise en prose au $X V^{e}$ siècle. Actes du VI colloque international sur le moyen français, Milan, 4-6 mai 1988, éd. Sergio Cigada et Anna Slerca, Milan, 1991, p. 245-255, citation aux p. 246-247 (je souligne); analyse dont la pertinence a été mise à l'épreuve d'un corpus étoffé de mises en prose de la fin du Moyen Âge par M. Colombo Timelli, qui la cite (« Pour une "défense et illustration"... », partic. p. 215 et n. 23).

129. S. Huot, « Ci parle l'aucteur... », p. 42. 
lorsqu'il est différent de l'auteur - partagent avec les vers originels l'espace écrit de chaque manuscrit ${ }^{130}$. Si l'on adopte le point de vue du lecteur, la voix des rubriques précède même continuellement celle du texte; elle est d'autant plus prégnante qu'elle est mise en valeur par sa couleur rouge et par sa brièveté - même relative, comme dans Lond 1. S'y déploie, en amont de chaque unité textuelle, une rhétorique qui obéit à un genre bien distinct de celui du poème allégorique en octosyllabes, et qui pourtant a continuellement partie liée avec lui.

1. Rubriques et marqueterie verbale : la quintessence du «Pèlerinage»? Le rédacteur des rubriques de Lond 1 tire constamment profit de l'élasticité qui caractérise la syntaxe du moyen français pour englober, dans ses titres intermédiaires, le plus d'informations possible. À force de dilater ses phrases, il semble s'être souvent trouvé un peu à l'étroit dans les espaces qui lui avaient été réservés - pourtant généreux, notamment par rapport à $\mathrm{BnF} 13$ et $\mathrm{BnF} 22$.

Contrairement aux rubricateurs de ces copies précoces, l'auteur des titres intermédiaires de Lond1abanniles phrases nominales. Noncontentdecomposer exclusivement des énoncés verbaux, il privilégie les phrases complexes : pas un seul de ses 44 premiers titres ne se présente sous la forme d'une phrase simple, articulée autour d'un seul noyau verbal. Plusieurs verbes sont toujours inclus : coordonnés (10 occurrences sur les 44 premières rubriques) ou hiérarchisés par subordination ( 6 fois) ou encore, dans la plupart des cas (28 fois), reliés par des coordonnants et subordonnants multiples. Certaines rubriques comptent plusieurs unités syntaxiques assez indépendantes pour qu'on puisse les analyser comme des phrases distinctes; ce qui permet d'enchaîner, dans un seul titre intermédiaire, jusqu'à 8 verbes différents ${ }^{131}$.

Ce goût pour l'hypotaxe est très répandu au milieu du $\mathrm{xv}^{\mathrm{e}}$ siècle, notamment à la cour de Bourgogne ${ }^{132}$. Il est aussi caractéristique des mises en prose, au-delà de ce milieu. Ainsi Jean Galopes, dans sa mise en prose du Pèlerinage de l'âme, a-t-il tendance à « verticaliser la syntaxe » de son modèle ${ }^{133}$. Une simple comparaison entre $\mathrm{BnF} 4$ et Lond 1 montre toutefois que le recours à l'hypotaxe varie grandement selon les rubricateurs ${ }^{134}$.

130. Ibid. : « Just as the performer's remarks are external to the text that he delivers and yet an integral part of his overall performance, so the rubric is external to the written text, yet internal to the space of the book. »

131. La rubrique qui précède les v. 2005-2638 ne comporte pas moins de 8 verbes, répartis entre deux phrases indépendantes. Le cas n'est pas exceptionnel.

132. Voir par exemple Jens Rasmussen, La prose narrative française du XVe siècle. Étude esthétique et stylistique, Copenhague, 1958, p. 26 et p. 41-42; F. Suard, « Guillaume d'Orange ». Étude du roman en prose, Paris, 1979, p. 263; etc.

133. Frédéric Duval, « La mise en prose du Pèlerinage de l'âme de Guillaume de Digulleville par Jean Galopes », dans Romania, t. 128, 2010, p. 394-427 et t. 129, 2011, p. 129-160, au t. 129, p. 137.

134. Dans la famille R II, c'est le ms. fr. 824 ( $\mathrm{BnF} 4$ ) qui a été retenu pour cette comparai- 
Alors que celui de $\mathrm{BnF} 4$ compose des phrases à la structure stéréotypée, toutes ou presque s'ouvrant sur un verbe de parole directement suivi d'une complétive, celui de Lond 1 déploie une panoplie beaucoup plus grande de modes de subordination. Il préfère les circonstancielles et les relatives aux complétives, la première catégorie lui offrant un vaste éventail de possibilités. Ce sont ces deux types de construction qui lui permettent de rattacher à une trame principale, dont le contenu rejoint souvent les autres systèmes de rubriques, des détails qui lui sont exclusifs. Propositions temporelles, explicatives et finales articulent, à partir des octosyllabes de Guillaume, un récit circonstancié comme on les aime à la cour de Bourgogne. Quant aux relatives, elles servent à distiller des détails sur les attributs allégoriques, que ses concurrents laissaient au corps du poème la charge de préciser.

Le travail qu'a accompli le rubricateur de Lond 1 s'apparente à une mise en prose particulièrement resserrée, et parfois lacunaire, des trois Pèlerinages en octosyllabes. À ses collègues dérimeurs, il emprunte les techniques de « marqueterie » qu'ils ont mises au point ${ }^{135}$ et qui se déploient notamment dans la mise en prose du Pèlerinage de vie humaine par le clerc anonyme d'Angers ${ }^{136}$. De même, dans les rubriques du manuscrit de Claude et Louise, la matière est démantelée, sélectionnée de manière plus drastique encore que dans une véritable mise en prose, et réorganisée dans le cadre d'une syntaxe hiérarchisée. Les larges contours de la phrase permettent à la fois de laisser de côté aussi peu d'informations que possible et de réorganiser les données du texte dans une construction plus continue, aux articulations logiques et chronologiques plus saillantes.

$\mathrm{Au}$ gré de cette refonte, il convient de renoncer à une partie de la matière de chacun des chapitres, même si la sévérité des coupes varie selon le calibre de ces unités. Pour ce faire, le rubricateur de Lond 1 a presque toujours privi-

son, en vertu de sa date de copie (1444, voir ci-dessus note 61), assez proche de celle de Lond 1.

135. Le terme « marqueterie » est notamment employé par Anne Rochebouet pour caractériser les techniques de composition et d'écriture de la cinquième mise en prose du Roman de Troie, compilation autant que dérimage (A. Rochebouet, «D'une pel tout entiere sans nulle cousture ». La cinquième mise en prose du «Roman de Troie ». Édition critique et commentaire, thèse de doctorat, Univ. Paris-IV Paris-Sorbonne, 2009, p. 311; je remercie l'auteur d'avoir mis à ma disposition son travail en attendant sa publication prochaine aux éditions Classiques Garnier); ou encore par Sandrine Hériché-Pradeau à propos de l'une des compilations de Jean Wauquelin, Les faicts et les conquestes d'Alexandre le Grand, éd. S. Hériché-Pradeau, Genève, 2000 (Textes littéraires français, 527), p. LIX-LXII.

136. Le Pèlerinage en prose étant destiné à une « lecture solitaire, en huis clos », il a été mis en forme dans cette intention. «Inopérant [dans ce cadre], l'encodage de la versification est remis en cause : le prosateur est conduit à accomplir à la fois une déstructuration du texte et sa réécriture. Pour cela, il déplace des éléments de phrase, introduit des mots nouveaux, des formules adaptées, et ainsi invente un balisage différent du texte qui permet au lecteur de trouver ses repères » (Françoise Bourgeois, « Le manuscrit de la reine Charlotte de Savoie ou la renaissance d'un texte », dans Le « Pèlerinage de Vie humaine » en prose de la reine Charlotte de Savoie, éd. Anne-Marie Legaré, Ramsen-Rotthalmünster, 2004, p. 214-223, à la p. 215). Une analyse approfondie des procédés du dérimeur est proposée dans les pages suivantes. 
légié le début des chapitres. Ainsi la rubrique du chapitre I-7 - « Comme saint Pierre tient les clefz de la cité que le seigneur d'icelle lui avoit bailleez » (fol. 2va, en tête des v. 169-226) - n'y fait-elle écho qu'aux deux premiers vers du chapitre : «La clef baillié en avoit | a saint Pierre, en qui se fioit » ${ }^{137}$. Le phénomène compte assurément quelques exceptions, telle la rubrique du chapitre I-19, pourtant assez long (v. 1059-1278), qui synthétise le segment textuel à venir : «Cy dit l'acteur comme il vit Raison sermonner au prone en commun et declaire la signifiance du glaive et des clefz, et comment il en doivent user chascun en son office ${ }^{138}$. De tels cas sont bien rares par rapport aux résumés tronqués qui, rendant compte seulement du début du chapitre - expression qu'il faut entendre, selon les cas, de manière plus ou moins restrictive -, représentent une majorité écrasante ${ }^{139}$. Attendue pour les chapitres les plus développés, cette tendance à la sélection est plus étonnante dans les chapitres relativement brefs. Quoiqu'une telle méthode ne soit pas propre à ce témoin et caractérise plus d'une mise en prose rubriquée de la même époque ${ }^{140}$, elle soulève plusieurs questions sur la manière de travailler et sur la fonction même de la rubrique : le rubricateur se contente-t-il d'une lecture partielle de chaque chapitre? ou bien choisit-il volontairement de mettre en valeur des passages saillants plutôt que de procéder à un découpage homogène? La question rejaillit sur la localisation et le contenu des enluminures. Aux deux niveaux, seule l'étude systématique d'un plus grand nombre de manuscrits rubriqués mènerait à des réponses satisfaisantes.

En attendant, dans le détail, les rubriques de Lond 1 recyclent des fragments dérimés du Pèlerinage, prolongés et liés au moyen de résumés synthétiques élaborés par le rubricateur et de quelques autres adjonctions de son $\mathrm{cru}^{141}$. Ses propres synthèses prédominent en quantité : sur les quelque 1400 mots des 45 premières rubriques, plus de 1000 (soit 80 \%) ressortissent au résumé. Cette masse intègre environ 190 mots tirés du poème ${ }^{142}$. Parmi ces derniers, très peu de mots isolés, mais plutôt des groupes de mots ou des propositions ${ }^{143}$. Les deux plus volumineuses sont représentatives de

137. PVH1, p. 6, v. 169-170.

138. Lond 1 , fol. $7 \mathrm{vb}$.

139. La rubrique précédant le chap. I-10 (fol. 3vb, v. 379-478) renonce par exemple à rendre compte du contenu des v. 423-478; la rubrique précédant le chap. I-14 (fol. 5a, v. 571-622) ne résume guère que les v. 571-577; etc.

140. Par exemple Gérard de Nevers (voir M. Marchal, « Mise en chapitres... », p. 191).

141. On pourra discerner la part respective de ces différents types de matériaux en se reportant à l'Annexe I, où les emprunts directs au Pèlerinage sont signalés.

142. J'en ai compté 188 mais des emprunts ténus ont pu m'échapper.

143. De nouveau, ces emprunts rapprochent le travail du rubricateur de celui des dérimeurs de la fin du Moyen Âge. Ainsi l'auteur de la mise en prose du Cligès de Chrétien de Troyes, qui travailla vers 1455, emprunte-t-il lui aussi à son modèle un certain nombre de mots choisis, qu'il intègre à sa prose pour y faire alterner « de façon raffinée archaïsmes et nouveautés » (Gilles Roques, « Les variations lexicales dans les mises en prose », dans Mettre en prose..., p. 9-31, à la p. 30). 
la technique employée : « Le heaume signifie Actrempance [...], la gorgiere Sobrieté [...], les gantelés Continence [...], l'espee Justice »144; « Le fourrel de l'espee signifie Humilité [...], la renge a nom Perseverence [...], la targe a nom Prudence ${ }^{145}$. La plupart des emprunts littéraux correspondent à deux types de contenu : d'une part des caractéristiques ou attributs de figures allégoriques ${ }^{146}$, d'autre part des gloses du vocabulaire allégorique de Guillaume ${ }^{147}$. Les rares adjonctions relèvent d'ailleurs presque exclusivement de ce dernier type et représentent moins de $10 \%$ du volume des 45 premières rubriques ${ }^{148}$. Elles visent en majorité, et plus nettement encore que le texte du poème, à l'interprétation allégorique. Tel est notamment le cas de la rubrique indiquant la signification de Jérusalem, dès la première station du Pèlerin : par cette ville « doit estre entendu paradis et les joies qui y sont ${ }^{149}$. On compte, au total, une dizaine de commentaires construits sur le même ressort. Outre ces ajouts exégétiques, quelques autres détails absents du poème visent à guider l'enlumineur. Au douzième chapitre du livre I, le rubricateur lui fournit une solution commode pour représenter le « signe thau » découvert par le Pèlerin : «Il vit le signe thau ou front d'une teste ${ }^{150}$. De même, lors du débat opposant Nature et Grâce de Dieu, il l'aide, au prix d'une confusion entre les maisons de Raison et de Grâce de Dieu, à rendre visible la hiérarchie entre les deux personnages. Ainsi est-il précisé que la seconde est à sa fenêtre - en réalité la fenêtre de la tourelle où Raison est retournée à l'issue du dialogue précédent : « Comment Nature [...] vient parler et tencer a Grace Dieu, qui est en une fenestre de sa tournelle ${ }^{151}$. De tels ajouts, marginaux dans la rédaction des rubriques, semblent avoir été mis à profit par les enlumineurs : de telles suggestions ont suscité des échos dans le programme iconographique ${ }^{152}$.

Ces deux types d'adjonctions suffisent à prouver que les rubriques s'adressent, selon des modalités différentes, à deux catégories de destinataires au moins : les miniaturistes et les commanditaires. Dans les années 1460, les

144. Lond 1, fol. $23 \mathrm{vb}$.

145. Lond 1, fol. 25va.

146. Quelques exemples : « aornee d'escharboucles, d'estoilles et ceintte du tissu verd » (fol. 3b, d'après les v. 236 et 306-307 du poème allégorique), « qui a les mains soubz ses aisselles [...], les yeulx reluisans [...] en forme d'une vieille » (fol. 10va, d'après les v. 1505 et 1509-1515), « en sa bouche avoit ung balai » (fol. 13a, d'après les v. 2029-2030), « ung villain ensourcillé [...] qui portoit ung baston de cornilier » (fol. 29vb, d'après les v. 5095-5098), etc.

147. Exemples : « le hauberjon qui Force a nom » (fol. 23a, d'après le v. 4027) ou encore « qui a nom Memoire » (fol. 28a, d'après les v. 4885-4887).

148. Elles représentent à peu près 120 mots sur les 1400 de cette première série, soit $9 \%$.

149. Lond 1 , fol. 1 b, au début du chap. I-2.

150. Lond 1, fol. 4va, dans une rubrique qui annonce le contenu des v. 503-536. Cette précision est exclusive à Lond 1 (voir Annexe II, p. 531).

151. Lond 1 , fol. 10va, au début du chap. I-23. Cette précision est propre à ce témoin et absente des quatre autres copies abondamment rubriquées. Voir Annexe II, p. 544-545.

152. Voir Lond 1, fol. 4va et 10va, ainsi que la description des enluminures correspondantes, Annexe I, p. 531 et 533. 
uns et les autres peuvent s'attendre à une rédaction qui suive des modèles rhétoriques bien rodés à la cour de Bourgogne.

2. Contraintes formelles : des rubriques formulaires ou créatives? - La comparaison des trois principales familles de rubriques repérées dans la tradition manuscrite du premier Pèlerinage permet de mesurer les contraintes qui ont pu peser sur le rédacteur des titres de Lond 1, ainsi que l'originalité de son travail. Il se distingue d'emblée de tous ses prédécesseurs par l'ampleur de ses titres. Les réserves ménagées par le copiste lui permettaient d'être disert et il l'a donc été, parfois même au-delà de la mesure prévue $^{153}$. Sur les 47 premiers chapitres, soit un peu plus de 6500 vers, la comparaison entre les manuscrits est suggestive (tab. 3).

\begin{tabular}{|l|r|r|r|r|}
\cline { 2 - 5 } \multicolumn{1}{c|}{} & BnF 13 & Brux 3 & BnF 4 & Lond 1 \\
\hline Nombre de rubriques & 43 & 68 & 60 & 47 \\
\hline Volume total (mots) & 666 & 1810 & 1415 & 1544 \\
\hline Volume moyen (mots) & 15 & 27 & 24 & 33 \\
\hline
\end{tabular}

TAB. 3. Quantité des rubriques (v. 1-6502).

On observe un contraste net entre le manuscrit le plus précoce (milieu du XIV siècle), BnF 13, et les plus tardifs : dans le premier, les titres sont rares (4.3) et chacun est, en moyenne, moins développé (de moins de la moitié aux deux tiers). L'opposition entre la famille composée de Brux 3 et BnF 4 et celle que constitue le seul Lond 1 s'exprime selon des modalités différentes. En effet, Brux 3 et BnF 4 présentent des rubriques nombreuses et relativement longues, tandis que Lond 1 porte des rubriques à peine plus nombreuses que BnF 13 (et BnF 22), mais beaucoup plus développées.

$\mathrm{Du} \mathrm{XIV}^{\mathrm{e}}$ au $\mathrm{XV}^{\mathrm{e}}$ siècle, on observe non seulement la dilatation des titres, mais surtout leur standardisation progressive : leurs attaques, notamment, deviennent de plus en plus uniformes. Dans les plus anciennes copies, les titres, plus concis, présentaient souvent une structure nominale, mais déployaient dans ce cadre limité un vocabulaire et des constructions variés ${ }^{154}$. Par contraste, une impression d'uniformité croissante se dégage des manuscrits $\mathrm{du} \mathrm{Xv}^{\mathrm{e}}$ siècle, singulièrement dans l'attaque des titres de Brux 3 et BnF 4 : devant l'interrogatif indirect « comme(nt) », omniprésent, on trouve de manière presque systématique la formule « $\mathrm{Ci}$ dit

153. Sur la présentation des rubriques un peu trop longues pour l'espace prévu, voir ci-dessous, p. 518.

154. En témoignent ces quelques exemples : « Grace Dieu qui parle a l'aucteur » (BnF 22, fol. $3 \mathrm{a})$; « Le prestre qui est official de Dieu » (BnF 22, fol. 4vb); « De loiauté » (BnF 22, fol. $7 \mathrm{~b})$; etc. 
l'aucteur... » $^{155}$ ou des variantes très proches : « L'aucteur devise... » ${ }^{156}$, «Ci parole l'aucteur... »157, etc. Dans Lond 1, l'interrogatif indirect est aussi très répandu (43 des 44 premières rubriques $)^{158}$. Le même usage est d'ailleurs commun à des proses de contenu très différent, comme Cleriadus et Meliadice ou Gérard de Nevers ${ }^{159}$. Dans la première moitié du $\mathrm{xv}^{\mathrm{e}}$ siècle, « comme(nt) » est devenu l'indicateur formel, lexical et grammatical des rubriques au sein du texte, comme l'encre rouge les met en vedette visuellement dans la page. Autour de cet interrogatif devenu conventionnel, le rubricateur de Lond 1 a tenté de varier la syntaxe en introduisant « comme(nt)» tantôt par des verbes de parole - « dire », « declairer » ou « raconter ${ }^{160}$ - ; tantôt par le verbe « estre » ou des équivalents associés au déictique « ci » ${ }^{161}$; tantôt enfin directement, comme support exclusif d'interrogatives indirectes fondées sur une ellipse ${ }^{162}$. On observe toutefois que ses efforts de variété se réduisent au fil du parcours. La part d'expérimentation semble se réduire à mesure que le rubricateur met au point son système : son dialogue avec les conventions propres aux années 1450 trouve progressivement une solution qu'il semble avoir jugée à son goût.

3. Voix du rubricateur, voix du narrateur, voix du Pèlerin. - Dans tous ces manuscrits, l'instance énonciative des rubriques est différente de celle qui sert d'ancrage à la narration. Dans le Pèlerinage, le narrateur est une entité savamment construite, notamment grâce à une poignée de traits biographiques. Ceux-ci ont souvent été relevés et commentés, d'abord parce qu'ils font écho à l'existence historique de Guillaume - à son statut de moine cistercien appartenant à l'abbaye de Chaalis, revendiqué dès le prologue ${ }^{163}$; à son patronyme, hérité de son géniteur; à l'âge de trente-six ans qu'il aurait eu au moment de son songe, d'après l'évaluation de Raison ${ }^{164}$; peut-être

155. Brux 3, fol. 2b; etc. Voir aussi BnF 4, fol. 2vb; etc.

156. Brux 3, fol. 1va; etc. Voir aussi BnF 4, fol. 1va; etc.

157. Brux 3, fol. 2a (deux occurrences); etc. Voir aussi BnF 4, fol. 1vb et 2b; etc.

158. La seule rubrique dont il soit absent est la suivante : « $\mathrm{Cy}$ aprés est la vision... » (fol. 1b, en tête du chap. I-2).

159. Voir l'édition des rubriques de plusieurs témoins de Cleriadus et Meliadice dans M. Colombo Timelli, « Titres, enluminures, lettrines... », p. 99-118. Sur la construction syntaxique des rubriques dans le témoin bruxellois de Gérard de Nevers, voir M. Marchal, « Mise en chapitres... », p. 190.

160. «Cy dit l'acteur comme... » (fol. 7vb, en tête du chap. I-19), « Cy declaire l'acteur [nom] et comment... » (fol. 9vb, chap. I-21), « Cy raconte le pelerin comment... » (fol. 10a, chap. I-22).

161. « Cy est comme(nt)» apparaît à quatre reprises, contre une seule occurrence pour chacune des formules suivantes : «Cy aprés est comment » (fol. 2vb, en tête du chap. I-8), « Cy aprés s'ensuit comment » (fol. 3b, chap. I-9).

162. Dans Lond 1, cette construction concerne 32 des 45 premiers titres.

163. V. 31-34, relevés et commentés dans E. Faral, « Guillaume de Digulleville... », p. 6 ; commentés à nouveaux frais, par exemple, dans F. Pomel, «"Je est un autre"... », p. 112-114; puis dans P. Maupeu, Pèlerins de vie humaine..., p. 169.

164. «Grant temps a que tu commenças | ne onques puis tu ne finas; | se xxxvi ans disoie, | je cuit que pou mesprendroie » (v. 5779 à 5782), précision notamment relevée par E. Faral 
même à l'embonpoint qui expliquerait son incapacité à porter les armes ${ }^{165}$. Ce narrateur s'adresse à son lecteur tantôt comme à un élève, tantôt comme à un égal. Sa posture est magistrale lorsqu'il met en scène son statut de clerc soucieux d'instruire le commun des chrétiens ${ }^{166}$; mais la relation au lecteur devient parfois horizontale en raison de l'humilité du Pèlerin, qui n'est autre que le narrateur et qui ne fait pas mystère, au fil du poème, de ses manquements répétés, à la lumière desquels il se ravale au niveau de ses destinataires, puisqu'il est pécheur au même titre qu'eux ${ }^{167}$. Que l'instance énonciative s'exprime à la première personne du singulier, le plus souvent dans la posture de l'éducateur, ou que la figure du Pèlerin se voie attribuer des discours à la première personne, les verbes aux personnes de l'interlocution abondent dans le poème. Et même lorsqu'il prend la forme d'un récit à la troisième personne, il n'est jamais présenté comme objectif, le relais focal du Pèlerin servant toujours d'intermédiaire entre ce qui est donné à voir et le lecteur ${ }^{168}$. Le poème est donc riche en dialogues amor-

dans sa quête de données biographiques sur le moine de Chaalis (« Guillaume de Digulleville... », p. 1, partic. n. 3). Faut-il suivre P. Maupeu lorsqu'il s'appuie sur l'élimination d'une telle mention dans la seconde rédaction du Pèlerinage pour inférer que cet âge serait celui de Guillaume lors de la composition du premier Pèlerinage de 1330 (Pèlerins de vie humaine..., p. 169, n. 3)? Ce n'est pas certain : la mise à jour de cette date dans la seconde rédaction eût été plus probante. Sa suppression pourrait aussi bien traduire la volonté de débarrasser le je-Pèlerin d'une caractéristique circonstancielle qui ne semblait plus opportune au rédacteur du second Pèlerinage. Y sont en effet supprimées, par rapport à la première rédaction, « bon nombre de précisions qui particularisaient et humanisaient le Pèlerin » (F. Pomel, «"Je est un autre"... », p. 115).

165. Telle est, du moins, l'explication proposée par Grâce de Dieu, qui reproche au Pèlerin : « trop es cras et as trop d'oint | dessous l'ele et trop es drus, | trop reveleus et trop peüs. | Tiex choses si te font si gros | que le pourpoint dessur le dos | Sans grevance ne puez porter » (PVH1, v. 3922-3927). Ces vers sont cités et analysés de manière nuancée dans P. Maupeu, Pèlerins de vie humaine..., p. 170 : « La description caractérise moins le Pèlerin qu'elle n'accuse la propension humaine aux plaisirs charnels. Néanmoins, combinée notamment au nom propre dont le corps est dépositaire, elle contribue à esquisser une figure singulière. »

166. Le prologue du Pèlerinage, dans sa première rédaction, pourrait conduire à assimiler le narrateur à un prédicateur et le poème à un sermon (ibid., p. 49). Cette parenté n'a pas échappé aux enlumineurs : plusieurs ont représenté au frontispice une scène de prédication (R. Gay-Canton et G. Veysseyre, « Books exclusively for the laity?... »). Sur son écho dans certaines rubriques, voir ci-après, p. 511 et suiv.

167. Sur les touches autobiographiques non dénuées « d'humour voire d'ironie » par lesquelles le narrateur se plaît à « mettre à distance un moi ancien », voir F. Pomel, «"Je est un autre"... », p. 115. Sur les différentes dimensions du « je » allégorique dans le Pèlerinage, voir aussi P. Maupeu, Pèlerins de vie humaine..., p. 97-171 (chap. « Voix de l'auteur et statut du sujet dans le premier Pèlerinage »), où sont distingués par l'analyse le « sujet éthique », ayant pour «but exclusif d'asseoir la légitimité de la voix énonciatrice définie comme le relais de l'auctoritas » et le «je-Pèlerin », n'ayant « d'existence que générique, comme synecdoque généralisante de tout individu » (ibid., 171).

168. Ce paramètre de la narration est particulièrement perceptible lorsque le Pèlerin relate les stations de son voyage au cours desquelles il observe plus qu'il n'agit. Tel est le cas au livre I et, dans une moindre mesure, au livre IV. 
cés, clos et entrecoupés par des développements narratifs qui ne dérogent jamais à l'effet de focalisation interne.

À l'inverse, la troisième personne envahit tout l'espace des rubriques. Qui plus est, cette troisième personne émane d'une instance qui manie presque exclusivement la narration. C'est ainsi que toutes les allocutions qui, dans le texte, étaient assumées par un narrateur s'exprimant à la première personne, sont transposées dans les rubriques en unités de récit. Certes, deux instances énonciatives sont distinguées, mais selon une bipartition entre auteur historique du texte et personnage de fiction - auquel peut éventuellement être confié le récit -, plutôt que selon la tripartition perçue par la narratologie moderne : auteur, narrateur, personnage. Il y aurait quelque anachronisme à en être surpris. Dans Lond 1 , le songeur et l'auteur sont confondus. En témoigne l'une des premières rubriques, qui attribue le poème à « Guillaume de Guileville, moinne » ${ }^{169}$. Le Pèlerin, à la fois personnage et narrateur, prend le relais dès la rubrique suivante : «Comment le pelerin vit aux carneaulx de la cité les sains docteurs qui enseignoient les gens a faire ailles pour voler en la cité... » ${ }^{170}$; et restera présent jusqu'à la fin de son pèlerinage ${ }^{171}$. Par la suite, pour désigner cette entité, alternent dans les rubriques de premier comme de second plan les termes « acteur » et « pelerin ». Ici comme dans le ms. BnF, fr. 1137 - copie de la mise en prose du Pèlerinage par le clerc anonyme d'Angers ${ }^{172}$-, les deux substantifs sont employés par le rubricateur de manière interchangeable ${ }^{173}$. Dans Lond 1, le contenu de la rubrique située en tête des vers 4747-4776 prouve leur équivalence : « Comment l'acteur despoulla ses armeures et comment Grace Dieu le redarguë de ce que le pelerin ne la requiert d'avoir quelque ung qui les li porte » ${ }^{174}$. Le groupe nominal « le pelerin » a ici une valeur anaphorique qui correspond à celle d'un pronom personnel. Son emploi montre que, par leur contenu référentiel, les deux expressions « l'acteur » et « le pelerin » sont superposables dans l'usage du rédacteur des rubriques. Néanmoins « pelerin », cinq fois plus employé qu' « acteur », est nettement privilégié ${ }^{175}$. Quoi qu'il en soit, la personne 1 du narrateur s'efface au gré de ces modifications pour céder le pas à une omniprésente personne 3 .

Lond 1 suit par ailleurs un autre procédé de transposition en usage dans les rubriques de la fin du Moyen Âge : celui qui consiste à annoncer les échanges verbaux de manière synthétique, comme des objets de discours, et

169. Lond 1, fol. 1b. Voir la rubrique, Annexe I, p. 529.

170. Lond 1, fol. 1va. Voir la rubrique, Annexe I, p. 530.

171. La dernière rubrique dit : «Comment le pelerin gesant en son lit vit la Mort a deux piez estant sus le bout de son lit, qui tenoit une faulz et le vouloit tuer » (Lond 1, fol. 74b).

172. G. Veysseyre, Notice du ms. BnF, fr. 1137, dans Jonas, http://jonas.irht.cnrs.fr/ manuscrit/73989, consulté $1^{\mathrm{er}}$ avril 2014.

173. P. Maupeu, Pèlerins de vie humaine..., p. 299.

174. Lond 1, fol. 27va; je souligne.

175. Dans les 44 premières rubriques de Lond 1 , on trouve 25 occurrences de « pelerin » contre 5 d'« acteur ». L'écart semble se creuser encore dans la suite du manuscrit. 
non pas sous la forme de discours directs résumés qui conserveraient leur statut de discours rapporté. Ainsi, lorsque le Pèlerin est promu du statut d'observateur, relais focal de la narration, à celui de locuteur dans sa rencontre avec Grâce de Dieu, la rubrique qui manifeste cette nouvelle dimension du personnage est la suivante : «Cy aprés est comment le pelerin queroit escherpe et bourdon et en ce querant il rencontra Grace Dieu et parla a elle ${ }^{176}$. Par la suite, ce seront toujours des verbes de parole, ou des substantifs relevant du même champ sémantique, qui apparaîtront dans les rubriques annonçant des dialogues ${ }^{177}$. À l'échelle du manuscrit entier, une seule rubrique (I-33) fait exception à l'exclusion des discours directs : « Comment le pelerin print le hauberjon et comment il demande a Grace les noms des armeures dont il doit estre armé, et elle lui dist : "Le hauberjon Force est de signifiance. Le heaume signifie Actrempance, la gorgiere Sobrieté, les gantelés Continence, l'espee Justice" »178.

Pourquoi cette unique apparition du discours direct, pour citer en abrégé un discours émanant d'un personnage qui a très souvent la parole et qui délivre, au fil du pèlerinage, des enseignements plus fondamentaux encore que ce décryptage de l'armement nécessaire au bon cheminement du Pèlerin? Il n'est pas impossible que le rubricateur ait souhaité produire ici une liste à valeur pédagogique, à un moment où la diversification du vocabu-

176. Fol. 2vb, je souligne. Le texte fait ici accéder la parole du Pèlerin au rang de discours direct à l'issue de deux étapes ménageant une gradation : le Pèlerin, resté muet au cours du récit face aux découvertes surprenantes de la première partie de son pèlerinage - dont il ne rend compte qu'à l'issue de son songe, comme narrateur -, prend la parole pour la première fois en tant que personnage suite à la sollicitation de Grâce de Dieu. Le premier échange entre les deux personnages est rapporté par le narrateur sous la forme de deux discours indirects : «Courtois fu, ce me sembla, | quar premiere me salua | en moi doucement demandant | que j'aloië ainsi querant » (v. 249 à 252); puis « Lors li ai je respondu | si comme il m'estoit avenu | que d'aler estoie excité | en Jherusalem la cité » (v. 267 à 270). Ce n'est qu'après cet intermède constituant une première étape que l'échange entre les deux personnages prendra la forme de discours directs, qui semblent rapportés dans leur intégralité : Grâce de Dieu intervient de nouveau la première (v. 275 à 282) avant que le Pèlerin n'assouvisse une curiosité qu'il présente comme potentiellement dangereuse en exprimant enfin la question qui lui brûle la langue : «Adonc ne me peu plus tenir, | comment qu'il m'en deust avenir, | que tout ne vousisse savoir | et son nom et qui elle estoit. | "Dame, dis je, vostre nom, | vostre païs et region | et qui vous estes tout de voir | voudroië voulentiers savoir, | si vous pri[ë], dites le moi [...]" » (v. 283 à 291). Le poème ménage ici une savante gradation, grâce à l'emploi concerté de deux types de discours rapportés, entre le premier échange, simple prise de contact relevant de la courtoisie, et le dialogue suivant, qui permet au Pèlerin d'exposer sa soif de savoir et à Grâce de Dieu de commencer à l'assouvir. Parvenir à rendre compte d'une structure aussi élaborée par le truchement des rubriques eût été un tour de force.

177. « ... et si devise qui elle est » (fol. 3b), « Comment le vicaire respond a Raison » (fol. 5b). Le rubricateur diversifie quelque peu le vocabulaire qu'il emploie, puisqu'il a aussi recours aux verbes demander et dire (rubrique du chap. I-33 : Annexe I, p. 535).

178. Voir aussi cette rubrique, Annexe I, p. 535. C'est au cours du chapitre ainsi introduit qu'à la demande du Pèlerin, Grâce de Dieu lui dévoile la signification des armes qu'elle vient de lui confier en sus de l'écharpe et du bourdon : haubergeon, heaume, gorgère, gantelets et épée. 
laire allégorique servant à désigner les armes pouvait prendre en défaut la mémoire des lecteurs. C'est ainsi que le rubricateur concentre en deux lignes un code allégorique disséminé dans le chapitre ${ }^{179}$, renforçant ainsi la valeur mnémonique que le moine de Chaalis avait déjà conférée à bien des segments de son premier Pèlerinage ${ }^{180}$. Cette valeur récapitulative est confirmée par un autre phénomène d'autant plus remarquable qu'il est, lui aussi, presque exclusif à cette rubrique : sa redondance par rapport à la rubrique précédente ${ }^{181}$. Les deux titres énoncent en effet la signification du haubergeon en usant presque de la même formulation ${ }^{182}$. Cette répétition ne trouve pas son origine dans le poème où, après un premier vers définitoire - «Ce haubergon Force a non » (PVH1, v. 4027) -, Grâce de Dieu en vient rapidement à exposer les qualités de cette arme défensive telles que les ont éprouvées « li champion | Jhesucrist anciennement 》 (PVH1, v. 40284029) ${ }^{183}$. La seule rubrique incluant un discours direct est donc doublement atypique, par sa forme, englobant ce discours enchâssé, mais aussi par son contenu, puisqu'elle comporte une donnée tirée non du chapitre qu'elle annonce mais de celui auquel elle met fin : c'est au vers 4027 que Grâce de Dieu a dévoilé la signification allégorique du haubergeon ${ }^{184}$. Qui plus est, cette dernière information était déjà mise en exergue dans le titre précédent. Il y a lieu de croire qu'emporté par une volonté didactique encore plus fervente qu'ailleurs, le rédacteur des rubriques a ici enfreint trois des règles qu'il s'était lui-même implicitement fixées - ou que du moins, consciemment ou non, il respectait par ailleurs.

C'est que, de même que la subdivision du texte en chapitres, le contenu

179. Voir Annexe I, sources de la rubrique au sein même du Pèlerinage.

180. Les procédés mnémotechniques mis en œuvre par le moine de Chaalis ont été analysés en détail dans Susan Hagen, Allegorical remembrance. A study of the Pilgrimage of the Life of Man as a medieval treatise on seeing and remembering, Athènes-Londres, 1990 - ouvrage dont le caractère trop systématique est souligné à juste titre par F. Pomel, « Mémoire, mnémotechnie et récit de voyage allégorique. L'exemple du Pèlerinage de vie humaine de Guillaume de Digulleville », dans Medieval memory. Image and text, éd. Frank Willaert, Herman Braet, Thom Mertens and Theo Venckeleer, Turnhout, 2004, p. 77-98, notamment p. 97. Reste qu'à l'échelle microstructurale, bien des développements du Pèlerinage ont partie liée avec les techniques mnémoniques développées à partir du XIII ${ }^{\mathrm{e}}$ siècle. Ainsi Guillaume n’hésite-t-il pas à investir les listes de péchés, de vertus ou d'articles de la foi qui forment alors le fonds commun de la catéchèse. F. Pomel, qui signale l'origine théologique de tels enseignements (ibid., p. 89), y joint d'autres exemples pour montrer que procédés allégoriques et mnémoniques convergent dans le creuset de Guillaume, au profit de ses ambitions didactiques (ibid., p. 93).

181. Celle qui ouvre le chap. I-32, au fol. 23. Voir Annexe I, p. 535.

182. Le premier énoncé - « le hauberjon qui Force a non » (fol. 23a) - est repris en substance sous la forme suivante : «Le hauberjon Force est de signifiance » (fol. 23vb).

183. L'enseignement de Grâce de Dieu sur l'efficacité du haubergeon en tant qu'arme de défense occupe les v. 4028 à 4054 et semble assez persuasif pour que le Pèlerin se résolve à l'endosser immédiatement (v. 4055).

184. De même que les répétitions d'un titre à l'autre, de tels déplacements de l'information sont rarissimes dans le système des rubriques de Lond 1. 
des rubriques est tiraillé entre des impératifs multiples dont le poids respectif varie d'une occurrence à une autre. Les conventions du genre, liées à des impératifs matériels, imposent la brièveté ${ }^{185}$. Face au Pèlerinage, le rubricateur a allié pragmatisme et concision pour faire tenir ses interventions dans les quelques lignes qui lui sont périodiquement octroyées, l'une de ses méthodes récurrentes consistant à annoncer la plupart des discours directs par un simple verbe de parole, éventuellement accompagné de compléments lapidaires. Ce faisant, il renonce, à une exception près, à rendre compte en détail d'échanges dont le lecteur est ainsi invité à aller découvrir la teneur dans le poème.

4. Les rubriques de Lond 1 : la première place au récit. - La dimension du Pèlerinage qui est le plus nettement mise en valeur par les rubriques du manuscrit de Claude et de Louise est sa teneur narrative. En la matière, Lond 1 s'oppose frontalement à Brux 3 et BnF 4. Dans ces deux dernières copies, l'ensemble des rubriques semble reproduire à l'infini le dispositif de l'un des frontispices les plus répandus, qui représente le narrateur comme un clerc en position d'instructeur ${ }^{186}$. L'importante grisaille inaugurale du manuscrit de Philippe le Hardi représente ainsi le narrateur à la tribune, dans la situation éminente de celui qui instruit une foule socialement hétérogène ${ }^{187}$. Cette image, la seule prévue à l'échelle du Pèlerinage, trouve ensuite un relais régulier dans la formule d'attaque de presque tous les titres intermédiaires : «L'auteur dit que... »188. Plus encore que l'itinéraire du Pèlerin et les expériences qu'il acquiert au fil de son chemin, ce qui est mis en valeur par ce sujet grammatical omniprésent, c'est l'autorité de l'auteur du poème. Sa position d'orateur, représentée dans l'illustration initiale et relayée par des rubriques particulièrement répétitives, permet aussi de faire advenir dans l'espace du livre un nouveau mode de lecture, qui apparaît comme une transposition légitime de la réception orale prévue par Guillaume lui-même. Dans Brux 3, ce n'est plus la voix de l'orateur qui est chargée de transmettre le message contenu dans les couplets d'octosyllabes à rimes plates : le texte est si étroitement encadré par les mentions « l'auteur dit que... », etc., que le rubricateur semble assumer cette position de guide auprès d'un lecteur qui découvrirait désormais le Pèlerinage par la vue plutôt que par l'ouie. La référence à l'auteur, insistante, encadre plusieurs rubriques, et notamment : «Ci dit l'aucteur comment il vit Raison sermonner au prone en commun et devise la senefiance du glaive et des clés et comment il en doivent ouvrer. L'aucteur ${ }^{189}$. Le narrateur y

185. L’obligation de brièveté est une « difficulté inhérente à l'exercice » de composition des rubriques, comme le rappelle C. Roussel, « Les rubriques de la Belle Hélène... », p. 207.

186. M. Camille, The illustrated manuscripts..., p. 73-78.

187. Frontispice analysé $i b i d$.

188. Voir ci-dessus, p. 505-506.

189. Fol. 9a (je souligne), en tête du chapitre qui comprend les v. 1059-1260. Cette mani- 
devient constamment « une instance commentant [l'action], à côté de la figure du Pèlerin » ${ }^{190}$. Ainsi le rubricateur se propose-t-il non seulement de garantir l'autorité du narrateur en mettant en scène sa position éminente, mais encore d'encadrer son message pour aider les lecteurs individuels à y accéder plus sûrement.

La continuité établie entre le frontispice et les rubriques où « l'auteur » occupe une position de prévalence n'est pas aussi nette dans BnF 4. Il s'ouvre, lui aussi, sur une vignette représentant un clerc prêchant depuis la tribune face à un groupe d'auditeurs. Toutefois cette illustration, en tête de la première colonne d'octosyllabes, est suivie d'une longue série d'enluminures de même format qu'elle, qui réduisent l'importance symbolique du frontispice par rapport à celui de Brux 3, seule illustration de ce dernier volume. En outre, dans $\mathrm{BnF} 4$, les scansions ménagées par les rubriques et par les images sont indépendantes et disjointes les unes des autres, de sorte qu'elles se font concurrence plutôt que de se renforcer l'une l'autre. Peu mis en valeur, les titres intermédiaires figurent au milieu d'apparats de nature différente qui les offusquent partiellement. Pour autant, le rôle des rubriques est le même dans Bnf 4 que dans Brux 3, et quoique la complétive contenue dans chacun des titres intermédiaires de Bnf 4 donne à lire un condensé des aventures du Pèlerin, tous sont étroitement subordonnés à la figure du narrateur-instructeur.

Dans Lond 1, la voix du narrateur et même le personnage du Pèlerin sont beaucoup moins omniprésents. L’absence fréquente de toute proposition introductive devant l'interrogatif initial «comme(nt) » y estompe la voix du narrateur. Comme dans les deux manuscrits précédents, on passe d'une personne 1 à une personne 3 entre le corps du poème et les titres intermédiaires, mais le récit du Pèlerin et les leçons du narrateur sont transposés directement dans les rubriques sans que la médiation d'une voix auctoriale soit toujours matérialisée. En outre, dès lors que le Pèlerin n'est que spectateur d'une action et qu'il n'interagit pas avec les représentants plus ou moins maléfiques du monde, il est absent de la rubrique. En conséquence, 14 des 46 premières rubriques sont dépourvues de toute formule désignant le Pèlerin ou le narrateur : à peine plus d'un quart des occurrences, certes, mais dans un texte où le Pèlerin est omniprésent, le phénomène reste remarquable, surtout par comparaison avec les deux manuscrits rubriqués de la famille R II. Ainsi les rubriques du manuscrit de Claude et Louise favorisentelles un accès de plain-pied au récit allégorique, sans que le truchement du narrateur y soit trop sensible. Son autorité reste tacite dans cette copie qui favorise, dans les rubriques comme dans d'autres apparats, l'identification

festation redondante de l'autorité du narrateur structure d'autres rubriques similaires du livre I. Voir fol. 10b (en tête des v. 1261-1302); fol. 11va (en tête des v. 1431-1464); fol. 11vb (en tête des v. 1465-1502); fol. 15vb (en tête des v. 2005-2392); etc.

190. Ursula Peters, Das Ich im Bild. Die Figur des Autors in volkssprachigen Bilderhandschriften des 13. bis 16. Jahrhunderts, Cologne, 2008 (Pictura et poësis, 22), p. 145. 
du lecteur avec le Pèlerin fournissant le relais focal du récit. Si le Pèlerin, comme spectateur extérieur d'une scène, s'efface ainsi des rubriques, c'est pour que le lecteur soit placé dans la même position que lui. Et lorsqu'il est aux prises avec les difficultés de son pèlerinage ici-bas, les rubriques ne rappellent pas non plus constamment au lecteur qu'il a affaire à un récit dispensé par un « acteur » s'adressant à lui - directement ou par image - et qui viendrait médiatiser le récit.

En s'abstenant de rapporter sans cesse au narrateur le contenu du Pèlerinage, et en tâchant d'intégrer à ses titres autant de détails que l'y autorisent les réserves, l'auteur des rubriques de Lond 1 aboutit à un apparat plus vivant, plus circonstancié, plus autonome, plus fluide enfin qu'aucun de ses prédécesseurs. Prétend-il pour autant fournir une alternative brève et autonome au long poème de Guillaume?

5. Les rubriques en série : un substitut possible au corps du poème? - Il est un espace du manuscrit où les titres intermédiaires peuvent être mis en série : la table des rubriques. Or, Lond 1 ne semble pas avoir reçu une telle table ${ }^{191}$. Cet apparat courant n'était pas encore systématique dans les années $1460^{192}$, et n'est pas non plus fréquent dans la tradition manuscrite des Pèlerinages en vers ${ }^{193}$. C'est que les rubriques développées y sont rares et qu'il n'est pas d'usage de consigner dans une table la succession des noms qui attribuent en marge les abondants discours directs. Cette tradition consistant à faire circuler le texte sans table a eu tendance à perdurer dans les avatars plus tardifs du poème allégorique. Ainsi, lorsqu'il sera passé à la prose, le Pèlerinage continuera souvent de circuler sans tables : parmi les neuf copies connues de la mise en prose du clerc anonyme d'Angers, trois seulement en sont dotées ${ }^{194}$, et dans les trois cas, la liste des chapitres est

191. On peut toujours envisager qu'une telle table ait été perdue, mais l'état de conservation du manuscrit n'incite nullement à le penser : le premier feuillet de texte est mis en scène comme tel, avec ses décorations marginales et ses armoiries. Il est peu probable qu'il ait jamais été précédé de quoi que ce soit. De même, l'issue des trois Pèlerinages (fol. 191) étant suivie, dans le même cahier, d'une page puis d'un feuillet blancs (fol. [192]), il est peu probable qu'une table ait jamais suivi la fin de la trilogie.

192. M. Colombo Timelli, « Pour une "défense et illustration"... », p. 203, n. 3.

193. Sur la rareté des manuscrits dotés de tables parmi les nombreux témoins des Pèlerinages, voir G. Veysseyre, « Lecture linéaire ou consultation ponctuelle? Structuration du texte et apparats dans les manuscrits des Pèlerinages », dans Guillaume de Digulleville. Les « Pèlerinages » allégoriques..., p. 315-330, aux p. 321-329.

194. Les trois manuscrits dotés de tables sont les suivants : Bibl. de Genève, fr. 182; Paris, Bibl. de l'École nat. sup. des beaux-arts, Masson 80; BnF, fr. 1646. Le premier au moins a déjà été pointé comme un manuscrit qui, à l'instar du Pèlerinage imprimé, se distingue de la rédaction originelle de 1465 « tant sur le plan formel que textuel », en conjuguant « une mise en valeur renouvelée de la structuration et la création d'un sommaire, avec un rajeunissement de la langue et des interventions personnelles » (F. Bourgeois, « Réécriture de la mise en prose du Pèlerinage de vie humaine dans le ms. BnF, fr. 12461 », dans Guillaume de Digulleville. Les « Pèlerinages » allégoriques..., p. 351-364, aux p. 351-352). 
divisée en quatre tables distinctes, qui précèdent chacun des livres correspondants ${ }^{195}$. Si cette disposition éclatée est héritée d'un Pèlerinage en vers, elle fournit un argument de plus contre la possibilité que Lond 1 ait été amputé de tables originellement intégrées au manuscrit.

Même en l'absence de table, lire un Pèlerinage articulé par des rubriques, en s'en tenant à ces dernières et aux vignettes qui les accompagnent, paraît a priori un usage possible de Lond $1^{196}$. Est-ce en vue d'une telle lecture accélérée que les commanditaires auraient demandé un tel apparat? Le contenu n'incite pas à le penser. En effet, chaque titre est absolument indépendant des précédents sur le plan syntaxique et référentiel, si bien que chacune des rubriques peut être lue isolément, sans avoir connaissance ni du corps du poème ni, surtout, des rubriques précédentes. Ainsi les pronoms, qui impliqueraient une reprise anaphorique d'une rubrique à l'autre, sont-ils proscrits - à l'exception de la toute première rubrique, sans doute reprise à l'identique d'une copie précédente ${ }^{197}$. Le contenu des titres, tout comme celui des images, est pourtant répétitif. Le Pèlerin, notamment, y est omniprésent. Or celui-ci, tout comme les personnages qui le guident ou le menacent pendant plusieurs chapitres successifs, est toujours désigné par une dénomination transparente, généralement identique d'une rubrique à l'autre, et ne nécessitant donc pour être comprise aucun recours aux titres figurant en amont $^{198}$. Cette indépendance référentielle de chaque rubrique est la norme dans d'autres œuvres ${ }^{199}$ comme elle l'est dans les autres copies du Pèlerinage, de manière plus ou moins stricte. Ainsi les rubricateurs de $\mathrm{BnF} 4$ et Brux 3 s'autorisent-ils parfois à recourir à quelques pronoms anaphoriques; par exemple : « Ci li dit Grace Dieu la senefiance du sanc » ${ }^{200}$. Même si une telle anaphore est marginale dans le système des rubriques de cette famille, il est significatif que l'on n'en trouve aucun cas dans Lond 1. Cette autonomie de chaque rubrique donne des indications sur les fonctions qui leur ont été assignées lors de leur rédaction. Il ne s'agit manifestement pas de fournir

195. Dans le ms. BnF, fr. 1646 par exemple, elles se trouvent aux fol. $1-2 \mathrm{v}, 59 \mathrm{v}-61,109 \mathrm{v}-$ $110 \mathrm{v}$ et $136 \mathrm{v}-138$.

196. Dans la copie des Pèlerinages qui nous concerne comme dans d'autres manuscrits contemporains, l'association d'une rubrique en prose et d'une miniature, emblématique des manuscrits de luxe du $\mathrm{xv}^{\mathrm{e}}$ siècle, $\mathrm{y}$ aurait la fonction suivante : « to invite the readers to read from rubric to rubric as they examine each miniature » (R. Emmerson, « Translating images... », p. 285).

197. Voir ci-dessous, p. 520.

198. Sur l'emploi fréquent du terme « Pèlerin » dans les différents systèmes de rubriques, voir ci-dessus, p. 508.

199. On s'en persuadera notamment en lisant la série des rubriques de la prose Cleriadus et Meliadice, éditées d'après le ms. Turin, Bibl. Nazionale Universitaria, L.II.2, dans M. Colombo Timelli, « Titres, enluminures, lettrines... », p. 114-115, annexe 3. Le nom du protagoniste, Cleriadus, y est repris d'une rubrique à l'autre, sans que l'auteur des titres ait cherché à recourir à des pronoms ou à d'autres outils anaphoriques pour éviter sa répétition.

200. Respectivement fol. 27b dans Brux 3, cité ici, et fol. 29a dans BnF 4, qui porte là la même leçon à quelques variantes orthographiques près; je souligne. 
une alternative au corps du Pèlerinage, un résumé comparable, par exemple, à celui qui figure à l'ouverture du ms. Lyon, Bibl. mun. 768 (686) ${ }^{201}$. Car, s'il prétendait donner à lire un condensé du poème de Guillaume, le rubricateur de Lond 1 aurait sans doute travaillé à tisser une continuité plutôt que de doter chaque titre d'une autonomie sémantique et syntaxique coûteuse en espace. Le rôle dévolu aux rubriques semble donc être double : d'une part gloser les images pour favoriser leur compréhension, d'autre part aider les lecteurs à se situer dans le long poème, soit qu'ils y cherchent une scène isolée, soit qu'ils reprennent une lecture interrompue en cours de route. Dans tous les cas, les rubriques favorisent une lecture individuelle active au détriment d'un usage collectif, en particulier oral.

La copie réalisée pour Claude de Montaigu et Louise de La Tour est innervée de titres de chapitre particulièrement développés. Ceux-ci attestent l'écart important qui sépare la lecture orale en quatre journées originellement prévue par Guillaume de Digulleville dans son prologue ${ }^{202}$ et les conditions effectives dans lesquelles le Pèlerinage était lu par la noblesse bourguignonne au milieu du $\mathrm{Xv}^{\mathrm{e}}$ siècle. Les apparats développés dans ce milieu invitent désormais à une lecture dont le rythme au moins s'apparente à celui des mises en prose contemporaines, « textes à feuilleter et à relire ${ }^{203}$. Il faut imaginer là une lecture fragmentée, distribuée en plages plus brèves et plus nombreuses que les quatre journées prévues à l'origine; et une lecture individuelle plutôt que collective, privée et silencieuse plutôt que publique et oralisée ${ }^{204}$. Tout au plus les habitudes des lecteurs bourguignons pouvaient-elles être légèrement contrariées, dans leur fréquentation de Lond 1, par ses chapitres moins calibrés que ceux d'autres proses contemporaines et leur offrant ainsi des pauses moins régulières.

6. Des « lecteurs professionnels » en amont des destinataires. - Ces destinataires ont toutefois été précédés, au cours de la réalisation de Lond 1, par une catégorie de lecteurs particulièrement susceptibles de s'en tenir aux ajouts rubriqués, plutôt que de parcourir l'ensemble du poème : le ou

201. Fol. 1a-5a. Pour une édition de ce résumé, voir PVH1, p. 425-444. Le contenu du Pèlerinage y est condensé en 608 octosyllabes à rimes plates, peut-être par le copiste du manuscrit lui-même; du moins le résumé est-il de la même main que la suite du Pèlerinage, et le manuscrit de Lyon en est-il le seul témoin connu.

202. Voir notamment les v. 19-20 : « Avant se doivent tous bouter | touz asseoir et escouter » (PVH1, p. 1) et les pauses matérialisées explicitement entre les différents livres. Il est vrai qu'il est difficile, face à un tel prologue, de mesurer la part des lieux communs, notamment en matière de référence à l'oralité. Reste que Guillaume n'était en rien contraint de diviser son récit en quatre livres et que les pauses qu'il a ménagées rendaient en effet son poème propice à une lecture en quatre temps.

203. M. Marchal, « Mise en chapitres... », p. 185.

204. À l'instar, de nouveau, des proses contemporaines, dont l'« existence atteste sans doute d'un $[s i c]$ goût de plus en plus prononcé pour une lecture individuelle et privée » (ibid.). 
les illustrateurs. Ainsi plusieurs enlumineurs, même lorsqu'ils avaient élaboré un cycle iconographique en adéquation avec le texte, ont été surpris en flagrant délit de lecture partielle, pour s'en être tenus au contenu des rubriques. Par exemple le concepteur des enluminures du manuscrit BnF, nouv. acq. fr. 7514, l'une des deux copies du Chatelain de Coucy et la dame de Fayel, récit composé par le dénommé Jakemés ${ }^{205}$. Le peintre s'y est inspiré « plus souvent du contenu de la rubrique pour faire son dessin que de l'ensemble du chapitre, ce qui laisse penser qu'il s'était peut-être contenté des renseignements donnés par ces titres sans prendre soin de lire le chapitre entier avant de peindre ${ }^{206}$. Une telle méthode ne prévaut pas partout, comme l'attestent plusieurs exemples contraires : les miniatures disséminées tout au long de la copie en cinq volumes de la mise en prose cyclique des Quatre filz Aymon ou Renaut de Montauban puisent dans le texte des éléments absents des rubriques. L'enlumineur Loyset Liédet, qui travaille là sur la commande du duc de Bourgogne Charles le Téméraire, y prouve constamment qu'il s'est livré à une lecture approfondie de l'œuvre ${ }^{207}$. De même, le Maître de Wavrin qui a illustré le manuscrit KBR, 9631, copie d'une mise en prose du Roman de la Violette, a-t-il fait usage à la fois des rubriques et du texte ${ }^{208}$.

À quelle catégorie d'enlumineurs appartient le miniaturiste qui a partiellement empli les réserves de Lond 1? Il est plus difficile de le dire que pour Loyset Liédet, du fait même de l'abondante tradition manuscrite du Pèlerinage. En effet, contrairement aux Quatre filz Aymon dont la mise en prose est conservée dans un seul manuscrit, le Pèlerinage a donné lieu à de nombreuses copies, très souvent enluminées ${ }^{209}$. En conséquence, les sources des peintres ayant illustré l'œuvre, particulièrement au $\mathrm{Xv}^{\mathrm{e}}$ siècle, peuvent être aussi bien iconographiques que textuelles; voire inclure le texte lui-même, les rubriques qui y ont été insérées et les instructions spécifiquement destinées aux enlumineurs par certains copistes ${ }^{210}$. Certains cycles iconographiques ou certaines miniatures isolées peuvent révéler clairement que l’une de

205. Sur la tradition manuscrite de ce roman, voir Jakemés, Le Roman du Châtelain de Coucy et de la Dame de Fayel, éd. et trad. Catherine Gaullier-Bougassas, Paris, 2009, p. 83-88.

206. D. Quéruel, « La naissance des titres... », p. 53. L’impression générale exprimée par D. Quéruel est globalement confirmée dans F. Suard, « Le Chastellain de Coucy : du vers à la prose... », p. 27 (« Les vignettes [...] redoublent la rubrique, qu'elles illustrent sur un mode souvent plaisant »), à l'exception d'une enluminure qui puise dans le texte des informations absentes de la rubrique à laquelle elle est associée (ibid., p. 28).

207. D. Quéruel, « La naissance des titres... », p. 60.

208. « Si la rubrique est un point de référence privilégié par l’illustrateur, il n’en demeure pas moins que le miniaturiste connaît le contenu textuel avec précision » (M. Marchal, « Mise en chapitres... », p. 192).

209. Voir ci-dessous, note 226.

210. M. Camille en fournit plusieurs exemples, et notamment celles qu'Oudin de Cavarnay adresse à Remiet dans le ms. BnF, fr. 823 (The illustrated manuscripts..., p. 106-113 et 267-268). 
ces trois sources a été prépondérante. Ainsi le ms. Paris, BnF, fr. 376 a-t-il un modèle identifiable dans un autre témoin : il reprend le frontispice du recueil des trois Pèlerinages conservé à la bibliothèque Sainte-Geneviève ${ }^{211}$. À l'inverse, l'influence du texte est directe et profonde sur le manuscrit de Heidelberg, qui a été conçu par un lecteur particulièrement attentif : « a "thinking" artist highly attuned to the allegorical meaning of his text and interpreting it visually for an intellectual audience ${ }^{212}$.

Rien d'aussi clair dans Lond 1, si ce n'est une concordance remarquable entre les rubriques et les vignettes réalisées. Lorsque le rubricateur ajoute au texte un détail concret pour faciliter la mise en image d'un objet allégorique ou d'une scène, l'enlumineur lui emboîte volontiers le pas ${ }^{213}$. On ne peut guère, pour autant, le soupçonner d'avoir lu les seules rubriques. De fait, il arrive assez souvent qu'il représente, à l'extrémité gauche du cadre, le Pèlerin de dos ou de trois quarts en train d'assister à une scène sans y participer véritablement. Tel est notamment le cas lors de la remise des « oignements » à l'official ${ }^{214}$, lorsqu'il délivre le sacrement de mariage à un couple de laïcs ${ }^{215}$, lorsque Moïse tonsure un certain nombre de $\operatorname{clercs}^{216}$, lorsque Nature proteste auprès de Grâce de Dieu suite à la transsubstantiation ${ }^{217}$, etc. Dans tous ces cas, récits, dialogues et descriptions supposent évidemment la présence du Pèlerin en tant que relais focal; toutefois aucun mot, ni nom ni pronom, ne le désigne dans les rubriques de ces chapitres. Il faut donc que l'enlumineur ait lu le poème pour songer à montrer le Pèlerin, alors qu'il reste un témoin extérieur à la scène dans le poème, et que sa présence est passée sous silence dans les titres correspondants - à moins que l'enlumineur ne s'inspire là du modèle fourni par un Pèlerinage antérieur ${ }^{218}$.

Quoi qu'il en soit, peut-on retenir l'hypothèse émise par Richard K. Emmerson, à savoir que la mise en œuvre de rubriques développées combinées à des images aurait invité les lecteurs à négliger le texte en vers pour

211. Ms. Paris, Bibl. Sainte-Geneviève, 1130. Un écart chronologique assez important sépare les deux manuscrits, celui de Sainte-Geneviève ayant été réalisé v. 1390 alors que son dérivé date $d u$ second quart $d u x^{e}$ siècle. Toutefois l'imitation à laquelle se livra le peintre ayant réalisé le frontispice du ms. fr. 376 fut assez minutieuse pour induire Paulin Paris en erreur quant à sa date de confection (ibid., p. 114, n. 23).

212. Voir M. Camille, The illustrated manuscripts..., p. 267 et 78-89, pour une étude approfondie de ce manuscrit.

213. Voir ci-dessus, p. 504.

214. Chap. I-13, fol. 4vb.

215. Chap. I-15, fol. $6 \mathrm{~b}$.

216. Chap. I-16, fol. 6 va.

217. Chap. I-23, fol. 10va.

218. Le Pèlerin n'est pas toujours représenté assistant au mariage, à la tonsure des clercs ou au banquet de Moïse. Ainsi par exemple, dans BnF 4, ces scènes sont-elles peintes de telle manière que le lecteur les découvre directement, sans passer par le relais du Pèlerin qui n’y est pas figuré. Son absence ne surprend d'ailleurs guère, même dans un manuscrit où les rubriques égrènent à l'envi le nom de l'auteur : c'est bel et bien l'autorité du narrateur qu'elles cherchent à promouvoir, et non le personnage du Pèlerin. 
laisser leur regard sauter d'une enluminure ainsi glosée à la suivante ${ }^{219}$ ? Pas véritablement, compte tenu de l'absence de tout élément anaphorique, pronom ou verbe vicaire, unissant ces rubriques.

7. Rubriques et vignettes : deux apparats indissociables. - Dans Lond 1, comme dans bien des volumes contemporains, les rubriques et les miniatures, systématiquement associées, doivent se partager l'espace ménagé par le copiste, soit ici entre neuf et quinze unités de réglure. En réalité, le rubricateur étant intervenu le premier après le copiste, l'enlumineur a dû se satisfaire de l'espace qui restait, une fois les titres intermédiaires consignés en rouge - du moins les titres de premier niveau, puisqu'on a vu que les rubriques attribuant des discours directs viennent se placer aux marges du poème. Dans plus d'un cas, les tensions qui habitent cet espace sont perceptibles dans la page actuelle, l'enlumineur donnant l'impression d'avoir été acculé, sous la pression de rubriques excessivement développées, à coloniser certains des espaces situés en-dehors du rectangle de justification ${ }^{220}$. Ailleurs, il s'est résigné à réaliser sa vignette dans un rectangle dont la largeur est très nettement supérieure à la hauteur ${ }^{221}$. Même lorsqu'il peint ses miniatures au sein de l'espace justifié, l'enlumineur les inscrit régulièrement dans un cadre en forme de polygone plutôt que de rectangle, s'étendant sur la ligne incomplète qui suit souvent la rubrique. On a l'impression que les miniatures viennent ainsi épouser au plus près les contours du texte, ou à l'inverse qu'un fragment de texte est venu empiéter sur l'espace rectangulaire de la vignette ${ }^{222}$. Par contraste, il arrive aussi que les derniers mots de la rubrique n'occupent pas la fin de la ligne et que le cadre de la miniature soit néanmoins tracé à la ligne suivante ${ }^{223}$, sans être précédé d'un bout-deligne, en sorte qu'il reste une portion de ligne blanche entre rubrique et

219. Voir ci-dessus, n. 196.

220. Dès lors qu'une vignette se trouve à l'extrémité d'une colonne, elle tend à coloniser la marge de tête ou de la marge de queue. Ainsi la miniature du fol. 10a s'étend-elle dans la marge inférieure, celles des fol. 22vb et 24a dans la marge supérieure. Le même débordement ne s'observe jamais dans les marges de gouttière, de couture, ni même dans l'entrecolonne.

221. Certaines miniatures réalisées sous des rubriques particulièrement développées ont vu leur hauteur réduite d'autant, jusqu'à ne représenter que deux tiers de leur propre largeur (fol. 10va, 21va, 22va, etc.), voire à peine plus de la moitié (fol. 13a, et plus encore fol. 27b).

222. Voir au fol. 1va, où les mots « la loi » semblent mordre sur le rectangle de la vignette; au fol. $3 \mathrm{~b}$, où il en va de même pour les mots « elle est »; au fol. $6 \mathrm{~b}$, où le mot « mariaige » s'inscrit dans le coin supérieur gauche de la vignette; au fol. 6va, où les mots « toute leur vie » occupent la même position; etc. R. Emmerson y voit un signe de continuité entre les rubriques et les images, une invitation à lire les secondes comme un prolongement des premières, « [as] the miniature is introduced by a rubric that leads directly into the image, breaking its upper frame » (« Translating images... », p. 287). Son analyse n'exclut pas la précédente : un problème d'ordre technique, celui que posait la tension entre dimension des réserves et développement des rubriques, a pu être surmonté en imbriquant étroitement les mots rubriqués et les images, favorisant ainsi jeux et continuité entre ces deux apparats.

223. Voir par exemple aux fol. 2va, 3vb, 4b, 12vb, etc. 
vignette. Cela arrive rarement, et les artisans ont travaillé à saturer l'espace de la colonne. Le principe du rectangle plein n'est cependant jamais étouffant, d'abord parce que les rubriques et les images peintes y ménagent des respirations tout aussi lumineuses que le seraient des blancs; ensuite grâce à la générosité des marges ${ }^{224}$.

Les relations qui unissent rubriques et enluminures ne sont pas limitées au délicat partage de l'espace des colonnes. Dans chaque manuscrit rubriqué et enluminé, le contenu des titres en rouge peut se répercuter sur celui des images : le miniaturiste effectue sa besogne après le rubricateur, et il a donc sous les yeux des titres intermédiaires qui peuvent influencer son interprétation du poème et les motifs qu'il choisit pour l'illustrer. Dans le cas singulier du Pèlerinage, l'influence peut aussi s'exercer des enluminures aux rubriques, non pas dans une même copie, mais d'un manuscrit à un autre. En effet, le premier Pèlerinage de Guillaume de Digulleville a été associé très tôt, voire dès sa composition, à un cycle iconographique original et conséquent ${ }^{225}$. Une majorité des copies comportent des enluminures, souvent nombreuses ${ }^{226}$, et ce depuis les témoins les plus anciens ${ }^{227}$. Or, par contraste, on a vu que la subdivision en chapitres y est assez rare, surtout avant le $\mathrm{Xv}^{\mathrm{e}}$ siècle. Aussi le sujet et la position des enluminures présentes

224. Dans Lond 1, l'espace de la page est presque également réparti entre marges et colonnes justifiées, les marges occupant $54 \%$ de la surface de la page; de telles proportions sont courantes parmi les témoins de PVH1 (G. Veysseyre, « Une trilogie... », p. 290, partic. n. 8).

225. Voir M. Camille, The illustrated manuscripts..., p. 1-19 (« Introduction : Guillaume de Deguileville and the image »). La question de savoir si Guillaume a conçu, en même temps que son Pèlerinage, un programme d'illustrations demeure délicate à résoudre. Le poème lui-même contient quelques données sur le sujet, notamment en deux lieux-clés : d'une part la description de l'équerre de paix, dont le poème prévoit la représentation (citée et analysée ibid., p. 10), d'autre part l'intervention du narrateur lorsqu'il affirme avoir commandé une représentation picturale de Satan, au prétexte que la rhétorique textuelle était insuffisante à peindre sa monstruosité : «Ordené ai que painturee | elle soit ci et figuree | pour que qui voudra la voie » (PVH1, v. 11479-11481, cités et analysés dans M. Camille, The illustrated manuscripts..., p. 12-13). En-dehors de ces deux images, assurément prévues, la question reste pendante. M. Camille la déplace d'ailleurs du côté de la tradition manuscrite du premier Pèlerinage : du fait du grand nombre de manuscrits illustrés du poème, il considère que le cycle iconographique fait partie intégrante de la transmission du poème (ibid., p. 5).

226. On compte 40 manuscrits enluminés de la première rédaction du Pèlerinage (sur 69 copies connues), auxquels s'ajoutent 8 copies restées inachevées, où des réserves avaient été ménagées pour les illustrations. En moyenne, ces manuscrits comptent 67 miniatures chacun. Par contraste, seules quelque 20 copies du poème ne prévoyaient, dès leur confection, aucune image (G. Veysseyre, «Une trilogie... », p. 291-292).

227. M. Camille, The illustrated manuscripts..., p. 20-65 (chap. I : « The earliest illustrations of the Pelerinage de vie humaine »), partic. p. 20, où il est question de la plus ancienne copie datée du poème, le ms. New York, Morgan Library and Museum, 772, confectionné en 1348 et comportant 110 miniatures (ibid., p. 306; voir aussi ci-dessus, note 15). Le ms. Munich, Bayerische Staatsbibl., gall. 30, à peu près contemporain du précédent, comporte quant à lui 127 illustrations (ibid., p. 303 et ci-dessus, note 15). Ce ne sont pas des exemples isolés, loin de là (voir la note précédente). 
dans les manuscrits ayant servi de modèles ont-ils pu exercer une influence notable sur la structuration en chapitres de leurs descendants. Les représentations les plus répandues ont aussi pu contribuer à modeler les titres des manuscrits ultérieurs; mieux, avec le cycle iconographique d'un manuscrit ont pu être copiés des fragments de rubriques qui y accompagnaient les images. Ainsi, soit à l'échelle d'un seul manuscrit, soit à l'échelle plus vaste d'une tradition manuscrite complexe, on observe des échanges dialogiques entre cycles iconographiques et programmes de rubriques.

Ces interactions dynamiques permettent de rendre compte d'au moins une des incongruités que présente, au premier regard, la titulature de Lond 1. Parmi ces éléments d'abord énigmatiques figure l'emploi, parmi les premiers titres rubriqués, du mot histoire au sens de « représentation picturale d'une scène à plusieurs personnages ${ }^{228}$. La clausule de plusieurs de ces rubriques prend la forme de consignes destinées à l'enlumineur : «Cy commence le Pelerinaige de vie humainne exposé sus le Roumant de la Rose. Hystoire comment il songe en dormant en son lit et aprés come il escript son livre » ${ }^{229}$; «L'istoire est seulement du cherubin qui deffend l'entree ou ${ }^{230}$ l'espee » ${ }^{231}$. De ces deux directives, la première n'a manifestement pas été appliquée, puisque la description qu'elle propose est en porte-à-faux par rapport au frontispice $^{232}$. En outre, la première comprend un pronom anaphorique dépourvu de toute source d'anaphore, le sujet du verbe songe ne pouvant se rattacher que de manière très lâche, par une anaphore bien insatisfaisante, au nom précédent Pèlerinaige qui abrite la notion de Pèlerin. L'usage est d'autant plus surprenant que, même lorsqu'il serait licite d'employer un pronom anaphorique entre deux rubriques successives, le rubricateur ne le fait jamais. Alors pourquoi aurait-il employé un pronom anaphorique dépourvu de toute source dans sa première rubrique? Sans aucun doute parce qu'il n'a pas composé lui-même cette rubrique, mais qu'il en a hérité, d'une manière ou d'une autre. D'ailleurs, les deux mentions d'istoires précédemment citées ne sont pas l'apanage de Lond 1 : d'autres copies du Pèlerinage présentent en ces deux points des rubriques analogues. Tel est notamment le cas de $\mathrm{BnF} 4$ et Brux $3^{233}$. Sans que l'analogie que présentent ici leurs rubriques soit

228. DMF : Dictionnaire du moyen français, version 2012 (ATILF, CNRs/Nancy université), en ligne (www.atilf.fr/dmf, consulté le 24 mars 2015).

229. Fol. 1a, rubrique est copiée à longues lignes sous le frontispice sur toute la largeur de la page et non seulement d'une colonne comme toutes les rubriques et vignettes qui suivent.

230. La graphie ou est ici une forme de la préposition $o$ (d) (« avec, au moyen de »).

231. Fol. 1va. Voir le début de cette rubrique en Annexe I, p. 530.

232. Pour une description détaillée de ce frontispice, voir Annexe I; ou encore G. Veysseyre, « Une trilogie... », p. 313-314 et n. 90.

233. Ces derniers portent les rubriques suivantes : « Ci commence la devision du songe au moyne. Histoire du moyne qui songe » ( $\mathrm{BnF} 4$, fol. $1 \mathrm{~b}$; je souligne, dans ce cas comme dans les suivants), et « $\mathrm{Ci}$ commence la devision du songe au moine. Hystore d'un moine qui songe en son lit » (Brux 3, fol. 1va); puis « Comment l'aucteur devise la deffense de l'entree de la cité. Histoire de Cherubin qui tient une espee ardant a la porte de la cité pour deffendre l'entree. 
inattendue, puisque leurs titres intermédiaires remontent probablement à un modèle commun ${ }^{234}$, la présence de ces deux mentions dans Brux 3 fait problème. En effet, aucune de ces deux consignes ne trouve de traduction idoine dans l'iconographie. D'abord, la scène que représente le frontispice ne correspond nullement à la rubrique citée : ce n'est pas un moine en train de songer qui y est figuré, mais un prédicateur s'adressant, du haut de sa chaire, à la foule ${ }^{235}$. En outre, cette rubrique n'est pas la première, mais la seconde, si bien qu'elle se trouve au verso du premier feuillet, au recto duquel ont été copiés, à la suite du frontispice, les vers 1 à 33 du Pèlerinage ${ }^{236}$. La mention invitant à représenter Chérubin gardant la Jérusalem céleste est en décalage plus patent encore avec l'illustration de Brux 3. En effet, pour tout cycle iconographique, le Pèlerinage de Philippe le Hardi ne comporte que le frontispice évoqué. Aucune autre miniature n'y a été prévue, comme l'atteste l'absence totale de réserves au-delà de la première page. Ainsi l'appel lancé par la rubrique à la réalisation d'une miniature est-elle incompatible avec la mise en page. Si le rubricateur l'a consignée sans y réfléchir, ou en dépit de cette difficulté, c'est qu'il l'a héritée d'un modèle.

8. Le rubricateur de Lond 1, «éditeur » du poème. - Sylvia Huot évoque, à propos de deux témoins du Roman de la Rose, le rôle du scribe en tant qu' « éditeur » lorsqu'il adjoint des rubriques au texte ${ }^{237}$. Le terme est plus ou moins approprié selon la manière dont le rubricateur se positionne par rapport à l'instance d'émission du texte qu'il scande de ses titres intermédiaires. Néanmoins, quels que soient ses choix, ils nous informent à la fois sur sa réception du texte et sur le rôle qu'il prétend jouer dans sa transmission. Deux options se sont précédemment dégagées face au feuilletage énonciatif qui caractérise le poème allégorique de Guillaume. La première consiste à servir de porte-voix régulier au narrateur en rappelant que tous les énoncés émanent de la voix de cet « acteur ». Tel est le parti qu’a pris le rédacteur des rubriques désormais conservées dans Brux 3 et BnF 4. Loin de prétendre se substituer au narrateur, il amplifie constamment l'autorité de ce dernier en tant qu'entité dont émanent récit, dialogues et commentaires. Par ce choix, il se prive de l'autonomie nécessaire au travail d'un véritable « éditeur » du poème.

L'aucteur parle » (BnF 4, fol. 1a), et « Comment l'aucteur devise la deffense de l'entree de la cité. Hystoire de Cherubin qui tient I espié ardant a la porte de la cité pour deffendre l'entree. L'aucteur » dans le manuscrit de Philippe le Hardi (Brux 3, fol. 1va).

234. Voir ci-dessus, p. 489.

235. Qualifié par M. Camille de « magnificent grisaille picture », ce frontispice est longuement analysé dans The illustrated manuscripts..., p. 72-78.

236. La première rubrique (« Hic incipit sompnium peregrinationis humane vite »), de la même écriture que les suivantes, intervient entre le frontispice et la première colonne de texte.

237. S. Huot, « The scribe as editor : rubrication as critical apparatus in two manuscripts of the Roman de la Rose », dans L'esprit créateur, t. 27 : The poetics of textual criticism : Old French texts, 1987, p. 67-78, notamment p. 77. 
L'auteur des rubriques consignées dans Lond 1 a fait le choix opposé : mentionnant peu l'auteur - sauf à l'orée du songe, pour rappeler son identité -, il assume ensuite en son nom propre les récits brefs, les descriptions et les commentaires qui composent ses rubriques. Il ne sert donc pas seulement d'amplificateur aux voix contenues dans le poème, et tout particulièrement à celle du narrateur. Il conserve, par rapport à cette dernière, l'indépendance qui lui est nécessaire pour jouer le rôle d'un véritable « éditeur » du poème. Sans doute est-ce la raison pour laquelle il est le seul, parmi les trois systèmes de rubrication observés, qui fournisse à diverses reprises des interprétations du système allégorique construit par Guillaume de Digulleville - des interprétations suggérées par le poème lui-même :

«... Jherusalem, par laquelle doit estre entendu paradis et les joies qui y sont » (chap. I-2, fol. 1b);

«... comment les docteurs sont aux carneaulx, qui enseignent les gens a faire ailles et comment d'aucuns le font [...], et est entendu les sains apostres et aultres sains et prescheurs qui preschent les XII articles de la foi et $\mathrm{x}$ commendemens de la loi » (chap. I-4, fol. 1vb);

« ... comment l'official de Dieu vint au pelerin et comment il le lava en eaue, par quoi il est entendu le sacrement de baptesme » (chap. I-11, fol. 4b);

«... Comment le vycaire bailla a l'official III oingnemens, qui sont le cresme saint, le saint oile et l'oile des malades » (chap. I-13, fol. 4vb);

«... comment il conjoint ung homme et une femme ensemble, par quoi il est entendu le sacrement de mariaige » (chap. I-15, fol. 6b);

«... comme l'evesque Moÿses fist et consacra ses officiaulz, c'est assavoir les prestres » (chap. I-18, fol. 7va);

«... comment le pain fu mué en char et le vin en sang, [...] et de ce doit estre entendu le sacrement de l'autel » (chap. I-22, fol. 10a).

« Et Charité tenoit une lettre ouverte, qui est a entendre le Nouveau Testament » (chap. I-25, fol. 13a).

« et le bourdon signifie les x commendemens » (chap. I-28, fol. 21va).

Les enseignements de ce type sont au total assez rares; et si l'on n'avait pas sous les yeux le Pèlerinage, on pourrait aisément les imaginer de la plume de son auteur, tant ils sont rédigés à sa manière et dans son esprit. Le rubricateur édite là son poème au sens où il déplie des éléments restés implicites dans l'allégorie. Il le fait en introduisant ses explications par le biais de formules consacrées pour les gloses : verbe entendre au passif, signifier, c'est assavoir, etc. Quant à ses gloses, elles décryptent des objets allégoriques que Guillaume avait conçus de manière assez univoque pour les exempter de toute ambiguïté.

Les commentaires explicatifs du rubricateur, présents dans plus d'une glose sur trois à l'orée des 28 premiers chapitres, disparaissent ensuite totalement jusqu'à la fin du livre IV. Le rubricateur les a sans doute conçus comme une propédeutique au système du Pèlerinage, et plus largement aux modes de représentation inhérents à la littérature allégorique; ses destinataires n'étaient nécessairement familiers ni de l'un ni de l'autre. Une fois le méca- 
nisme enclenché, le rubricateur-éditeur suppose, comme Guillaume luimême, un lecteur qui progresse et qui n'aura plus besoin, à partir des longs développements touchant l'écharpe et le bourdon, de telles explications.

Par la suite, quoique le rubricateur n'élucide plus de manière aussi explicite le contenu allégorique, il travaille tout de même à faciliter l'approche du poème. Ainsi les résumés anticipés qu'il fournit en tête de chaque chapitre, en paraphrasant au moins les premiers développements de ces derniers, en élucident bien des difficultés, notamment en levant l'ambiguïté de certains des mots employés par Guillaume. Quelques exemples permettent de comprendre l'esprit dans lequel il a travaillé, en premier lieu la rubrique introduisant le chap. I-38 (v. 4815-4968), qui annonce l'entrée en scène du personnage de Mémoire. Cette dernière est d'abord désignée, dans le poème, par le nom « meschine ${ }^{238}$. Ce substantif, usuel au $\mathrm{xv}^{\mathrm{e}}$ siècle, est polysémique. En effet sa dénotation peut être large sur le plan de la catégorie sociale, mais restreinte sur le plan de l'âge, auquel cas il désigne une jeune fille; il peut aussi être général quant à l'âge, mais plus restrictif en termes de catégorie sociale, et renvoyer alors à une servante ${ }^{239}$. Pour orienter d'emblée son lecteur vers l'une de ces deux interprétations, le rubricateur de Lond 1 désigne Mémoire par le nom « chambriere » ${ }^{240}$, qui rend d'emblée perceptible son statut ancillaire ${ }^{241}$. Le rubricateur ne procède de cette manière que lorsque le co-texte immédiat lui semble dépourvu des informations permettant de comprendre un mot comme il se doit. Ainsi n'a-t-il pas renoncé, dans ses titres, à conserver le mot « pucelle » employé par Guillaume lors de l'entrée en scène de Raison (chap. I-14, fol. 5a). Ce substantif est tout aussi ambigu que meschine, puisqu'une pucelle peut être une « jeune fille » ou bien une « suivante » ${ }^{242}$; mais dans ce cas, le personnage entre en scène en descendant de l'une des «tournelle[s] » (v. 574) de son imposante maison, et surtout la figure est immédiatement identifiée par son nom (v. 575). Pour cette raison, le rubricateur s'en est tenu à la terminologie du Pèlerinage.

Il est d'autres cas où le rubricateur modifie le vocabulaire du poème allégorique en vers : lorsqu'il lui semble que le narrateur n'a pas employé le mot le mieux approprié. Un tel remaniement, caractéristique de l'esprit dans lequel furent composées les mises en prose de la fin du Moyen Âge,

238. PVH1, p. 149, v. 4815-4819 : « Ainsi qu'en ce point estoie | et qu'a moi tout seul devisoie, | Grace Dieu vi qui amenoit | une meschine qui n’avoit | Nulz iex... »

239. Robert Martin, art. « Meschine », dans $D M F$...

240. Fol. 28a, voir la rubrique, Annexe I, p. 536.

241. On observe ici un écart entre la paire BnF 13-BnF 22 d'une part et Brux 3, d'autre part. Dans les premiers, le terme meschine, employé dans le corps du poème allégorique, est calqué au sein des rubriques; dans Brux 3 au contraire, c'est le mot chamberiere qui est employé, comme dans Lond 1; BnF 4 n'offre pas ici de point de comparaison, ses chapitres n'étant pas délimités de la même manière (voir Annexe II, p. 552-553). Coïncidence ou héritage d'un modèle antérieur aux deux familles auxquelles appartiennent ces manuscrits, cet infléchissement lexical reflète les préoccupations pédagogiques des rubricateurs.

242. R. Martin, art. « Pucelle », dans $D M F . .$. 
s'observe notamment en tête du chapitre consacré à la tonsure par Moïse d'un certain nombre de clercs. Sous la plume de Guillaume, Moïse se munit d'« unes forces » pour « tondre » les futurs hommes d'Église ${ }^{243}$. Il s'agit de grands ciseaux employés, d'après les occurrences citées par le Dictionnaire du moyen français, non seulement pour couper les cheveux, mais encore pour tondre les moutons ${ }^{244}$. Ce n'est sans doute pas par hasard ni par souci du mètre que le poète cistercien, dont le verbe est volontiers pittoresque, a employé ce substantif. Suggère-t-il discrètement ainsi que les clercs tonsurés par Moïse, eux-mêmes pasteurs, sont guidés par un pasteur encore plus éminent qu'eux? Quoi qu'il en soit, il magnifie l'outil dont Moïse est doté. Le rubricateur dote le personnage de Moïse d'un outil moins impressionnant, puisqu'il évoque en tête du chapitre I-16 des « forcettez », forme diminutive répertoriée au sens générique de « petits ciseaux », notamment dans des textes évoquant les outils des médecins ou des chirurgiens ${ }^{245}$. Il est difficile de dire, dans ce cas, si l'enlumineur a suivi Guillaume ou le rubricateur : dans sa représentation de la scène de tonsure, les ciseaux utilisés par Moïse sont en grande partie cachés par la tête de l'un des aspirants (fol. 6va). Quoi qu'il en soit, le diminutif qui apparaît dans la rubrique rattache son auteur à la grande famille des remanieurs et des dérimeurs de la cour de Bourgogne, dont la tendance commune est de niveler les images et de rendre plus conventionnelles les descriptions de leur modèle ${ }^{246}$. Les forcettes semblent en effet plus usuelles que les forces entre les mains des clercs chargés de tonsurer leurs semblables. On les trouve ainsi dans la traduction française

243. PVH1, p. 27, v. 831-833.

244. R. Martin, art. « Forces », dans $D M F$.. Dans sa seconde acception, le terme est d'ailleurs encore employé dans la langue contemporaine; en témoigne notamment le Trésor de la langue française.

245. R. Martin, art. « Forcettes », dans $D M F$...

246. De telles transformations s'observent tout particulièrement lorsque des prosateurs bourguignons ont été amenés à dérimer des chansons de geste antérieures : les vocables, images pittoresques et récits de bataille qui caractérisaient leur rédaction versifiée ont alors été largement affadis. C'est notamment dans cet esprit que Jean Wauquelin remania la Belle Hélène de Constantinople (voir notamment l'introduction à Jean Wauquelin, La Belle Hélène de Constantinople : mise en prose d'une chanson de geste, éd. Marie-Claude de Crécy, Genève, 2002 (Textes littéraires français, 547), ou encore C. Roussel, « Les rubriques... », p. 202). Le phénomène, qui n'est d'ailleurs pas propre aux auteurs bourguignons, a souvent plus de portée que n'en ont les modestes ajustements observés ici. Comme le rappelle Michel Zink en évoquant le développement de la prose qui caractérise la fin du Moyen Âge et les nivellements génériques qui en résultent (voir aussi ci-dessus, n. 5), l'extension de « la narration en prose divisée en chapitres » a alors pour « conséquence que l'attente du public est la même quelle que soit l'histoire racontée, et qu'elle dérive d'une chanson de geste, d'un roman antique ou breton, d'un récit hagiographique. La vision du monde propre à chacun de ces genres perd dès lors de sa spécificité aux yeux du lecteur et se fond dans une sorte de syncrétisme idéologique commun à toute la littérature narrative » (M. Zink, La littérature française du Moyen Âge, Paris, 1992, p. 331-332). Par contraste, les rubriques insérées dans le poème de Guillaume de Digulleville ne modifient pas l'inscription générique d'un Pèlerinage qui demeure narratif, didactique et allégorique. 
(par Jean de Vignay) du Ludus scacchorum de Jacques de Cessoles, et même dans la version anglaise imprimée par Caxton, où il est respectivement question de «forcettes » et de « forcettis » 247 .

Dans l'ensemble, quel est l'écart de perception entre un lecteur découvrant le Pèlerinage dans la copie Lond 1 et celui qui aurait eu affaire à la masse continue d'octosyllabes consignés, par exemple, dans le précoce $\mathrm{BnF}$, fr. 1818? L’usager de Lond 1 est placé sous la double tutelle du narrateur et de son exégète. À la fois il y gagne et il y perd : son parcours est plus aisé, la segmentation du texte lui permet des pauses commodes et l'aide à se remémorer les épisodes antérieurs. En outre, quelques-unes des difficultés lexicales, ainsi qu'un certain nombre d'ambiguïtés, sont levées par les gloses que constituent les rubriques. Toutefois, découvrir le poème en suivant ce sentier balisé, c'est se priver de certains des plaisirs d'une lecture plus aventureuse. La perte est particulièrement sensible dans la partie médiane du poème, lorsque le Pèlerin est assailli par les différents vices. Le plaisir du texte - et les enseignements qui en découlent - tient là à une savante combinaison entre le connu et l'inconnu, le topique et l'incongru, le prévisible et la surprise. La plupart des lecteurs avaient sans doute en tête la liste des vices, égrenés par tous les catéchismes et par tous les prédicateurs de la fin du Moyen Âge ${ }^{248}$. Toutefois, comme leur ordre d'apparition n'est pas tout à fait uniforme et que Guillaume a su rehausser leurs attributs éculés à sa manière pittoresque, il assure à ses lecteurs le double plaisir d'identifier ces monstres composites grâce à leurs traits usuels tout en les découvrant sous un jour renouvelé. D'ailleurs, pour conserver l'attention de son lecteur au long des épisodes concernés, le narrateur retarde volontiers le moment où le péché se nomme : c'est tardivement qu'y est dévoilée une identité dont les contours se dessinent par touches successives, dans les réponses aux questions souvent pressantes du Pèlerin ${ }^{249}$. Dans la version rubriquée, tout effet de suspens est sapé par le dévoilement anticipé du nom, qui se fait dès le titre du chapitre ou de la série de chapitres à venir. Ce n'est sans doute pas le seul infléchissement induit par la segmentation en chapitres rubriqués, mais c'est le plus évident.

La présence de rubriques dans les cinq témoins examinés accentue la coloration didactique du premier poème allégorique de Guillaume. À force

247. William Caxton, The Game and Playe of the Chesse, éd. Jenny Adams, Kalamazoo (Mich.), 2009 (Middle English Texts Series), chap. III, 1.318 (je remercie Florence Bourgne de m'avoir signalé l'emploi du terme dans ces deux textes).

248. On la trouve par exemple dans l'Elucidarium, puis dans ses diverses traductions romanes (Martha Kleinhans, "Lucidere vault tant a dire comme donnant lumiere ». Untersuchung und Edition der Prosaversionen 2, 4 und 5 des « Elucidarium », Tübingen, 1993, par exemple p. 542-543); dans la Somme le roi de frère Laurent dont la troisième partie est un traité des vices (éd. Édith Brayer et Anne-Françoise Leurquin-Labie, Paris, 2008, p. 113-172); etc.

249. Ainsi Ire fournit-elle bien des informations sur sa nature (v. 8797-8873) avant de dévoiler enfin son nom : « Ire sui la reboulee » (v. 8877). Les péchés suivants procéderont tous de même, créant chez le lecteur par l'intermédiaire du Pèlerin un effet d'attente. 
de faire ressortir l'armature du poème, elles pourraient donner l'impression à un lecteur un peu pressé qu'il a affaire à un traité plutôt qu'à un poème narratif, à une liste de figures allégoriques plutôt qu'à une voie littéraire. C'est au prix de tels infléchissements que le Pèlerinage a pu être reçu dans un milieu bourguignon dont les habitudes de lecture différaient largement de celles qui avaient prévalu parmi les premiers destinataires.

La trilogie de Pèlerinages conservée dans le ms. BL, Add. 22937, copie de luxe commandée dans les années 1460 par un couple d'aristocrates bourguignons, restée inachevée et sans descendance ${ }^{250}$, résulte d’un projet dont les ambitions sont attestées par son important volume textuel, puisque les trois Pèlerinages y étaient réunis; par ses enluminures nombreuses; et surtout - sa principale originalité - par ses rubriques développées, rédigées ad hoc. Ces dernières n'équipent pas seulement le poème allégorique d'un type d'apparat associé à la plupart des proses du xve siècle : mises en série, elles constituent une forme de dérimage - certes abrégé et fragmentaire - du Pèlerinage de vie humaine en octosyllabes.

Leur rédacteur n'est sans doute autre que le copiste, surtout si Lond 1 a été produit selon les mêmes modalités que BnF 13. En effet les marges de ce dernier portent trace de titres apposés dans une écriture de tout petit module, qui auraient dû être rognés après avoir été reportés à l'encre rouge dans les réserves prévues à cet effet, mais dont certains nous sont restés ${ }^{251}$. Il est probable que des titres d'attente analogues se trouvaient dans les marges de Lond 1. Toutefois on ne saurait exclure l'hypothèse que le manuscrit de Claude de Montaigu et Louise de La Tour ait eu un ancêtre immédiat, voire plusieurs, qui auraient pu fournir le modèle aussi bien de ses titres intermédiaires que de son programme iconographique.

Quel que soit le niveau auquel se situe son intervention, l'auteur des rubriques consignées dans Lond 1 a travaillé avec soin, sous le poids de différentes contraintes et en direction de plusieurs destinataires. Les rubriques qu'il a conçues, sans parvenir toujours à embrasser la totalité de chaque chapitre, sont pertinentes, homogènes et efficaces. Leur contenu et leur forme ont dû permettre de guider à la fois les enlumineurs et les lecteurs, même s'il

250. Dans Lond 1, les v. 8904 à 10059 du Pèlerinage ont été copiés selon un ordre problématique. Sans que l'on observe de solution de continuité matérielle, les séquences se suivent ainsi : v. 9860-10059 (fol. 50a-50vb), v. $9071-9859$ (fol. 51a-54vb), v. $8904-9070$ (fol. 55a-55vb), enfin v. 10060-13540 (fol. 56a-74vb). Or ces vers sont copiés selon l'ordre attendu dans tous les autres témoins consultés à ce jour. D’autres fautes spécifiques à Lond 1 sont absentes du reste de la tradition manuscrite : la substitution de « Pour aussi » à « D'ouïr aussi » au v. 4097 de PVH1; celle de « Fait ne vous en pourroit laver | Ne l'eaue qui fait le moulin tourner » aux v. 5331-5332 de PVH1 (« L'eaue qui le moulin tourner | Fait ne vous en pourroit laver »); l'omission de «que penser » au v. 10281 de PVH1 (« Je ne sceu que penser ne faire »); etc. Autant d'indices que ne nous sont parvenus ni descendants, ni modèles proches de cette copie bourguignonne.

251. Voir Annexe II, notes 140, 150, etc. 
n'est pas certain que ces derniers en aient fait grand usage : le manuscrit est dépourvu de toute marque de lecture ${ }^{252}$. Qu'il ait été utilisé ou non par ses premiers possesseurs, toujours est-il qu'il ménageait la possibilité d'un parcours fragmenté, joignant l'utilité d'une lecture instructive au plaisir de contempler de belles images.

L'existence d'un tel manuscrit est un facteur d'explication du faible succès de la mise en prose angevine du premier Pèlerinage en milieu bourguignon : elle y est représentée par un seul témoin, ce qui est peu quand on sait le goût de ce milieu pour les mises en prose d'horizons variés. Il est vrai que le Pèlerinage en prose a été rédigé tardivement, en 1465, à un moment où le phénomène des mises en prose avait déjà pris un essor décisif ${ }^{253}$. Et surtout le déploiement d'une structuration en chapitres, articulés par des titres relevant de la mise en prose, combinés ou non avec des illustrations, s'est peutêtre imposé pour le Pèlerinage en milieu bourguignon depuis le règne de Philippe le Hardi et son manuscrit KBR, 10197-10198 (confectionné avant la fin du XIV ${ }^{\mathrm{e}}$ siècle). Ce n'est sans doute pas un hasard si c'est au milieu bourguignon que se rattachent trois des manuscrits dotés de rubriques développées - par ordre chronologique de réalisation, le manuscrit de Philippe le Hardi; le ms. BnF, fr. 12462, cédé par une princesse bourguignonne à sa fille lors du départ de cette dernière pour la Savoie ${ }^{254}$; enfin la trilogie de Lond 1.

252. Le manuscrit est exempt d'annotations, et notamment de marginalia. Or, même si l'on a pu écrire que les notes marginales tendaient à se raréfier dans les manuscrits du bas Moyen Âge par rapport à ceux du Moyen Âge central (François Dolbeau, « Les usagers des bibliothèques », dans Histoire des bibiothèques françaises, t. I, Les bibliothèques médiévales du VIe siècle à 1530, dir. André Vernet, rééd., Paris, 2008, p. 522-550, aux p. 532-533), les témoins du premier Pèlerinage en octosyllabes soit sont exceptionnels, soit amènent à mettre en doute l'assertion de F. Dolbeau. En effet les commentaires marginaux y abondent, y compris dans les manuscrits très soignés (voir G. Veysseyre, « Manuscrits à voir, manuscrits à lire, manuscrits lus? Les marginalia du Pèlerinage de vie humaine comme indices de sa réception médiévale », dans The « Pèlerinage » allegories..., p. 47-63, partic. p. 62 à propos du ms. Arras, Bibl. mun. 532 (845), où le texte, illustré de 105 miniatures, est aussi abondamment annoté). Contrairement à bien d'autres copies du premier Pèlerinage, Lond 1 est dénué de notes marginales. Je n'y ai pas repéré non plus de traces de cire qui pourraient laisser penser qu'une chandelle est restée longtemps allumée au-dessus de ses feuillets ouverts (indice invoqué par Marie-Hélène Tesnière à propos d'un manuscrit de Charles $\mathrm{V}$, lors d'une conférence inédite donnée le 4 février 2011 à l'École normale supérieure de Paris sous le titre « Les manuscrits de Charles V ont-ils été lus? »).

253. C'est surtout au milieu du $x^{\mathrm{e}}$ siècle que la mise en prose se répandit (G. Doutrepont, Les mises en prose..., p. 3). Deux dérimages sont répertoriés avant 1400 (ibid., p. 363) et le phénomène reste peu dynamique avant 1445 environ (ibid.). Les travaux en cours pour « refaire Doutrepont » permettront sans doute d'affiner sa chronologie et de mettre en lumière de nouveaux cas avant 1445, sans bouleverser toutefois les acquis (M. Colombo Timelli, « Refaire Doutrepont? Projet pour un nouveau répertoire des mises en prose des $\mathrm{XV}^{\mathrm{e}}$ et $\mathrm{XVI}^{\mathrm{e}}$ siècles », dans Le moyen français, t. 63, 2008, p. 109-115 et t. 64, 2009, p. 1-12; et Nouveau répertoire des mises en prose (XIV ${ }^{e}-X V I^{e}$ siècle), dir. Maria Colombo Timelli, Barbara Ferrari, Anne Schoyman et François Suard, Paris, 2014).

254. Voir G. Veysseyre, « Une trilogie... », p. 300. 
Sans élucider toutes les difficultés inhérentes à des octosyllabes composés avant 1350 et riches en mots rares, ces titres intermédiaires permettaient aux lecteurs d'en aborder la lecture avec l'assistance de rubricateurs qui amplifiaient, relayaient ou prolongeaient l'effort didactique de Guillaume de Digulleville.

Il ne nous est guère parvenu, en guise de mise en prose du Roman de la Rose composé par Guillaume de Lorris et Jean de Meung, que le Roman de la Rose moralisé de Jean Molinet, conservé dans deux manuscrits seulement, et dont les ambitions dépassent celles d'un simple dérimage. Pourtant l'état de langue du Roman de la Rose du $\mathrm{XIII}^{\mathrm{e}}$ siècle, reflétant une composition antérieure au triptyque de Guillaume, et son succès, plus éclatant encore que celui des Pèlerinages jusqu'à la fin du $\mathrm{xv}^{\mathrm{e}}$ siècle, auraient pu appeler d'autres tentatives de mise en prose ${ }^{255}$. Le travail des rubricateurs s'est-il substitué à un dérimage en bonne et due forme, tout particulièrement à la cour de Bourgogne? La mise en ligne progressive de nombreux témoins du Roman de la Rose ${ }^{256}$ permettra peut-être de débusquer, dans l'un d'eux, un réseau de titres comparable aux rubriques qui scandent le manuscrit BL, Add. 22937. En attendant, la question demeure.

Géraldine VEYsSEYRE.

\title{
ANNEXES
}

\author{
I \\ RubriQues ET ENLUMINURES \\ DU Ms. Londres, BL, AdD. 22937 (CHAP. I-1 À II-5)
}

Cette édition se limite aux rubriques de premier plan, celles pour lesquelles le copiste a ménagé des réserves d'au moins une unité de réglure entre deux vers. L'édition couvre le premier tiers environ du Pèlerinage, soit la portion du manuscrit où presque toutes les enluminures répondant aux rubriques ont été réalisées. Par la suite, les enluminures manquent mais les méthodes du rubricateur ne changent guère, de telle sorte que l'échantillon ci-après est représentatif.

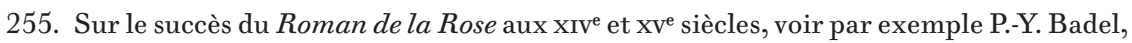
Le «Roman de la Rose »..., notamment p. Ix; F. Duval, Lectures françaises de la fin du Moyen Âge : petite anthologie commentée de succès littéraires, Genève, 2007 (Textes littéraires français, 587), p. 138-140; etc.

256. Sur cette numérisation, qui accorde d'abord la priorité aux copies du XIII ${ }^{\mathrm{e}}$ siècle, voir le site du projet « Roman de la Rose Digital Library », [en ligne :] http://romandelarose.org/ (consulté 2 avril 2014). 


\section{Conventions éditoriales :}

- Éléments de repérage précédant le texte de la rubrique : foliotation; numéro du livre et du chapitre; vers (entre parenthèses) du passage introduit par la rubrique, d'après l'édition de Johann Jakob Stürzinger [PVH1].

- Présentation du texte de la rubrique :

Le texte a été ponctué et les abréviations développées (entre parenthèses).

La barre verticale | signale un changement de ligne.

Les crochets droits [ ] encadrent, le cas échéant, la restitution de lettres en fin de ligne masquées sous l'enluminure.

Gras : mots empruntés au texte, verbatim ou presque (source indiquée en note). Italique : données ou explications absentes du texte, ajoutées par le rubricateur.

- Enluminure : après la rubrique figurent la mesure en unités de réglure [UR] et l'analyse de l'enluminure correspondante.

\section{Fol. 1 (frontispice) :}

Peinture bipartite occupant le tiers supérieur du feuillet ${ }^{1}$ : sur la gauche, dans un cadre architectural porté par des colonnes, un noble seigneur en habit orné de fourrure montre un livre ouvert posé sur un banc, dans le socle duquel d'autres ouvrages pourraient aisément être rangés ${ }^{2}$. Sur la droite, un rêveur endormi dans son lit, auprès duquel ne figure pas le traditionnel miroir avec la Jérusalem céleste.

Fol. 1a; chap. I-1 (v. 1-34) :

Cy commence le Pelerinaige de vie | humainne exposé sus le Roumant | de la Rose ${ }^{3}$. Hystoire $^{4}$ comme(n)t il songe en | dorma(n)t en son lit ${ }^{5}$, et ap(ré)s co(mm)e il esc(ri)pt so(n) livre.

Fol. 1b; chap. I-2 (v. 35-58) :

Cy aprés est la vision que Guillaume | de Guileville, moine ${ }^{6}$, vit en son dorma(n)t ${ }^{7}$, |

1. Cette description doit beaucoup à U. Peters, Das Ich..., p. 150. La moitié gauche du frontispice ne montre pas la production du livre, mais la lecture du Roman de la Rose, évoquée dans le prologue et la rubrique, dans le sillage du programme iconographique de certains manuscrits du Roman de la Rose (R. Emmerson, « Translating images... », p. 275-277; à la p. 276, reprod. en noir du fol. 1 de Lond 1; aussi cité dans U. Peters, Das Ich..., p. 150, n. 124).

2. Sur la fréquence, dans la réalité comme dans les enluminures, des meubles combinant siège et coffre à livres, voir Geneviève Hasenohr, «L'essor des bibliothèques privées aux XIv et $\mathrm{xv}^{\mathrm{e}}$ siècles », dans Histoire des bibliothèques françaises, t. I : les bibliothèques médiévales, du VI e siècle à 1530, dir. André Vernet, Paris, 1989, p. 215-263, aux p. 219-220.

3. D'après PVH1, p. 1, v. 11. Sur les implications de cette rubrique, mettant en scène les liens entre le Pèlerinage et le Roman de la Rose, au point de suggérer que le premier devrait être lu à la manière du second, voir R. Emmerson, « Translating images... », p. 283-284.

4. Sur le sens du mot hystoire dans cette rubrique, et plus généralement sur sa formulation, voir ci-dessus, p. 520.

5. Cf. PVH1, p. 2, v. 34.

6. Sur la reprise de données biographiques de Guillaume de Digulleville dans les rubriques de ce manuscrit, voir U. Peters, Das Ich..., p. 146.

7. Cf. PVH1, p. 2, v. 31-34. 
c'est assavoir une cité moult noble dont | le pavement estoit d'or ${ }^{8}$ et d'argent no(m)|mee Jher(usa) $\mathbf{l}(\mathbf{e}) \mathbf{m}^{9}$, par laquelle doit estre $e(n)$ te $(n) d u \mid$ paradis et les joies qui y sont.

11 UR. - La Jérusalem céleste.

Fol. 1va; chap. I-3 (v. 59-94) :

Comment le pelerin vit aux carneaulx | de la cité les sains docteurs qui enseignoie(n)t | les gens a faire ailles pour voler en la | cité et comment il y avoit qui recueilloie(n)t | plumes et comme(n)çoient a faire ailles et voler | par dessus le cherubin qui gardoit le | passaige et l'entree de la ville atout une | espee ardant. L'istoire est seulement $\mathrm{du} \mid$ cherubin qui deffend l'entree ou l'espee ${ }^{10}$.

11 UR. - À gauche un ange armé, à droite la Jérusalem céleste, vue de plus près que dans l'enluminure précédente.

Fol. 1vb; chap. I-4 (v. 95-124) :

Cy est comment les docteurs sont aux | carneaulx, qui enseignent les gens a | faire ailles et comment d'aucuns le font $\mid, c o(m)$ me il est dit en l'escripture prochainne $\mid$ cy contre, et est entendu les sains apostres | et aultres sai $(n)$ s et prescheurs qui preschent | les XII articles de la foi et $X \mathrm{co}(m) m e(n) \operatorname{deme}(n)$ s de | la loi.

11 uR. - À l'arrière-plan, la Jérusalem céleste; à l'intérieur de ses murailles, quatre docteurs, le gardien chérubin adossé à une tour. Au premier plan à gauche, le pèlerin sous l'aspect d'un voyageur fortuné (en manteau court) et non d'un moine. Au milieu, deux aspirants à la Jérusalem céleste, aussi en vêtement noble.

Fol. 2a; chap. I-5 (v. 125-142) :

Cy aprés s'ensuit comme saint Benoit | mist une eschele pour faire entrer les pe|lerins par dessus les murs en la cité | qui estoient de son ordre, fussent noirs, | blans ou gris $^{11}$, et co(m)me(n)t il mo(n)te[n]t a lui | aux carneaulz.

14 UR. - La Jérusalem céleste, représentée comme dans les enluminures précédentes, Chérubin veillant toujours au pied de sa tour. Un seul des quatre docteurs est visible aux créneaux. Il fait entrer par deux échelles deux moines blancs et deux moines noirs.

Fol. 2b; chap. I-6 (v. 143-168) :

Comment saint François faisoit mon|ter les gens en la cité contre mont une | corde et les aultres d'aultre maniere de | tous coustés qui les font marcer a eulz.

14 UR. - Cadre vide.

Fol. 2va; chap. I-7 (v. 169-226) :

Comme saint Pierre tient les clefz de | la cité que le seigneur d'icelle lui avoit | bailleez.

11 UR. - Jérusalem, vue de plus près encore : à gauche, plusieurs bienheureux, parmi lesquels au moins une femme noble; à droite, saint Pierre.

8. Cf. PVH1, p. 2, v. 46.

9. Cf. PVH1, p. 2, v. 38.

10. Sur cette rubrique et le mot istoire, voir ci-dessus, p. 520-521.

11. Cf. PVH1, p. 5, v. 141. 
Fol. 2vb; chap. I-8 (v. 227-294) :

Cy aprés est comment le peleri(n) queroit | escherpe et bourdon, et en ce q(ue)rant il | rencontra Grace Dieu et parla a elle.

13 UR. - Devant un paysage, à gauche, le pèlerin, sous les traits du même homme noble qu'en tête du chap. I-4; à droite, Grâce de Dieu, jeune femme richement parée.

Fol. 3b; chap. I-9 (v. 295-378) :

Cy aprés s'ensuit | comme(n)t Grace Dieu, | qui estoit si belle, si paree et aornee d'eschar|boucles, d'estoilles ${ }^{12}$ et ceintte du tissu verd ${ }^{13} \mid$ se fait cognoistre au peleri(n) et si devise qui | elle est.

9 UR. - Scène très similaire à la précédente, mais vue de plus loin; le paysage inclut, au loin à droite, la maison de Grâce de Dieu.

Fol. 3vb; chap. I-10 (v. 379-478) :

Comme(n)t Grace | Dieu monstre | sa maison au peleri(n) qui a tours et cloche ${ }^{14}$ | et laquelle pent en l'air ${ }^{15}$, et $\mathbf{y}$ a une $\mathbf{p}(\mathbf{a r})$ fonde $\mid$ riviere devant ${ }^{16}$.

11 UR. - Au premier plan une rivière; sur la rive, à gauche, le pèlerin et Grâce de Dieu; au second plan et à droite, la demeure de Grâce de Dieu.

Fol. 4b; chap. I-11 (v. 479-502) :

Cy est com|ment l'offici|al de Dieu vint au pelerin et coment il | le lava en eaue ${ }^{17}$, par quoi il est entendu | le sacrement de baptesme.

14 UR. - Devant un arrière-plan très semblable au précédent, Grâce de Dieu (à gauche) et l'official (sur le chemin à droite), de part et d'autre du pèlerin qui se baigne dans la rivière.

Fol. 4va; chap. I-12 (v. 503-536) :

Cy est comme | le pelerin estoit | en la maison de Grace Dieu, en laquelle il | vit le signe thau ${ }^{18}$ ou front d'une teste et $\mid$ une verge tortue ${ }^{19}$ et ung evesque ${ }^{20}$.

11 UR. - À l'entrée de la maison de Grâce de Dieu, de gauche à droite : Grâce de Dieu, le pèlerin, une grosse tête sans corps et un évêque.

Fol. 4vb; chap. I-13 (v. 537-570) :

Comment | le vycaire | bailla a l'official III oingnemens ${ }^{21}$ qui so(n)t | le cresme saint, le sai $(n)$ t oile et l'oile des ma|lades, et comme $(n) \mathrm{t}$ il doit oi $(n)$ dre les cham|pions de Dieu $^{22}$, sains et malades.

11 UR. - À l'entrée de la maison de Grâce de Dieu, l'official (au centre) est agenouillé devant l'évêque (à droite) qui lui remet un coffret sous le regard du pèlerin (à gauche).

12. Cf. PVH1, p. 11, v. 306-307.

13. Cf. PVH1, p. 8, v. 236.

14. Cf. PVH1, p. 14, v. 407.

15. Cf. PVH1, p. 14, v. 403.

16. Cf. PVH1, p. 14, v. 410-411.

17. Cf. PVH1, p. 16 , v. $482-483$.

18. Cf. PVH1, p. 17, v. 505.

19. Cf. PVH1, p. 17, v. 515; dans ce ms. «Une verge au bout tortue ».

20. Cf. PVH1, p. 18, v. 536.

21. PVH1, p. 18, v. 537.

22. PVH1, p. 18, v. 540. 
Fol. 5a; chap. I-14 (v. 571-622) :

Comment, | ai(n)si q(ue) le | vicaire et l'official devisoient de leurs oi|gnemens, Raison vint a eulz parler de | une tour en forme d'une pucelle ${ }^{23}$.

12 UR. - Au premier plan, devant un paysage, de gauche à droite : Raison devant la tour dont elle vient de sortir, l'official et l'évêque.

Fol. 5b (v. 623-633) :

Comment le vicaire respond a Raison ${ }^{24}$.

Ibid. (v. 634-702) :

Cy respont Raison au vicaire.

Fol. 5vb (v. 703-796) :

Raison respond a l'acteur.

Fol. 6b; chap. I-15 (v. 797-830) :

Comment | l'official | emporta les oingnemens et comment | il co(n)joint ung homme et une fe(m)me e(n)se(m)ble ${ }^{25}$, | par quoi il est entendu le sacrement ${ }^{26}$ de | mariaige.

14 UR. - Au premier plan, devant la maison de Grâce de Dieu, de droite à gauche : l'homme, l'évêque qui les unit, la femme, enfin le pèlerin en spectateur.

Fol. 6va; chap. I-16 (v. 831-932) :

Comment | l'esveq(ue) Moÿsés | fait ordres | et fait aucu(n)s clers en leur bailla(n)t $\operatorname{coro}(n)$ ne et | leur fait ou petite forcettez la coro(n)ne, et co(m)me(n)t | Raison leur remonstre ce qu'i doivent faire | toute leur vie.

12 UR. - Au premier plan, devant un édifice, sept personnages de taille inégale. Les deux plus grands sont Raison, à gauche, et l'évêque, à droite. Agenouillés devant l'évêque, quatre clercs tonsurés; derrière Raison (à gauche), le pèlerin en spectateur.

Fol. 7a; chap. I-17 (v. 933-1000) :

Comment le pelerin demanda a l'evesq(ue) | Moÿse le glaive ${ }^{27}$ et comme Moÿse lui | baille sus condicion. L'acteur dit.

14 UR. - En blanc : ni cadre, ni enluminure, ni bordure.

Fol. 7va; chap. I-18 (v. 1001-1058) :

Cy aprés s'ensuit comme l'evesque Moÿsés | fist et consacra ${ }^{28}$ ses officiaulz, c'est assavoir | les prestres, et comme(n)t il le(ur) bailla le glaive | de punicio(n) et les clefz de lier et deslier.

12 UR. - En blanc : ni cadre, ni enluminure, ni bordure.

23. Cf. PVH1, p. 19, v. 573-574.

24. Cette rubrique et les deux suivantes sont les seules qui, tout en introduisant des discours directs, occupent une UR entière de la justification. Mais aucune n'est suivie d'une enluminure ou d'une réserve. Sur cette ambiguïté, voir ci-dessus, p. 490-491, note 87.

25. Cf. PVH1, p. 26, v. 807.

26. PVH1, p. 26 , v. 815.

27. Cf. PVH1, p. 40, v. 1275-1276.

28. Ms. consancra. Corr. pour le sens. 
Fol. 7vb; chap. I-19 (v. 1059-1278) :

Cy dit l'acteur comme il vit Raison ser|monner au prone ${ }^{29}$ en commun et declai|re la signifiance du glaive et des clefz, | et comment il en doive(n)t user chascu(n) | en son office.

9 UR. - En blanc : ni cadre, ni enluminure, ni bordure.

Fol. 9a; chap. I-20 (v. 1279-1430) :

Comment, qua(n)t le pelerin ot demandé | a l'evesque Moÿsés le glaive et les clefz, | l'evesq(ue) engaigna le glaive ${ }^{30}$ et en troucela | les clefz et tout lui bailla.

12 UR (enluminure endommagée, surtout à droite). - Au premier plan, on discerne le pèlerin à gauche et l'évêque à droite.

Fol. 9vb; chap. I-21 (v. 1431-1464) :

Cy declaire l'acteur du disner Moÿsés | et comment il se esmerveilla des | choses qu'il vit en ce digner : $\operatorname{co}(\mathrm{m}) \mathrm{me}(\mathrm{n}) \mathrm{t} \mid$ le pain fut mué en $\operatorname{char}^{31}$ et le vin en $\mid \mathbf{s a n g}^{32}$ en la table Moÿsés, et comment | Grace de Dieu lui aida a ce faire.

14. UR. - Le pèlerin (à gauche) devant un autel (à droite), sur lequel sont posés un calice et une patène. Derrière l'autel, l'évêque (de face, au centre) et Grâce de Dieu (de face, à sa droite).

Fol. 10a; chap. I-22 (v. 1465-1518) :

Cy raconte le pelerin comme(n)t il reto(ur)na | a Raison pour savoir la cause pour quoi | Moÿsés avoit mué le pain en char et le | vin en sang, et Raison lui respondit q(u'e)lle | ne savoit pas la cause. Et de ce doit estre | entendu le sacrement de l'autel.

14. UR (dont 4 UR dans la marge de queue). - Dans le même décor, Raison (à gauche) et le pèlerin (au centre) en conversation devant l'autel.

Fol. 10va; chap. I-23 (v. 1519-1980) :

Comment Nature, qui a les mai(n)s soubz | ses aisselles ${ }^{33}$ et les yeulx reluisans ${ }^{34}$ en | forme d'une vieille ${ }^{35}$, vient parler et te(n)cer | a Grace Dieu, qui est en une fenestre de | sa tournelle.

11 UR. - De droite à gauche : Grâce de Dieu à la fenêtre de sa tourelle, Nature, le pèlerin en spectateur.

Fol. 12vb; chap. I-24 (v. 1981-2004) :

Comment Nature, qui est a genouz, cria | merci a Grace Dieu; et Grace Dieu lui per|donne et deffend que jamais ne parle con|tre elle.

12 uR. - Grâce de Dieu et Nature dans le même décor, mais Nature est agenouillée.

29. Cf. PVH1, p. 34, v. 1061-1062.

30. PVH1, p. 41, v. 1280.

31. Cf. PVH1, p. 46, v. 1447.

32. Cf. PVH1, p. 46, v. 1449.

33. PVH1, p. 48, v. 1509.

34. Cf. PVH1, p. 48 , v. 1510.

35. PVH1, p. 48, v. 1505. 
Fol. 13a; chap. I-25 (v. 2005-2638) :

Comme(n)t | Penitence | et Charité | ysserent d'une cha(m)bre ${ }^{36}$ et vi(n)dre(n)t a la table ou | Moÿsés et ses gens dignoie(n)t (et) prescherent l'u(n)e | aprés l'autre a la table. Penite(n)ce en sa bouche | avoit ung balai ${ }^{37}$, en l'une des mai(n)s unez $\mathbf{v}\left(\right.$ er ges $^{38} \mid$ verdes et en ${ }^{39}$ l'autre ung maillet ${ }^{40}$. Et Charité | tenoit une l(ett)re ouverte qui est a e(n)tendre le | Nouveau Testament. Et le disner est e(n)tendu | le jeudi ${ }^{41}$ absolut du soupper de N(ost)re | Seigneur et ses apostres.

10 UR. - De part et d'autre d'une table, deux groupes. Au premier plan à gauche, de gauche à droite : Charité avec sa lettre ouverte et Pénitence avec les attributs cités par la rubrique; au second plan à droite, derrière la table, de gauche à droite, deux convives laïcs et l'évêque.

Fol. 16b; chap. I-26 (v. 2639-3358) :

Cy est co(m)ment les pelerins qui s'aco(m)pai|gnent de Penite(n)ce et de Charité par con|fession et contricion vont a la table | de Moÿsés et reçoivent du relief de | son digner, c'est assavoir le corps $\mathrm{Jh}(\mathrm{es}) \mathrm{uc}(\mathrm{ri})$ st.

14 UR. - Le repas de quatre pèlerins vêtus en nobles à la table de Moïse. Ce dernier, qui porte mitre et crosse, derrière la table à droite, sert en compagnie de Charité (qui porte toujours sa lettre); du même côté de la table que les pèlerins, à gauche, Pénitence, son balai toujours à la bouche.

Fol. 20a; chap. I-27 (v. 3359-3664) :

Comment Grace Dieu mena le peleri(n) | la ou estoient ses joiaux et comment | elle lui baille escherpe et bourdon et | lui devise l'escripture et figure des XII | sonnectes et des aultres joiaux.

13 UR. - Dans un intérieur, le pèlerin (à gauche) vient de recevoir de Grâce de Dieu (à droite) une besace qu'elle a tirée d'un grand coffre à l'extrémité droite.

Fol. 21va; chap. I-28 (v. 3665-3748) :

Comment Grace Dieu aide le peleri(n) a | mettre l'escherpe qui a XII sonnectes | qui signifient les XII articles de la foi; | et le bourdon signifie les $X$ co(m)me(n)deme $(n) s$.

12 UR. - Les mêmes dans le même décor et les mêmes positions : Grâce de Dieu aide le pèlerin à placer la besace sur son épaule.

Fol. 22a; chap. I-29 (v. 3749-3812) :

Comment Grace Dieu bailla le bourdo(n) | au pelerin et comment il lui expose | de ce qu'il n'est pas ferré au bout.

13 UR. - Les mêmes dans le même décor, d'un peu plus près (le coffre n'est plus visible) et en position inverse : Grâce de Dieu remet au pèlerin le bourdon. Le paysage entrevu par la porte de gauche diffère légèrement du précédent, de même que les traits et vêtements des personnages : le peintre est apparemment un autre.

36. PVH1, p. 64, v. 2015.

37. PVH1, p. 64, v. 2029-2030.

38. Sélection d'éléments contenus dans PVH1, p. 64, v. 2027-2028.

39. Ms. en répété.

40. PVH1, p. 64, v. 2026.

41. PVH1, p. 74, v. 2370. 
Fol. 22va; chap. I-30 (v. 3813-3836) :

Comme(n)t le | peleri(n) fut mené en la chambre de Grace Dieu | et comment Grace Dieu lui monstre ses | armes, qui sont tant belles et sont pe(n)dues | au long d'une perche $^{42}$.

11 UR. - Les mêmes dans le même décor. Le pèlerin est à gauche; Grâce de Dieu, au centre, lui montre, suspendus à une perche à l'extrême droite au-dessus du coffre, désormais fermé : (du fond vers l'avant) un heaume, un pourpoint, une cotte de mailles, deux gantelets et une gorgère. Le style est à nouveau celui du premier peintre.

Fol. 22va; chap. I-31 (v. 3837-3908) :

Comment | Grace Dieu arma le peleri(n) et lui devise | les noms des armeures, comme du ga(m)beso(n) | et de l'enclume a forger sus.

Fol. 22vb.

11 UR. - Les mêmes dans le même décor et du même style. Grâce de Dieu, cette fois à gauche, remet au pèlerin, au centre, le pourpoint. Les autres armes restent suspendues.

Fol. 23a; chap. I-32 (v. 3909-4054) :

Comment le pelerin vestit le hauber|jon qui Force a nom ${ }^{43}$ et comme il | parle a Grace Dieu.

11 UR. - Les mêmes personnages dans le même décor, dans des positions à nouveau inversées. Le pèlerin, à gauche, vêtu de la cote de mailles par-dessus son pourpoint, parle avec Grâce de Dieu. Les autres armes sont toujours suspendues.

Fol. 23vb; chap. I-33 (v. 4055-4344) :

Comment le pelerin print le hauberjo(n) ${ }^{44}$ | et comment il demande a Grace les no(m)s des armeures dont il doit estre armé, | et elle lui dist : « Le hauberjon Force est | de signifia(n)ce. Le heaume signifie $\operatorname{Actre(m)pa(n)ce~}{ }^{45}$, | la gorgiere Sobrieté $^{46}$, les gantelés Co(n)tine(n)ce ${ }^{47}$, | l'espee Justice ${ }^{48}$ ».

Fol. 24a :

10 UR (empiétant sur la marge de tête). - Les mêmes dans le même décor. Grâce de Dieu, à droite, reprend la cotte de mailles du pèlerin, à gauche, et tend la main gauche vers la perche pour y suspendre le vêtement.

Fol. 25va; chap. I-34 (v. 4345-4514) :

Comment Grace Dieu ceint l'espee au | pelerin et lui baille la targe. Le fourrel | de l'espee signifie Humilité ${ }^{49}$, la renge a nom | Perseverence $^{50}$ et la targe a nom Prudence $^{51}$.

42. PVH1, p. 119, v. 3816.

43. PVH1, p. 125 , v. 4027.

44. Cf. PVH1, p. 126, v. 4055.

45. Raccourci de PVH1, p. 127, v. 4083-4086.

46. PVH1, p. 128, v. 4117-4119.

47. PVH1, p. 130 , v. 4200.

48. PVH1, p. 132, v. 4251.

49. PVH1, p. 135 , v. 4353-4354.

50. PVH1, p. 136 , v. 4405.

51. PVH1, p. 138, v. 4453. 
10 UR. - Les mêmes dans le même décor. La perche est nue. Grâce de Dieu, à droite face au lecteur, équipe le pèlerin, à gauche et de dos, son bourdon posé au sol.

Fol. 26b; chap. I-35 (v. 4515-4746) :

Comment le pelerin est armé et comm[ent] | il tient son bourdon et son escherpe et | comment il se plaint des armes a G(ra)ce Die[u].

9 UR. - À la sortie de l'édifice précédent, le pèlerin en armes, à gauche, et Grâce de Dieu, à droite, se saluent devant un paysage. À l'arrière-plan de celui-ci, à droite, la demeure de Grâce de Dieu.

Fol. 27va; chap. I-36 (v. 4747-4776) :

Comment l'acteur despoulla ses ar|meures et comment Grace Dieu le | redargüe de ce $q(u e)$ le peleri(n) ne la requiert ${ }^{52} \mid$ d'avoir quelq(ue) ${ }^{53}$ ung qui les li porte.

10 UR. - Les mêmes devant un paysage où la demeure de Grâce de Dieu n'est plus visible. Grâce de Dieu, à droite, parle au pèlerin, qui retire la cotte de mailles par-dessus sa tête, le heaume déjà à ses pieds.

Fol. 27vb; chap. I-37 (v. 4777-4814) :

Comment l'acteur se desconforte et | regrecte ses armes a par lui.

11 UR. - Le pèlerin de face devant un paysage, portant bourdon et écharpe, se lamente.

Fol. 28a; chap. I-38 (v. 4815-4968) :

Comment Grace Dieu amene une cha(m)|briere au pelerin pour porter ses armes, | qui a nom Memoire ${ }^{54}$, laquelle n'a nulz | yeulz devant, mais derriere.

11 UR. - Au premier plan, devant un paysage : à gauche Mémoire, de face, les yeux clos; devant elle, Grâce de Dieu s'adresse au pèlerin qui lui fait face, à droite, appuyé sur son bourdon.

Fol. 28vb; chap. I-39 (v. 4969-4982) :

Comme(n)t | Grace Dieu e[t] | le pelerin | midre(n)t les armeures sus Memoire, qui | a les yeulz derriere, et co(m)me(n)t le pelerin | va querir et demander a Moÿsés du relief 55 de son digner.

11 uR (dont 3 uR dans la marge de queue). - Côte à côte, les deux scènes successives mentionnées : à gauche, Grâce de Dieu et le pèlerin mettent sur la tête de Mémoire un baluchon contenant les armes du pèlerin; à droite, le pèlerin s'agenouille devant l'autel qui le sépare de Moïse, représenté en évêque.

Fol. 29a; chap. I-40 (v. 4983-5066) :

Comment, quant le peleri(n) ot eu du relief | et qu'il l'ot mis en son escharpe, comme(n)t | il retourna a Grace Dieu et Grace Dieu | lui respont; et Memoire, qui est derriere | le pelerin, qui porte les armeures.

11 UR. - Au premier plan, devant un paysage, la séparation de Grâce de Dieu (à gauche) et du pèlerin (à droite), besace au côté et bâton à la main. Derrière lui, plus loin à droite, se tient Mémoire, son baluchon toujours sur la tête.

52. Ms. requier. Corr. pour la grammaire et le sens.

53. Ms. queque. Corr. pour la grammaire et le sens.

54. Cf. PVH1, p. 151, v 4885-4887.

55. Ms. relie. Corr. pour le sens. 
Fol. 29va ${ }^{56}$ (après env. 4 ur de blanc, à l'encre noire) :

Explicit le livre premier | et le second encommencier ${ }^{57}$.

15 uR. - Devant un paysage, le pèlerin (à droite) chemine, suivi de Mémoire (au centre).

Ibid. (chap. II-1, v. 5067-5092) :

Cy s'ensuit le second livre de Pelerinai|ge humain. Et premier comment | s'en va son chemin le pelerin, pensant | et disant en soi ce qui est aprés. Et Memoi|re qui l'ensuit qui porte ses armeures.

Fol. 29vb; chap. II-2 (v. 5093-5162) :

Comment le pelerin rencontre ung | villain e(n)sourcillé ${ }^{58}$ et rechigné qui por|toit ung baston de cornilier ${ }^{59}$, et parlent | ensemble.

12 UR. - Devant un paysage, le pèlerin (à gauche) parle à Rude Entendement (à droite).

Fol. 30b; chap. II-3 (v. 5163-5210) :

Comment Raison vient a l'encontre | de Rude Entendement, et le pelerin derrie [re] | Raison, et Memoire derriere le pelerin, | et comment Raison et Rude E(n)te(n)dement $\mathrm{p}(\mathrm{ar}) \mathrm{le}[\mathrm{nt}]$.

11 UR. - Devant un paysage, les quatre personnages mentionnés, dans les positions indiquées. De gauche à droite : Mémoire avec son baluchon sur la tête, le Pèlerin, Raison et Rude Entendement, fermement appuyé sur son bâton comme le Pèlerin sur son bourdon. Raison est une jeune femme noble en robe blanche (comme aux fol. 5a et 6va), mais elle porte un voile.

Fol. 30va; chap. II-4 (v. 5211-5632) :

Comment Raison lit sa commission | devant le villain Rude Entendement | qui tient ung lourd baston en la main.

11 ur. - Cadre vide.

Fol. 32vb; chap. II-5 (v. 5633-6198) :

Comment Raison fait passer le pelerin | maugré Rude Entendement ${ }^{60}$ et comment | il se complaint qu'il ne peut porter ses ar|mes.

11 ur. - Devant un paysage, le pèlerin (à gauche), enfin armé, suivi de Raison qui le soutient légèrement; en face, Rude Entendement appuyé sur son bâton, dans une posture qui suggère qu'il recule.

56. Page reproduite en noir et blanc dans R. Emmerson, « Translating images... », p. 286.

57. Fait rare parmi les témoins du Pèlerinage en vers, l'explicit du premier livre est ici en deux octosyllabes réguliers, présentés comme tels.

58. Sélection de PVH1, p. 159, v. 5095-5096.

59. PVH1, p. 159, v. 5097-5098.

60. Raccourci de PVH1, p. 177, v. 5679-5682. 


\section{II \\ TABleau SyNoptique Des CiNQ TÉMOINS du Pèlerinage dotés de RubriQues déVeloppées}

Cette édition synoptique prend en compte les cinq manuscrits dotés des rubriques les plus développées. À l'exception des mss. Paris, BnF, fr. 1577 (BnF 13) et fr. 12462 (BnF 22), où l'on observe un seul niveau de rubriques, le système en comprend habituellement deux. Des rubriques relativement étoffées et variées divisent l'ensemble du texte en unités que l'on peut considérer comme des chapitres, tandis que des rubriques plus brèves servent seulement à attribuer les paroles des personnages. Dans le ms. Londres, Brit. Libr, Add. 22937 (Lond 1), des espaces sont réservés par le copiste entre les vers pour les premières seulement, alors que les rubriques de discours direct sont placées à côté des vers, débordant dans les marges. Dans les mss. Bruxelles, BR, 10987-10988 (Brux 3) et Paris, BnF, fr. 824 (BnF 4), c'est le contenu, non la présentation, qui permet de faire le tri. Dans tous les cas, l'édition ci-après se limite aux rubriques longues et exclut celles qui attribuent les discours.

Les manuscrits se distinguent en premier lieu selon qu'ils tissent ou non des rapports entre rubriques et illustrations; en second lieu selon le soin apporté par le copiste à réserver un espace aux rubriques.

- BnF 13 (milieu du xive siècle) : les espaces ont été réservés au sein de la justification ${ }^{61}$. Chaque rubrique est suivie d'une initiale ornée (lettrine fleuronnée bleue et rose, sur fond d'or, se prolongeant dans la marge sous forme de feuilles de vigne dorées) de 4 unités de réglure - contre des lettrines de même type, mais de 3 UR seulement, au niveau d'articulation suivant. En outre, si on trouve des rubriques sans enluminure, toutes les miniatures sont associées à une rubrique. Les miniatures sont de facture très soignée, usant de feuille d'or et d'une large palette de couleurs. L'écriture est la même que celle du texte, quoique de module légèrement supérieur. Il s'agit, dans la classification d'Albert Derolez, d'une textualis libraria ${ }^{62}$. En général l'espace réservé est suffisant et les rubriques n'empiètent donc guère sur les marges.

- BnF 22 (milieu du xive siècle) ${ }^{63}$ : les rubriques sont de la même main que le reste du Pèlerinage, copiées dans une textualis libraria du même module. Par leur fréquence comme par leur contenu, elles sont presque identiques à celles de $\mathrm{BnF} 13$, et mises en page de même. Aussi les deux manuscrits sont-ils groupés ci-après dans la même colonne, sous BnF 13, les variantes de BnF 22 étant signalées en note. De fait, le seul écart sensible concerne le rapport des titres aux illustrations. Comme BnF 13, BnF 22 est scandé de miniatures de très belle facture, caractérisées par l'usage de la feuille d'or et par une riche palette de couleurs; mais alors que $\mathrm{BnF} 13$ comporte presque autant de miniatures que de titres rubriqués, beaucoup des rubriques de BnF 22 ne sont pas illustrées. Lorsque rubrique et image sont associées, la miniature suit généralement le titre, mais elle peut aussi la précéder.

61. Sur la date de ce manuscrit, voir G. Veysseyre, « Liste des manuscrits... », p. 433, notice $\mathrm{n}^{0} 53$.

62. Albert Derolez, The palaeography of gothic manuscript books, from the twelfth to the early sixteenth century, Cambridge, 2003.

63. Sur la date de ce manuscrit, réalisé vers 1348, voir G. Veysseyre, « Liste des manuscrits... », p. 433, notice $n^{\circ} 62$. 
- Brux 3 (dernier quart du XIv siècle $^{64}$ ) : à l'exception de la rubrique liminaire (Hic incipit sompnium peregrinationis humane vite, fol. 1a), dont l'écriture n'apparaît pas ailleurs, la main qui a écrit les rubriques coïncide avec celle qui a copié uniformément l'ensemble du poème ${ }^{65}$. Les rubriques fonctionnent ici indépendamment de toute iconographie : une miniature unique, en grisaille, est placée au début du manuscrit. Le copiste a pris grand soin de réserver des espaces, réguliers et suffisamment amples, aux deux niveaux : titres développés et rubriques de discours. Les secondes ne sont pas transcrites ci-après, mais leur présence est signalée par des points de suspension entre crochets. À défaut de présentation différenciée, elles ont été éditées ou exclues de la présente annexe selon des critères de contenu et de longueur : exclues celles qui se limitaient à un mot interrogatif (facultatif), un sujet grammatical, un verbe de parole et un complément d'objet (direct ou indirect), le tout n'occupant pas plus d'une unité de réglure; exclues aussi les formules coordonnant deux verbes de paroles selon des modalités semblables aux précédentes ${ }^{66}$. Dès lors que la syntaxe est plus élaborée, le sens différent ou la réserve supérieure à une UR, la rubrique est retenue dans l'édition.

$-B n F 4$ (daté de 1444) ${ }^{67}$ : les rubriques sont de la même écriture (semi-hybrida libraria ${ }^{68}$ ) et de la même main que le reste du texte. Les réserves ménagées pour les rubriques sont peu régulières et souvent trop réduites. Le décalage s'aggrave au cours du livre I, tant pour les titres développés que pour les rubriques de discours. Par ailleurs, en dépit d'un cycle iconographique ambitieux, rubriques et enluminures forment deux systèmes indépendants et leurs positions coïncident rarement. La peinture est de moins bonne facture et moins luxueuse que dans BnF 13 et $\mathrm{BnF} 22$ : le cadre n'est pas doré mais jaune à l'extérieur et mauve à l'intérieur. À l'intérieur, des grisailles rehaussées de couleurs, d'une palette très réduite (trois couleurs ou quatre au maximum dans la plupart des cas). Comme dans Lond 1 et Brux 3, on trouve ici deux niveaux de rubriques. L'espace réservé est régulièrement d'une UR pour l'une comme pour l'autre. Comme pour Brux 3, les rubriques de discours sont omises ci-après, selon les mêmes critères de contenu et de présentation.

- Lond 1 : voir la description à l'Annexe I.

\section{Conventions éditoriales :}

[...] Omission de rubriques brèves introduisant un discours direct (Brux 3, BnF 4).

* présence d'une enluminure associée à la rubrique (les enluminures placées entre deux vers du corps du poème étant ignorées).

La position des rubriques développées est précisée en note quand elles débordent de l'espace réservé.

$N$. B. : Les notes du tableau sont placées à la suite, p. 556-557.

64. Voir ci-dessus, p. 485, note 59.

65. Il s'agit, dans la classification Derolez, d'une « Cursiva Libraria tending towards Bastarda », très proche de celle du ms. Reims, Bibl. mun., 1276, autre témoin du Pèlerinage, de la fin du XIve siècle (A. Derolez, The palaeography..., pl. 90).

66. Par exemple, fol. 6vb : « Rayson respont a l'aucteur et li dit » (une seule UR).

67. Voir ci-dessus, p. 485, note 61.

68. A. Derolez, The palaeography..., passim. 


\begin{tabular}{|c|c|}
\hline $\begin{array}{c}\text { BnF } 13 \text { (et BnF } 22 \text { : variantes) } \\
\left(\text { milieu du XIV }{ }^{\mathrm{e}} \text { s.) }\right. \\
69\end{array}$ & $\begin{array}{c}\text { Brux } 3 \\
\text { (dern. quart du XIV s.) }\end{array}$ \\
\hline $\begin{array}{l}\text { Fol. 1a (v. 1-34) })^{* 70} \text { : } \\
\text { Ci commence li romans de l'umain } \\
\text { voyage du viel moine qui est exposés } \\
\text { sus le Romans de la Rose. }\end{array}$ & $\begin{array}{l}\text { Fol. 1a (v. 1-34) }{ }^{71} \text { : } \\
\text { Hic incipit sompnium peregrinacionis humane vite }{ }^{72} \text {. }\end{array}$ \\
\hline $\begin{array}{l}\text { Fol. } 1 \mathrm{~b}(\mathrm{v} .35-66) \text { : } \\
\text { Ci parle l'aucteur. }\end{array}$ & $\begin{array}{l}\text { Fol. 1va (v. 35-58): } \\
\text { Ci commence la devision du songe au moine. Hystoire d'un } \\
\text { moine qui songe en son lit. }\end{array}$ \\
\hline \multirow[t]{3}{*}{$\begin{array}{l}\text { Fol. 1va (v. 67-132) : } \\
\text { Encore parle l'auteur. }\end{array}$} & $\begin{array}{l}\text { Ibid. (v. 59-94) : } \\
\text { Comment l'aucteur devise la deffense de l'entree de la cité. } \\
\text { Hystoire de Cherubin qui tient I espee }{ }^{74} \text { ardant a la porte de } \\
\text { la cité pour deffendre l'entree. L'aucteur. }\end{array}$ \\
\hline & $\begin{array}{l}\text { Fol. 2a (v. 95-124) : } \\
\text { Ci parole l'aucteur comment il vit haut as quarneaus les sains } \\
\text { docteurs qui enseignoient les gens a faire eles pour voler en la } \\
\text { cité. }\end{array}$ \\
\hline & \multirow[t]{2}{*}{$\begin{array}{l}\text { Ibid. (v. 125-142) : } \\
\text { Ci parole l'aucteur comment saint Benoit mist une eschiele } \\
\text { pour faire les entrer par dessus les murs de la cité. }\end{array}$} \\
\hline \multirow[t]{2}{*}{$\begin{array}{l}\text { Fol. 1vb (v. 133-164) }{ }^{* 76}: \\
\text { Ci parle de l'aide des sains. }\end{array}$} & \\
\hline & $\begin{array}{l}\text { Fol. } 2 \text { b (v. 143-168) : } \\
\text { Ci dit l'aucteur comment saint François faisoit monter ses } \\
\text { gens dedens la cité contremont sa corde. }\end{array}$ \\
\hline \multirow[t]{2}{*}{$\begin{array}{l}\text { Fol. } 2 \text { a (v. 165-226) : } \\
\text { Ci dit }{ }^{77} \text { comment l'aucteur s'apense } \\
\text { de querre bourdon et escherpe. }\end{array}$} & $\begin{array}{l}\text { Fol. 2va (v. 169-202): } \\
\text { Ci devise l'aucteur comment le seigneur de celle cité avoit } \\
\text { baillé les clés de cel huis a saint Pere, son vicaire. }\end{array}$ \\
\hline & $\begin{array}{l}\text { Fol. 2vb (v. 203-[...]-294) : } \\
\text { Ci parole l'aucteur comment il queroit escharpe et bourdon et } \\
\text { il encontra Grace Dieu, qui le mena avec soi. }\end{array}$ \\
\hline \multirow[t]{2}{*}{$\begin{array}{l}\text { Fol. } 2 \text { va (v. } 227-390) \text { : } \\
\text { De la }{ }^{78} \text { grace Dieu qui parle a l'auc- } \\
\text { teur. }\end{array}$} & \\
\hline & $\begin{array}{l}\text { Fol. 3b (v. 295-[...]-478) : } \\
\text { Comment Grace Dieu parole au moine et li devise qui elle est } \\
\text { et le maine avec soi. }\end{array}$ \\
\hline
\end{tabular}




\begin{tabular}{|c|c|}
\hline $\begin{array}{l}\text { BnF 4 } \\
(1444)\end{array}$ & $\begin{array}{l}\text { Lond } 1 \\
\text { (v. } 1460-1468)\end{array}$ \\
\hline Fol. 1a (v. 1-34)* : & Fol. 1a (v. 1-34)* : \\
\hline $\begin{array}{l}\text { Ci conmence le songe du Pelerina- } \\
\text { ge de la vie humaine, le premier li- } \\
\text { vre }^{73} \text {. }\end{array}$ & $\begin{array}{l}\text { Cy commence le Pelerinaige de vie humainne exposé sus le Rou- } \\
\text { mant de la Rose. Hystoire comment il songe en dormant en son } \\
\text { lit, et aprés come il escript son livre. }\end{array}$ \\
\hline Fol. 1b (v. 35-62)* : & Fol. 1b (v. 35-58)* : \\
\hline $\begin{array}{l}\text { Ci conmence la devision du songe au } \\
\text { moyne. Histoire du moyne qui son- } \\
\text { ge. }\end{array}$ & $\begin{array}{l}\text { Cy aprés est la vision que Guillaume de Guileville, moine, vit } \\
\text { en son dormant, c'est assavoir une cité moult noble dont le } \\
\text { pavement estoit d'or et d'argent nommee Jherusalem, par la- } \\
\text { quelle doit estre entendu paradis et les joies qui y sont. }\end{array}$ \\
\hline Fol. 1va (v. 63-94)* : & Fol. 1va (v. 59-94)* : \\
\hline $\begin{array}{l}\text { Conment l'aucteur devise la deffen- } \\
\text { se de l'entree de la cité. Histoire de } \\
\text { Cherubin qui tient une espee }{ }^{75} \text { ar- } \\
\text { dant a la porte de la cité pour def- } \\
\text { fendre l'entree. L'aucteur parle. }\end{array}$ & $\begin{array}{l}\text { Comment le pelerin vit aux carneaulx de la cité les sains doc- } \\
\text { teurs qui enseignoient les gens a faire ailles pour voler en la } \\
\text { cité et comment il y avoit qui recueilloient plumes et commen- } \\
\text { çoient a faire ailles et voler par dessus le cherubin qui gardoit } \\
\text { le passaige et l'entree de la ville atout une espee ardant. L'istoi- } \\
\text { re est seulement du Cherubin qui deffend l'entree ou l'espee. }\end{array}$ \\
\hline Fol. 1vb*. & Fol. 1vb (v. 95-124)* : \\
\hline $\begin{array}{l}\text { Fol. 2a (v. 95-124) : } \\
\text { Ci parole l'aucteur conment il vit } \\
\text { hault as quarneaus les sains doc- } \\
\text { teurs qui enseignoient les gens a } \\
\text { faire elles pour voler en la cité. }\end{array}$ & $\begin{array}{l}\text { Cy est comment les docteurs sont aux carneaulx, qui ensei- } \\
\text { gnent les gens a faire ailles et comment d'aucuns le font, com- } \\
\text { me il est dit en l'escripture prochainne cy contre, et est entendu } \\
\text { les sains apostres et aultres sains et prescheurs qui preschent } \\
\text { les XII articles de la foi et X commendemens de la loi. }\end{array}$ \\
\hline Fol. 2b (v. 125-142)* : & Fol. 2a (v. 125-142)* : \\
\hline $\begin{array}{l}\text { Ci parole l'aucteur conment saint } \\
\text { Benoit mist une eschiele pour les } \\
\text { faire entrer par dessus les murs de } \\
\text { la cité. }\end{array}$ & $\begin{array}{l}\text { Cy aprés s'ensuit comme saint Benoit mist une eschele pour } \\
\text { faire entrer les pelerins par dessus les murs en la cité qui } \\
\text { estoient de son ordre, fussent noirs, blans ou gris, et comment } \\
\text { il monte[n]t a lui aux carneaulz. }\end{array}$ \\
\hline Fol. 2 b (v. 143-168)*. & Fol. 2b (v. 143-168)* : \\
\hline $\begin{array}{l}\text { Fol 2va: } \\
\text { Ci parole l'aucteur conment saint } \\
\text { François faisoit monter ses gens } \\
\text { dedens la cité contremont sa corde. }\end{array}$ & $\begin{array}{l}\text { Comment saint François faisoit monter les gens en la cité } \\
\text { contre mont une corde et les aultres d'aultre maniere de tous } \\
\text { coustés qui les font marcer a eulz. }\end{array}$ \\
\hline Fol. 2va (v. 169-202)* : & Fol. 2va (v. 169-226)* : \\
\hline $\begin{array}{l}\text { Ci devise l'aucteur conment le sei- } \\
\text { gneur de celle cité avoit baillié les } \\
\text { clés de la porte a saint [fol. } 2 \mathrm{vb} \text { ] } \\
\text { Piere, son vicaire. }\end{array}$ & \multirow[t]{3}{*}{$\begin{array}{l}\text { Comme saint Pierre tient les clefz de la cité que le seigneur } \\
\text { d'icelle lui avoit bailleez. }\end{array}$} \\
\hline \multirow{4}{*}{$\begin{array}{l}\text { Ibid. (v. 203-[...]-294) : } \\
\text { Ci dit l'aucteur conment il queroit } \\
\text { escharpe et bourdon, et il encontra } \\
\text { Grace Dieu qui le mena avec soy. }\end{array}$} & \\
\hline & \\
\hline & Fol. 2vb (v. 227-294)* \\
\hline & $\begin{array}{l}\text { Cy aprés est comment le pelerin queroit escherpe et bourdon, } \\
\text { et en ce querant il rencontra Grace Dieu et parla a elle. }\end{array}$ \\
\hline Fol. 3va (v. 295-[...]-478)* : & Fol. 3b (v. 295-378)* : \\
\hline $\begin{array}{l}\text { Conment Grace Dieu parle au } \\
\text { moyne et li devise qui elle est et le } \\
\text { moyne avec soy. }\end{array}$ & $\begin{array}{l}\text { Cy aprés s'ensuit comment Grace Dieu, qui estoit si belle, si } \\
\text { paree et aornee d'escharboucles, d'estoilles et ceintte du tissu } \\
\text { verd se fait cognoistre au pelerin et si devise qui elle est. }\end{array}$ \\
\hline
\end{tabular}




\begin{tabular}{|c|c|}
\hline $\begin{array}{l}\text { Fol. 3va (v. } 391-478)^{* 79} \text { : } \\
\text { Grace Dieu qui parle a l'aucteur, et } \\
\text { l'aucteur a lui. }\end{array}$ & \\
\hline $\begin{array}{l}\text { Fol. } 4 \text { a (v. } 479-502)^{80} \text { : } \\
\text { De l'ofice le prestre, qui est official } \\
\text { de Dieu. }\end{array}$ & $\begin{array}{l}\text { Fol. 4vb (v. 479-502) : } \\
\text { Ci parole l'aucteur comment l'official de Dieu vint a li et com- } \\
\text { ment il le lava en l'eaue. }\end{array}$ \\
\hline \multirow[t]{2}{*}{$\begin{array}{l}\text { Fol. } 4 \text { b (v. } 503-570)^{* 81}: \\
\text { Ci parle de }{ }^{82} \text { l'evesque. }\end{array}$} & $\begin{array}{l}\text { Ibid. (v. 503-536) : } \\
\text { Ci parole l'auteur des choses que il vit dedens la meson Grace } \\
\text { Dieu. }\end{array}$ \\
\hline & $\begin{array}{l}\text { Fol. 5a (v. 537-570) : } \\
\text { Ci raconte l'aucteur les paroles que le vicaire dist a l'official } \\
\text { devant et comment il doit enoindre les champions de Dieu, } \\
\text { sains et malades, et seront pelerins. [Fol. 5b] L'aucteur parle. }\end{array}$ \\
\hline \multirow[t]{2}{*}{$\begin{array}{l}\text { Fol. } 4 \text { vb (v. } 571-796)^{*} \text { : } \\
\text { Comment Raison parle a l'official, } \\
\text { qui est prestre de Dieu. }\end{array}$} & $\begin{array}{l}\text { Fol. } 5 \mathrm{~b} \text { (v. 571-622): } \\
\text { Ci raconte l'aucteur comment Raison vint [fol. } 5 \mathrm{va}] \text { a eulz } \\
\text { tant comme il parloient ensemble. }\end{array}$ \\
\hline & $\begin{array}{l}\text { Fol. 5vb (v. } 623-[\ldots]-796) \text { : } \\
\text { Ci dit l'aucteur comment le vicaire respondi a Raison. }\end{array}$ \\
\hline $\begin{array}{l}\text { Fol. } 6 \text { b (v. } 797-830)^{* 84} \text { : } \\
\text { De loyauté. }\end{array}$ & $\begin{array}{l}\text { Fol. 7a (v. 797-830) : } \\
\text { Ci parole comme l'official emporta les oingnemens et com- } \\
\text { ment il conjoint I homme et une fame ensemble et retorna } \\
\text { arriere a Moÿsés. }\end{array}$ \\
\hline $\begin{array}{l}\text { Fol. 6va (v. 831-932) : } \\
\text { Raison qui parole. }\end{array}$ & $\begin{array}{l}\text { Fol. } 7 \mathrm{~b} \text { (v. } 831-[\ldots]-932) \text { : } \\
\text { Ci devise l'aucteur comment le vicaire les ordene et comme } \\
\text { Raison parle aprés eulz. }\end{array}$ \\
\hline \multirow[t]{2}{*}{$\begin{array}{l}\text { Fol. 7b (v. 933-1062) }{ }^{* 87} \text { : } \\
\text { Comme Moÿsés, qui evesque estoit, } \\
\text { faisoit son office }{ }^{88} \text {; et Grace Dieu } \\
\text { qui li aidoit }{ }^{89} \text {. }\end{array}$} & $\begin{array}{l}\text { Fol. 8a (v. 933-[...]-1000) : } \\
\text { Ci parole l'aucteur comment Moÿsés mist en servise les autres } \\
\text { qui la estoient chascun en son office. }\end{array}$ \\
\hline & $\begin{array}{l}\text { Fol. 8va (v. 1001-1028) : } \\
\text { Ci parole l'aucteur comment il fist les officiaulz et comment il } \\
\text { leur bailla le glaive de punicion et les cleis de lier et de deslier. }\end{array}$ \\
\hline
\end{tabular}




\begin{tabular}{|c|c|}
\hline & $\begin{array}{l}\text { Fol. 3vb (v. } 379-478)^{*} \text { : } \\
\text { Comment Grace Dieu monstre sa maison au pele- } \\
\text { rin qui a tours et cloche et laquelle pent en l'air, et } \\
\text { y a une parfonde riviere devant. }\end{array}$ \\
\hline Fol. 4vb (v. 479-502)* : & Fol. 4b (v. 479-502)* : \\
\hline $\begin{array}{l}\text { Ci parle l'aucteur coment l'oficial de Dieu vint } \\
\text { a li et conment il le lava en l'eaue. }\end{array}$ & $\begin{array}{l}\text { Cy est comment l'official de Dieu vint au pelerin et } \\
\text { coment il le lava en eaue, par quoi il est entendu le } \\
\text { sacrement de baptesme. }\end{array}$ \\
\hline Fol. 5a (v. 503-536)* : & Fol. 4va (v. 503-536)* : \\
\hline $\begin{array}{l}\text { Ci parole des chozes que il vit dedens la mai- } \\
\text { son Grace Dieu et conment il vit Moÿsés. }\end{array}$ & $\begin{array}{l}\text { Cy est comme le pelerin estoit en la maison de } \\
\text { Grace Dieu, en laquelle il vit le signe thau ou front } \\
\text { d'une teste et une verge tortue et ung evesque. }\end{array}$ \\
\hline Fol. 5b (v. 537-570)* : & Fol. 4vb (v. 537-570)* : \\
\hline $\begin{array}{l}\text { Ci raconte l'aucteur les paroles que le vicaire } \\
\text { dist a l'official devant et conment il doit oin- } \\
\text { dre }{ }^{83} \text { les champions de Dieu, sains et mala- } \\
\text { des, et seront pelerins. }\end{array}$ & $\begin{array}{l}\text { Comment le vycaire bailla a l'official III oingne- } \\
\text { mens qui sont le cresme saint, le saint oile et l'oile } \\
\text { des malades, et comment il doit oindre les cham- } \\
\text { pions de Dieu, sains et malades. }\end{array}$ \\
\hline Fol. 5vb (v. 571-622)* : & \multirow{4}{*}{$\begin{array}{l}\text { Fol. 5a (v. 571-796)* } \\
\text { Comment, ainsi que le vicaire et l'official devisoient } \\
\text { de leurs oignemens, Raison vint a eulz parler de } \\
\text { une tour en forme d'une pucelle. }\end{array}$} \\
\hline $\begin{array}{l}\text { Ci raconte l'aucteur conment Raison vint a } \\
\text { eulz tant conme il parloient ensemble. }\end{array}$ & \\
\hline $\begin{array}{l}\text { Fol. } 6 \text { a (v. 623-634) : } \\
\text { Ci dit l'aucteur conment le vicaire respont a } \\
\text { Raison et lui dit. }\end{array}$ & \\
\hline $\begin{array}{l}\text { Fol. } 6 \mathrm{~b} \text { (v. } 635-[\ldots]-796) \text { : } \\
\text { Ci respont Rayson au vicaire et lui dit en tel } \\
\text { manière. }\end{array}$ & \\
\hline Fol. 7va (v. 797-830)* : & Fol. 6b (v. 797-830)* : \\
\hline $\begin{array}{l}\mathrm{Ci} \text { parole l'aucteur conme l'official en pourta } \\
\text { les oingnemens et conment il }{ }^{85} \text { conjoint un }{ }^{86} \\
\text { home et une fame ensemble et retorna arriere } \\
\text { a Moÿse. }\end{array}$ & $\begin{array}{l}\text { Comment l'official emporta les oingnemens et com- } \\
\text { ment il conjoint ung homme et une femme ensem- } \\
\text { ble, par quoi il est entendu le sacrement de mariai- } \\
\text { ge. }\end{array}$ \\
\hline Fol. 7vb (v. 831-[...]-932)* : & Fol. 6va (v. 831-932)* : \\
\hline $\begin{array}{l}\text { Ci devise l'aucteur conment le vicaire les or- } \\
\text { donne et comment Raison parle aprés eulz. }\end{array}$ & $\begin{array}{l}\text { Comment l'esveque Moÿsés fait ordres et fait au- } \\
\text { cuns clers en leur baillant coronne et leur fait ou } \\
\text { petite forcettez la coronne, et comment Raison leur } \\
\text { remonstre ce qu'i doivent faire toute leur vie. }\end{array}$ \\
\hline Fol. 8va (v. 933-[...]-1000) : & Fol. 7a (v. 933-1000)* : \\
\hline $\begin{array}{l}\text { Ci parole l'aucteur conment il }{ }^{90} \text { ot volenté de } \\
\text { ce glaive avoir et conment il demanda a Moÿ- } \\
\text { sés et conment Moÿsés li bailla sus condicion. } \\
\text { L'aucteur parle. }\end{array}$ & $\begin{array}{l}\text { Comment le pelerin demanda a l'evesque Moÿse le } \\
\text { glaive et comme Moÿse lui baille sus condicion. } \\
\text { L'acteur dit. }\end{array}$ \\
\hline Fol. 9a (v. 1001-1028)* : & Fol. 7va (v. 1001-1058)* : \\
\hline $\begin{array}{l}\mathrm{Ci} \text { parole l'aucteur conment il fist les offi- } \\
\text { ciaulz et conment il leur baylla le glave de pu- } \\
\text { nicion et lez clés de lier et de deslier. }\end{array}$ & $\begin{array}{l}\text { Cy aprés s'ensuit comme l'evesque Moÿsés fist et } \\
\text { consacra } 91 \text { ses officiaulz, c'est assavoir les prestres, } \\
\text { et comment il leur bailla le glaive de punicion et les } \\
\text { clefz de lier et deslier. }\end{array}$ \\
\hline
\end{tabular}




\begin{tabular}{|c|c|}
\hline & $\begin{array}{l}\text { Fol. 8vb (v. 1029-1058) : } \\
\text { Ci parole l'aucteur comment Grace Dieu le reconforta et dist } \\
\text { qu'elle pouoit bien estre avec touz. }\end{array}$ \\
\hline \multirow[t]{2}{*}{$\begin{array}{l}\text { Fol. 8a (v. 1063-1278)*92 : } \\
\text { Comme Raison sermonne au pue- } \\
\text { ple. }\end{array}$} & $\begin{array}{l}\text { Fol. 9a (v. 1059-[...]-1260) : } \\
\text { Ci dit l'aucteur comment il vit Raison sermonner au prone en } \\
\text { commun et devise la senefiance du glaive et des clés et com- } \\
\text { ment il en doivent ouvrer. L'aucteur. }\end{array}$ \\
\hline & $\begin{array}{l}\text { Fol. 10b (v. 1261-1302): } \\
\text { Ci parole l'aucteur comment il ot volenté de ce glaive avoir et } \\
\text { comment il le demanda a Moÿsés et comment Moÿsés li bailla } \\
\text { le glaive et les clés seelees sus condicion qu'il n'en usast sanz } \\
\text { congié. L'aucteur. }\end{array}$ \\
\hline \multirow{2}{*}{$\begin{array}{l}\text { Fol. 9va (v. 1279-1430)*93 : } \\
\text { Comment Moïsés baille a l'auteur } \\
\text { le glaive et les clefz. }\end{array}$} & \\
\hline & $\begin{array}{l}\text { [fol. 10vb (v. 1303-[...]-1430) : } \\
\text { Ci parole l'aucteur comment Raison le conforta et li dist cause } \\
\text { pour quoi il li avoit baillié en tel maniere. }\end{array}$ \\
\hline $\begin{array}{l}\text { Fol. 10va (v. 1431-1464) }{ }^{* 94} \text { : } \\
\text { Comment Moÿsés donna a ses offi- } \\
\text { ciaus char a mengier et sanc a boi- } \\
\text { re. }\end{array}$ & $\begin{array}{l}\text { Fol. 11va (v. 1431-1464) : } \\
\text { Ci devise l'aucteur du disner Moÿsés et comment il se merveil- } \\
\text { la des choses que il vit a ce disner, comment le pain fu mué en } \\
\text { char et le vin en sanc a la table Moÿsés. L'aucteur. }\end{array}$ \\
\hline \multirow[t]{2}{*}{$\begin{array}{l}\text { Fol. 10vb (v. 1465-1518)*96 : } \\
\text { Comment Nature fu esbahie de ce } \\
\text { mengier que Moÿsés avoit donné. }\end{array}$} & $\begin{array}{l}\text { Fol. 11vb (v. 1465-1502) : } \\
\text { Ci parole l'aucteur comment il retorna a Raison pour savoir la } \\
\text { cause de ceste mutacion et comment elle li respondi qu'elle ne } \\
\text { savoit pas la cause. L'aucteur. }\end{array}$ \\
\hline & Fol. 12b (v. 1503-[...]-1638) : \\
\hline \multirow[t]{2}{*}{$\begin{array}{l}\text { Fol. } 11 \mathrm{~b}(\mathrm{v} .1519-1980)^{* 100} \text { : } \\
\text { Comment Nature reprent Grace } \\
\text { Dieu fierement. }\end{array}$} & $\begin{array}{l}\text { Ci parole l'aucteur comment Raison envoia parler Nature a } \\
\text { Grace Dieu et comment Nature et Grace Dieu parloient } \\
\text { ensemble. }\end{array}$ \\
\hline & $\begin{array}{l}\text { Fol. 13b (v. 1639-[...]-1834) : } \\
\text { Ci parole l'aucteur comment Grace Dieu respondi a Nature et } \\
\text { li dist qu'elle estoit mestresse dessus li en tous cas. Grace } \\
\text { respont a Nature. }\end{array}$ \\
\hline
\end{tabular}




\author{
Fol. 9b (v. 1029-1058) : \\ Ci parole l'aucteur conment Grace Dieu le \\ reconforta et dist qu'el pouoit bien estre avec \\ tous.
}

Fol. 9va (v. 1059-[...]-1260) :

$\mathrm{Ci}$ dit l'aucteur conment il vit Raison sermonner au prosne en conmun et devise la signifiance du glaive et des clés et conment il en doivent ouvrer, chascun en son office. L'aucteur parle.

Fol. 10vb (v. 1261-1278) :

Ci parole l'aucteur conment Moÿsés mist en servises les aultres qui la estoient, chascun en son office. Le pelerin [fol. 11a] parle du glaive flamboiant.

Ibid. (v. 1279-1288) :

L'aucteur parle.

Ibid. (v. 1289-[...]-1430) :

L'aucteur parle.

\begin{tabular}{|l} 
\\
Fol. $12 \mathrm{a}^{*}$.
\end{tabular}

Fol. 12b (v. 1431-1442) :

Ci devise l'aucteur du disner Moÿsés et conment il se merveilla des chozes que il vit a ce disner : conment le pain fu muer ${ }^{95}$ en char et le vin en sanc a la table Moÿsés, et fut signe de grant miracle. L'aucteur parle.

Ibid. (v. 1443-1464) :

L'aucteur parle.

Fol. 12va (v. 1464-1467) :

$\mathrm{Ci}$ parole l'aucteur conment il retorna a Raison pour savoir la cause de ceste mutacion et conment elle li respondi qu'elle ne savoit pas la cause. L'aucteur parle.

Ibid. (v. 1468-[...]-1502) * :

Ci dit l'aucteur conment Raison prie ${ }^{97}$ a Moÿsés qu'i lui voulsist enseignier la maniere de ce beau disner et pour quoy il l'avoit fait.

Fol. 12vb (v. 1503-[...]-2346) :

Ci parle l'aucteur conment Raison envoya parler Nature a Grace Dieu et conment Nature et Grace Dieu parlerent ensemble des chozes veues $^{98}$ devant $^{99}$.
Fol. 7vb (v. 1059-1278)* :

Cy dit l'acteur comme il vit Raison sermonner au prone en commun et declaire la signifiance du glaive et des clefz, et comment il en doivent user chascun en son office.
Fol. 9a (v. 1279-1430)* :

Comment, quant le pelerin ot demandé a l'evesque Moÿsés le glaive et les clefz, l'evesque engaigna le glaive et en troucela les clefz et tout lui bailla.

Fol. 9vb (v. 1431-1464)* :

Cy declaire l'acteur du disner Moÿsés et comment il se esmerveilla des choses qu'il vit en ce digner: comment le pain fut mué en char et le vin en sang en la table Moÿsés, et comment Grace de Dieu lui aida a ce faire.

Fol. 10a (v. 1465-1518)* :

Cy raconte le pelerin comment il retourna a Raison pour savoir la cause pour quoi Moÿsés avoit mué le pain en char et le vin en sang, et Raison lui respondit qu'elle ne savoit pas la cause. Et de ce doit estre entendu le sacrement de l'autel.

Fol. 10va (v. 1519-1980)* :

Comment Nature, qui a les mains soubz ses aisselles et les yeulx reluisans en forme d'une vieille, vient parler et tencer a Grace Dieu, qui est en une fenestre de sa tournelle. 
Fol. 14va (v. 1835-[...]-1850) :

Ci parole l'aucteur comment Nature respont et Grace li donne congié de toute sa volenté dire. Nature.

Fol. 14vb (v. 1851-1896) :

Ci dit l'aucteur comment Nature, quant elle ot congié, argüe encore avec Grace Dieu. Nature.

Fol. 15a (v. 1897-2004) :

Ci dit l'aucteur comment Grace respont a Nature contre ce qu'elle a argüé. Grace Dieu.

Fol. 14a (v. 1981-2004) :

Comme Nature s'agenoille aus piez Grace Dieu et li crie merci ${ }^{101}$

Fol. $14 \mathrm{~b} * 102$.

Ibid. (v. 2005-2530)*103 :

Penitance et Charité qui parlent de leur vertus.

Fol. 15vb (v. 2005-[...]-2392) :

Ci parole l'aucteur comment Penitance et Charité vindrent au disner Moÿsés et comment il prescherent l'un ${ }^{104}$ aprés l'autre. L'aucteur.

Fol. 18va (v. 2394-[...]-2458) :

Ci raconte l'aucteur comment Charité prescha aprés et leur dist pour quoi elle estoit venue.

Fol. 19a (v. 2459-[...]-2588) :

Ci raconte l'aucteur comme Charité lut le testament Jhesu

Fol. 17vb (v. 2531-2728)*109

Comment Charité parle de son jouel. Crist devant tous. Charité.

Fol. 20a (v. 2589-2638) :

Ci raconte l'aucteur comment Charité, qui est departerresse du relief, leur deffent que il ne viengnent s'il ne sont en estat si comme il doivent. Charité.

Fol. 20va (v. 2639-2686) :

Ci parole l'aucteur comment il alerent recevoir le relief et comment il passerent par Penitance et par Charité et comment Moÿsés leur donna. Et si parole d'aucuns autres maleurés qui ne passerent pas par ces II dames et comment chascun se contint.

Fol. 20vb (v. 2687-2714) :

Ci parole l'aucteur de la merveilleuse habundance de ce relief. L'aucteur parole.

Fol. 21a (v. 2715-[...]-2812) :

Ci parole l'aucteur comment il ala parler a Grace Dieu et comment elle li devisa la vertu du relief et les nons. L'aucteur.

Fol. 19a (v. 2729-3358)*114

Comment Charité et Sapience firent et cuirent le pain de vie. 


\begin{tabular}{|c|c|}
\hline & $\begin{array}{l}\text { Fol. 12vb (v. 1981-2004)* } \\
\text { Comment Nature, qui est a genouz, cria merci a } \\
\text { Grace Dieu ; et Grace Dieu lui perdonne et deffend } \\
\text { que jamais ne parle contre elle. }\end{array}$ \\
\hline & Fol. 13a (v. 2005-2638)* : \\
\hline $\begin{array}{l}\text { Fol. 19va (v. 2347-[...]-2458) : } \\
\text { Comment Penitance dit auz pelerins et con- } \\
\text { ment elle est chanceliere du relief }{ }^{105} \text { Moÿse }{ }^{106} \text {. }\end{array}$ & $\begin{array}{l}\text { Comment Penitence et Charité ysserent d'une } \\
\text { chambre et vindrent a la table ou Moÿsés et ses } \\
\text { gens dignoient et prescherent l'une aprés l'autre a } \\
\text { la table. Penitence en sa bouche avoit ung balai, en } \\
\text { l'une des mains unez verges verdes et en l'autre ung } \\
\text { maillet. Et Charité tenoit une lettre ouverte qui est } \\
\text { a entendre le Nouveau Testament. Et le disner est }\end{array}$ \\
\hline $\begin{array}{l}\text { Fol. } 20 \text { b (v. } 2459-[\ldots]-2592)^{* 107} \text { : } \\
\text { Si raconte l'aucteur conment Charité lut le } \\
\text { testament Jhesucrist devant tous }{ }^{108} \text {. }\end{array}$ & $\begin{array}{l}\text { entendu le jeudi absolut du soupper de Nostre } \\
\text { Seigneur et ses apostres. }\end{array}$ \\
\hline $\begin{array}{l}\text { Fol. 21va (v. 2593-2638) : } \\
\text { Cy parole l'aucteur conment il alerent rece- } \\
\text { voir le relief et conment il passerent par Peni- } \\
\text { tance et par Charité et conment Moÿse leur } \\
\text { donna }{ }^{110 .}\end{array}$ & \\
\hline Fol. 21vb (v. 2639-2667) : & \multirow{5}{*}{$\begin{array}{l}\text { Fol. 16b (v. 2639-3358)* } \\
\text { Cy est comment les pelerins qui s'acompaignent de } \\
\text { Penitence et de Charité par confession et contricion } \\
\text { vont a la table de Moÿsés et reçoivent du relief de } \\
\text { son digner, c'est assavoir le corps Jhesucrist. }\end{array}$} \\
\hline L'aucteur parle. & \\
\hline $\begin{array}{l}\text { Fol. 22b (v. 2668-2686) : } \\
\text { L'aucteur parle }{ }^{111} \text {. }\end{array}$ & \\
\hline $\begin{array}{l}\text { Fol. 22a (v. 2687-2718) : } \\
\text { Cy parole l'aucteur de la merveilleuse habun- } \\
\text { dance de ce relief. L'aucteur parle }{ }^{112} \text {. }\end{array}$ & \\
\hline $\begin{array}{l}\text { Fol. } 22 \mathrm{~b} \text { (v. 2719-2728) : } \\
\text { Ci devise l'aucteur conment il ala parler a } \\
\text { Grace Dieu et conment elle li devisa la vertu } \\
\text { du relief et les nons. L'aucteur parle }{ }^{113} \text {. }\end{array}$ & \\
\hline $\begin{array}{l}\text { Fol. 22va (v. 2729-[...]-2812) : } \\
\text { Ci devise l'aucteur conment Grace Dieu res- } \\
\text { pont a l'aucteur et conment elle li devisa la } \\
\text { vertu du relief et les nons. }\end{array}$ & \\
\hline
\end{tabular}




\begin{tabular}{|c|c|}
\hline & $\begin{array}{l}\text { Fol. 21vb (v. 2813-[...]-2920) : } \\
\text { Ci parole l'aucteur comment Grace Dieu li aprist en quel ma- } \\
\text { niere ce pain fu batu, molu et formé. Grace. }\end{array}$ \\
\hline & $\begin{array}{l}\text { Fol. 22va (v. 2921-2986) : } \\
\text { Ci parole Grace Dieu comment Nature envoia Aristote argüer } \\
\text { contre Sapience et comment Sapience li respondi. Aristotes. }\end{array}$ \\
\hline & $\begin{array}{l}\text { Fol. 23a (v. 2987-[...]-3252) : } \\
\text { Ci dit l'aucteur comme Sapience respont a Aristote. Sapience. }\end{array}$ \\
\hline & $\begin{array}{l}\text { Fol. 24vb (v. } 3253-[\ldots]-3306) \text { : } \\
\text { Ci parole Sapience et dit la cause pour quoi elle mist ce sou- } \\
\text { verain bien en tel forme et en tel maniere et comment elle est } \\
\text { souveraine mestresse. }\end{array}$ \\
\hline & $\begin{array}{l}\text { Fol. 25b (v. 3307-[...]-3358) : } \\
\text { Ci parole l'aucteur comment il demanda de ce relief a Grace } \\
\text { Dieu et comment elle li dist qu'il li estoit bien necessaire, mes } \\
\text { il li couvenoit avant avoir l'escharpe et le bourdon qu'il avoit } \\
\text { demandé. L'aucteur. }\end{array}$ \\
\hline $\begin{array}{l}\text { Fol. 23a (v. 3359-3664) : } \\
\text { Grace de Dieu qui }{ }^{118} \text { devise la se- } \\
\text { nefiance de l'escherpe }{ }^{119} \text { qui foy est } \\
\text { appelee. }\end{array}$ & $\begin{array}{l}\text { Fol. 25vb (v. 3359-[...]-3432) : } \\
\text { Ci parole l'aucteur comment Grace Dieu le mena la ou ses } \\
\text { joiaux estoient et comment elle li bailla escharpe et bourdon } \\
\text { et si devise les joiaus que il vit illec et la façon d'eus. } \\
\text { L'aucteur. }\end{array}$ \\
\hline & $\begin{array}{l}\text { Fol. 26b (v. 3433-3466) : } \\
\text { Ci devise l'aucteur la façon du bourdon. }\end{array}$ \\
\hline & $\begin{array}{l}\text { Fol. 26va (v. 3467-[...]-3588) : } \\
\text { Ci dit l'aucteur comment Grace Dieu li devise les condicions } \\
\text { et la maniere de ces joiaus. Grace Dieu. }\end{array}$ \\
\hline & $\begin{array}{l}\text { Fol. } 27 \mathrm{~b}(\mathrm{v} .3589-3654) \text { : } \\
\text { Ci li dit Grace Dieu la senefiance du sanc et pour quoi elle } \\
\text { estoit goutee. }\end{array}$ \\
\hline & $\begin{array}{l}\text { Fol. 27vb (v. 3655-3664) : } \\
\text { Comment l'aucteur respont Grace Dieu et prent l'escharpe. }\end{array}$ \\
\hline $\begin{array}{l}\text { Fol. } 25 \text { a (v. } 3665-3748) \text { : } \\
\text { Ci parle de la senefiance du bour- } \\
\text { don, qui est appelés Esperance. }\end{array}$ & $\begin{array}{l}\text { Fol. 27vb (v. 3665-3672) : } \\
\text { Ci dit l'aucteur comment il prist l'escharpe et la mist entor li, } \\
\text { et Grace Dieu li aida a mettre. }\end{array}$ \\
\hline & $\begin{array}{l}\text { Fol. } 28 \text { a (v. } 3673-[\ldots]-3752) \text { : } \\
\text { Ci parole l'aucteur du bourdon, comment Grace Dieu li ensai- } \\
\text { gne quel il est et que il en fera. }\end{array}$ \\
\hline
\end{tabular}




\begin{abstract}
Fol. 23a (v. 2813-[...]-2920) :
Ci parole Grace Dieu en quel maniere ce pain fu batu, molu et formé ${ }^{115}$.

Fol. 24a (v. 2921-[...]-2986) :

Ci parole Grace Dieu conment Nature envoya Aristote arguer contre Sapience et conment Sapience le respondi. Aristote parle ${ }^{116}$
\end{abstract}

Fol. 24va (v. 2987-[...]-3382) :

Ci dit l'aucteur conment Sapience respont a Aristote. Sapience parle ${ }^{117}$.

Fol. 27va (v. 3383-3432) :

L'aucteur parle ${ }^{120}$.

Fol. 27vb (v. 3433-[...]-3588) :

Cy devise l'aucteur la façon du bourdon ${ }^{121}$.

Fol. 29a (v. 3589-3654) :

Ci li dit Grace Dieu la segnefiance du sanc et pour quoy elle estoit goutee.

Fol. 29va (v. 3655-3674) :

Conment l'aucteur respont a Grace Dieu et prent l'escharpe.

Fol. 29vb (v. 3675-[...]-3798) :

$\mathrm{Ci}$ parole l'aucteur du bourdon, conment Grace Dieu li enseigne quel il est et que il en fera.

Fol. 30vb (v. 3799-[...]-3824) :

Ci dit l'aucteur conment Grace Dieu le mena en sa chambre pour choisir les armeures de quoy il vouloit estre armé et conment il li demanda les quelles li seroient bonnez et conment il se devoit armer ${ }^{122}$.
Fol. 20a (v. 3359-3664)* :

Comment Grace Dieu mena le pelerin la ou estoient ses joiaux et comment elle lui baille escherpe et bourdon et lui devise l'escripture et figure des XII sonnectes et des aultres joiaux.
Fol. 21va (v. 3665-3748)* :

Comment Grace Dieu aide le pelerin a mettre l'escherpe qui a XII sonnectes qui signifient les XII articles de la foi ; et le bourdon signifie les X commendemens. 


\begin{tabular}{|c|c|}
\hline Fol. 25va (v. 3749-3812) : & Fol. 28va (v. 3753-[...]-3812) : \\
\hline $\begin{array}{l}\text { Ci parle du bourdon qui n'est mie } \\
\text { ferré. }\end{array}$ & $\begin{array}{l}\text { Ci dit l'aucteur comment Grace Dieu li livra le bourdon et com- } \\
\text { ment il li desplaisoit qu'il n'estoit ferré et comment elle li mou- } \\
\text { stra qu'i li devoit souffire. L'aucteur. }\end{array}$ \\
\hline Fol. 26a (v. 3813-3836)* : & Fol. 29a (v. 3813-[...]-3856) : \\
\hline $\begin{array}{l}\text { Comme Grace Dieu monstra a }{ }^{123} \\
\text { l'aucteur les armeures de Peni- } \\
\text { tance. }\end{array}$ & \multirow{2}{*}{$\begin{array}{l}\text { Ci dit l'aucteur comment Grace Dieu le mena en sa chambre } \\
\text { pour choisir les armeures de quoi il vouloit estre armé et com- } \\
\text { ment il li demanda lesquelles li seroient bones et comment il se } \\
\text { devoit armer. }\end{array}$} \\
\hline \multirow{3}{*}{$\begin{array}{l}\text { Ibid. (v. 3837-3908): } \\
\text { La senefiance du gamboyson qui } \\
\text { Pacience a a non. }\end{array}$} & \\
\hline & Fol. 29b (v. 3857-[...]-3908) : \\
\hline & $\begin{array}{l}\text { Ci dit l'aucteur comment Grace Dieu l'arma et devisa les armeu- } \\
\text { res qu'elle li bailla et comment il ont non. }\end{array}$ \\
\hline \multirow{3}{*}{$\begin{array}{l}\text { Fol. 26va (v. 3909-4054): } \\
\text { La senefiance du haubergon qui } \\
\text { Force a a non. }\end{array}$} & Fol. 29vb (v. 3909-[...]-3998) : \\
\hline & $\begin{array}{l}\text { Ci dit l'aucteur comment il vesti le garnement et comment il } \\
\text { respondi a Grace Dieu qu'il ne le porroit porter et comment } \\
\text { Grace Dieu li respont. L'aucteur. }\end{array}$ \\
\hline & $\begin{array}{l}\text { Fol. 30va (v. 3999-[...]-4054) : } \\
\text { Ci parole l'aucteur comment elle li bailla I haubergon et com- } \\
\text { ment elle li devise et nomme et quel vertu il a. }\end{array}$ \\
\hline \multirow{4}{*}{$\begin{array}{l}\text { Fol. 27va (v. 4055-4344) }{ }^{126} \text { : } \\
\text { C'est la senefiance et les nons }{ }^{127} \\
\text { du hyaume, de la gorgiere, de la } \\
\text { targe, des gantelez et de l'espee. } \\
\text { Ces armes sont de Penitance. }\end{array}$} & Fol. 30vb (v. 4055-[...]-4319) : \\
\hline & $\begin{array}{l}\text { Ci parole l'aucteur comment il prist le haubergon et comment il } \\
\text { li demanda a veoir toutes les armeures de quoi il devoir estre } \\
\text { armé et comment elle li respondi et li monstre. L'aucteur. }\end{array}$ \\
\hline & \multirow{3}{*}{$\begin{array}{l}\text { Fol. 32vb (v. } 4320-[\ldots]-4514) \text { : } \\
\text { Ci raconte l'aucteur comment il s'escuse de prendre l'espee sans } \\
\text { forrel et comment Grace Dieu li baille. Le pelerin parle a Grace } \\
\text { Dieu : }\end{array}$} \\
\hline & \\
\hline \multirow{3}{*}{$\begin{array}{l}\text { Fol. 29b (v. } 4345-4746)^{128} \text { : } \\
\text { La senefiance du fourrel, qui } \\
\text { Humilité a non, et de }{ }^{129} \text { la renge, } \\
\text { qui Perseverance a non, et de la } \\
\text { targe, qui Prudence a non. }\end{array}$} & \\
\hline & $\begin{array}{l}\text { Fol. } 34 \mathrm{~b} \text { (v. } 4515-4572) \text { : } \\
\text { Ci parole l'aucteur comment il se complaint des armes et dit } \\
\text { qu'il le grievent trop. }\end{array}$ \\
\hline & $\begin{array}{l}\text { Fol. 34va (v. 4573-[...]-4746) : } \\
\text { Ci respont Grace Dieu et le blasme de ce qu'il lesse les armes et } \\
\text { comment il en }{ }^{130} \text { peut mal avenir. Grace. }\end{array}$ \\
\hline Fol. 32a (v. 4747-4776)*133 : & Fol. 35vb (v. 4747-[...]-4830) : \\
\hline $\begin{array}{l}\text { Comment l'aucteur desvesti hiau- } \\
\text { me, gorgiere et haubergon. }\end{array}$ & $\begin{array}{l}\text { Ci parole l'aucteur comment il se desarma et comment Grace } \\
\text { Dieu li dit que elle querroit aucun fort homme qui li porteroit } \\
\text { aprés li. }\end{array}$ \\
\hline
\end{tabular}




\begin{tabular}{|c|c|}
\hline & $\begin{array}{l}\text { Fol. 22a (v. } 3749-3812)^{*} \text { : } \\
\text { Comment Grace Dieu bailla le bourdon au pelerin et com- } \\
\text { ment il lui expose de ce qu'il n'est pas ferré au bout. }\end{array}$ \\
\hline \multirow{3}{*}{$\begin{array}{l}\text { Fol. 31a (v. 3825-[...]-3912) : } \\
\text { Ci dit l'aucteur conment Grace Dieu } \\
\text { l'arma et devisa les armeures qu'elle } \\
\text { li bailla et conment il ont non }{ }^{124} \text {. }\end{array}$} & Fol. 22va (v. 3813-3836)* : \\
\hline & $\begin{array}{l}\text { Comment le pelerin fut mené en la chambre de Grace Dieu } \\
\text { et comment Grace Dieu lui monstre ses armes, qui sont tant } \\
\text { belles et sont pendues au long d'une perche. }\end{array}$ \\
\hline & $\begin{array}{l}\text { Fol. 22va (v. 3837-3908)* } \\
\text { Comment Grace Dieu arma le pelerin et lui devise les noms } \\
\text { des armeures, comme du gambeson et de l'enclume a forger } \\
\text { sus. }\end{array}$ \\
\hline $\begin{array}{l}\text { Fol. 31va (v. 3913-[...]-4000): } \\
\text { Ci dit l'aucteur conment il vesti le } \\
\text { garnement et conment il respondi a } \\
\text { Grace Dieu qu'il ne le pourroit } \\
\text { porter et conment Grace Dieu li } \\
\text { respont. } \\
\text { Fol. 31vb*. }\end{array}$ & \multirow[t]{2}{*}{$\begin{array}{l}\text { Fol. 23a (v. 3909-4054)* } \\
\text { Comment le pelerin vestit le hauberjon qui Force a nom et } \\
\text { comme il parle a Grace Dieu. }\end{array}$} \\
\hline \multirow{3}{*}{$\begin{array}{l}\text { Fol. } 32 \mathrm{~b}(\mathrm{v} .4001-[\ldots]-4.514) \text { : } \\
\text { Ci parole l'aucteur conment elle li } \\
\text { bailla un haubergon et conment elle } \\
\text { li devise et nonme, et quel vertu il a. } \\
\text { L'aucteur parle }{ }^{125} \text {. }\end{array}$} & \\
\hline & $\begin{array}{l}\text { Fol. 23vb (v. 4055-4344)* : } \\
\text { Comment le pelerin print le hauberjon et comment il de-- } \\
\text { mande a Grace les noms des armeures dont il doit estre armé, } \\
\text { et elle lui dist : « Le hauberjon Force est de signifiance. Le } \\
\text { heaume signifie Actrempance, la gorgiere Sobrieté, les gan- } \\
\text { telés Continence, l'espee Justice». }\end{array}$ \\
\hline & $\begin{array}{l}\text { Fol. 25va (v. 4345-4514)* } \\
\text { Comment Grace Dieu ceint l'espee au pelerin et lui baille la } \\
\text { targe. Le fourrel de l'espee signifie Humilité, la renge a nom } \\
\text { Perseverence et la targe a nom Prudence. }\end{array}$ \\
\hline Fol. 36va (v. 4515-[...]-4572) : & \multirow{4}{*}{$\begin{array}{l}\text { Fol. } 26 \mathrm{~b} \text { (v. } 4515-4746)^{*} \text { : } \\
\text { Comment le pelerin est armé et comm[ent] il tient son bour- } \\
\text { don et son escherpe et comment il se plaint des armes a Gra- } \\
\text { ce Die[u]. }\end{array}$} \\
\hline $\begin{array}{l}\text { Ci dit l'aucteur conment Grace blas- } \\
\text { me le pelerin de ce qu'i lesse les ar- } \\
\text { mes et conment il en puet mal venir. } \\
\text { Grace Dieu parle. }\end{array}$ & \\
\hline $\begin{array}{l}\text { Fol. } 36 \mathrm{vb} \text { (v. } 4573-[\ldots]-4736) \text { : } \\
\text { Ci respont Grace Dieu et le blame de } \\
\text { ce qu'il lesse les armes et conment il } \\
\text { en puet mal venir }{ }^{131} \text {. }\end{array}$ & \\
\hline \multirow{2}{*}{$\begin{array}{l}\text { Fol. 38a (v. 4737-[...]-4830) : } \\
\text { L'aucteur parle a Grace Dieu, et con- } \\
\text { ment le pelerin se desarme de son ha- } \\
\text { bergon }^{132} \text {. }\end{array}$} & \\
\hline & $\begin{array}{l}\text { Fol. } 27 \mathrm{va}(\mathrm{v} .4747-4776)^{*} \text { : } \\
\text { Comment l'acteur despoulla ses armeures et comment Grace } \\
\text { Dieu le redargue de ce que le pelerin ne la requiert d'avoir } \\
\text { quelque ung qui les li porte. }\end{array}$ \\
\hline
\end{tabular}


Fol. 32b (v. 4777-4814) ${ }^{134}$ :

Comment l'aucteur regrete ses armez.

Fol. 32va (v. 4815-4968)*135 :

Comment Grace Dieu amaine a l'auteur une meschine qui Memoire ot non pour porter ses armes.
Fol. 36va (v. 4831-[...]-4852) :

Ci parole l'aucteur comment Grace Dieu revint a li et comment elle le commença a remponer.

Fol. 36vb (v. 4853-[...]-4944) :

Ci dit l'aucteur comment Grace Dieu li dit qu'il li ameine une chamberiere qui li portera ses armes et de quoi elle sert et le non d'icelle et comment il li baille les armes. Grace Dieu.

Fol. 37b (v. 4945-[...]-4968) :

$\mathrm{Ci}$ dit l'aucteur comment il leverent les armeures et les mistrent sus Memoi-[fol. 37va]-re et coument il ala querre du pain Moÿsés.

Fol. 33va (v. 4969-4982)*138 :

Comment l'aucteur met du pain Moÿsi en s'escherpe et s'en vait.

Ibid. (v. 4983-5044)*140 :

Comment l'aucteur s'en va, et Memoire avec li qui emporte ses armes.

\section{Ibid. (v. 4969-4974) :}

Ci parole l'aucteur comment il ala a Moÿsés querre le pain et comment il le mist en s'escharpe.

Fol. 37vb (v. 4975-[...]-5030) :

Ci dit l'aucteur comment il retorna a Grace Dieu et li pria qu'elle ne le lessast point et comment elle li respont que non fera elle se ce n'est par sa faute et conment elle fu invisible.

Fol. 38a (v. 5031-5066) :

Ci parole l'aucteur comment Grace Dieu li fu invisible et comment il s'en va, li et Memoire.

Fol. 34a (v. 5045-5066) :

Comment l'aucteur met a fin son premier livre exposé.

Fol. 34b (v. 5067-5092) ${ }^{142}$ :

Explicit le livre premier et commence le secont.
Fol. 38b (v. 5067-[...]-5162) :

Ci est la fin du premier livre et le ${ }^{143}$ secont conmence. Ci en ce commencement raconte l'aucteur qu'i encontra si comme il s'en aloit Rude Entendement qui tenoit I espié et li fist grant paour.

Ibid. (v. 5093-5162) :

Deça est ${ }^{144}$ I grant vilain ensourcillié et reboulé, apouyé sus I $\operatorname{gros}^{145}$ baston.

Fol. 34va*146.

Fol. 35a (v. 5163-5210)*148 :

Comment Raison moustre sa commission au vilain qui est apuiéz sus son baston.

Fol. 35b (v. 5211-5666) :

Comment Raison fait lire ${ }^{149}$ sa commission devant le vilain.
Fol. 39a (v. 5163-[...]-5218) :

Ci parole comment Raison parla a Rude Entendement et comment il la respondi et comment il fu confus. Raison. 


\begin{tabular}{|c|c|}
\hline & $\begin{array}{l}\text { Fol. } 27 \mathrm{vb}(\mathrm{v} .4777-4814)^{*} \text { : } \\
\text { Comment l'acteur se desconforte et regrecte ses armes a par } \\
\text { lui. }\end{array}$ \\
\hline & \multirow{3}{*}{$\begin{array}{l}\text { Fol. 28a (v. 4815-4968)* } \\
\text { Comment Grace Dieu amene une chambriere au pelerin } \\
\text { pour porter ses armes, qui a nom Memoire, laquelle n'a nulz } \\
\text { yeulz devant, mais derriere. }\end{array}$} \\
\hline $\begin{array}{l}\text { Fol. 39a (v. 4831-[...]-4952) : } \\
\text { Ci parole l'aucteur conment Grace } \\
\text { Dieu revint parler a li et conment elle } \\
\text { le conmença a remponner }{ }^{136} \text {. }\end{array}$ & \\
\hline \multirow{3}{*}{$\begin{array}{l}\text { Fol. 40a (v. 4953-[...]-5030): } \\
\text { Ci dit l'aucteur conment il leverent } \\
\text { les armeures et les mistrent sus Me- } \\
\text { moire, et conment il ala querre du } \\
\text { pain Moÿse }{ }^{137} \text {. }\end{array}$} & \\
\hline & $\begin{array}{l}\text { Fol. 28vb (v. } 4869-4982)^{*} \text { : } \\
\text { Comment Grace Dieu e[t] le pelerin midrent les armeures } \\
\text { sus Memoire, qui a les yeulz derriere et comment le pelerin } \\
\text { va querir et demander a Moÿsés du relief }{ }^{139} \text { de son digner. }\end{array}$ \\
\hline & $\begin{array}{l}\text { Fol. 29a (v. 4983-5066)* } \\
\text { Comment, quant le pelerin ot eu du relief et qu'il l'ot mis en } \\
\text { son escharpe, comment il retourna a Grace Dieu et Grace } \\
\text { Dieu lui respont; et Memoire, qui est derriere le pelerin, }\end{array}$ \\
\hline \multirow[t]{2}{*}{$\begin{array}{l}\text { Fol. 40va (v. 5031-5092): } \\
\text { Ci parole l'aucteur conment Grace } \\
\text { Dieu li fu invisible et conment il s'en } \\
\text { va, li et Memoire }{ }^{141} \text {. }\end{array}$} & \\
\hline & $\begin{array}{l}\text { Fol. 29va (v. 5067-5092): } \\
\text { Cy s'ensuit le second livre de Pelerinaige humain. Et pre- } \\
\text { mier comment s'en va son chemin le pelerin, pensant et } \\
\text { disant en soi ce qui est aprés. Et Memoire qui l'ensuit qui } \\
\text { porte ses armeures. }\end{array}$ \\
\hline \multirow{3}{*}{$\begin{array}{l}\text { Fol. 41a (v. 5093-[...]-5218) : } \\
\text { Ci fenist le premier livre du Peleri- } \\
\text { nage d'humaine }{ }^{147} \text { vie. [Fol. 41b] Ci } \\
\text { en ce conmencement raconte l'auc- } \\
\text { teur qu'i encontra, si com il s'en aloit, } \\
\text { Rude Entendement qui tenoit un } \\
\text { espié et li fist grant paour, que a } \\
\text { painne que le pelerin ne toumba de- } \\
\text { vant li. L'aucteur parle. }\end{array}$} & $\begin{array}{l}\text { Fol. } 29 \mathrm{vb}(\mathrm{v} .5093-5162)^{*} \text { : } \\
\text { Comment le pelerin rencontre ung villain ensourcillé et } \\
\text { rechigné qui portoit ung baston de cornilier, et parlent } \\
\text { ensemble. }\end{array}$ \\
\hline & $\begin{array}{l}\text { Fol. 30b (v. 5163-5210)* } \\
\text { Comment Raison vient a l'encontre de Rude Entendement, } \\
\text { et le pelerin derrie[re] Raison, et Memoire derriere le pele- } \\
\text { rin, et comment Raison et Rude Entendement parle[nt]. }\end{array}$ \\
\hline & $\begin{array}{l}\text { Fol. 30va (v. 5211-5632)* } \\
\text { Comment Raison lit sa commission devant le villain Rude } \\
\text { Entendement qui tient ung lourd baston en la main. }\end{array}$ \\
\hline
\end{tabular}


Fol. 38a (v. 5667-6198) :

Comment Raison prent l'aucteur $^{150}$ [fol. 38b] par la main devant le vilain.
Fol. 41va (v. 6199-6292) ${ }^{153}$ :

Comment Raison argüe l'aucteur et li fait connoistre son anemi.

Fol. 39va (v. 5219-[...]-5632) :

Ci devise l'aucteur la teneur de la commission Raison et la response du villain.

Fol. 42va (v. 5633-[...]-6176) :

Ci parole l'aucteur comment Raison fist passer le pelerin malgré Rude Entendement [fol. $42 \mathrm{vb}$ ] et comment il se complaint que il ne peut porter ses armeures et elle li ensaigne pour quoi ce est.

Fol. 46va (v. 6177-[...]-6252) :

Ci parole l'aucteur comment Raison l'osta du cors et comment il vit parfait ce que Raison li avoit dit et comme il vit son cors sanz Fol. 46vb] movoir. Raison.

Fol. 47b (v. 6253-[...]-6502) :

L'aucteur demande ci endroit a Raison comment il portast ses armes et que il les portast volentiers. Comment elle li dit quant et comment il les doit porter et comment il entra u cors.

42a (v. 6293-6502) 156

Comment Raison fait connoistre a l'aucteur que son cors est son anemi.

Fol. 43va (v. 6503-6904) :

Comment l'aucteur encontra en son chemin Huiseuse et Labour.

Fol. 49a (v. 6503-6552) :

Ci parole l'aucteur comment il commença son voiage et raconte aucunes des aventures qu'il trouva. 


\begin{abstract}
Fol. 42b (v. 5219-[...]-5666) :
Ci devise l'aucteur la teneur de la conmission Rayson et la response du villain.

Fol. 45va (v. 5667-[...]-6176) :

Ci raconte l'aucteur conment Rayson fist passer ${ }^{151}$ le pelerin malgré Rude Entendement et conment il se conplaint que il ne puet porter ses armeures, et elle li enseygne pour quoy ce est.
\end{abstract}

Fol. $45 \mathrm{vb}^{*}$.

Fol. 50b (v. 6177-[...]-6252) :

Ci parle l'aucteur conment Rayson l'osta du corps et conment y vit parfait ce que Rayson li avoit dit et conment il vit son corps sans mouvoir Rayson ${ }^{152}$

Fol. 51a (v. 6253-[...]-6552) :

L'aucteur demande a Rayson conment il portast ses armes et que il les portast volentiers. Conment elle li dist quant et conment il les doit porter et conment il entra u corps ${ }^{155}$.

\section{$[\ldots]$}

Fol. 32vb (v. 5633-6198)* :

Comment Raison fait passer le pelerin maugré Rude Entendement et comment il se complaint qu'il ne peut porter ses armes.

Fol. 35vb (v. 6199-6292)*154 :

Comment Raison tire contre le pelerin et le abbatit et lui ostit l'esprit du corps pour lui monstrer que son corps estoit son contraire, et comment l'esperit vole en l'air et voit villez et chasteaulz et aultres choses.

Fol. 36b (v. 6293-6502) ${ }^{157}$

Comment, quant l'esprit du pelerin fut retourné dedens son corps, pleure et se plaint a Grace Dieu pour ce qu'il estoit revenu si pesant.

Fol. 37b (v. 6503-6904)* :

Comment, quant l'acteur et pelerin aloit son chemin, vit deux chemins, et ou millieu avoit une longue et grosse haie d'espines qui a a nom Penitence. Et au commencement du chemin dextre se seoit ung natier appellé Occupacion, et est le chemin de paradis. Et au chemin senestre, qui est le chemin de piché, se seoit sur une pierre une damoiselle qui balloit des gans en sa main, appellee Oiseuse.

[...] 


\section{Notes du tableau en annexe II.}

69. Dans les variantes de $\mathrm{BnF} 22$ relevées en note, ont été omises les simples variantes graphiques et des différences ténues dans l'ordre des mots.

70. BnF 22, fol. 1a : frontispice quadripartite occupant la largeur des deux colonnes et les deux tiers supérieurs du feuillet; la première rubrique est en partie effacée par l'usure, notamment le mot umain.

71. Frontispice.

72. Dans Bnf 13, cette première rubrique, qui donne le titre de l'ensemble de l'œuvre, est d'une main différente de toutes les suivantes (écrites, rappelons-le, de la même main que le texte).

73. Ms. libre.

74. Ms. espie. Cette forme, résultant sans doute d'une confusion entre les noms espié et espee, doit être corrigée pour le sens. Le mot glaive est employé à diverses reprises dans le poème pour désigner l'objet en question (PVH1, v. 64, 74, 93).

75. Ms. espie. Voir la note précédente.

76. BnF 22, fol. $2 \mathrm{~b}$ : pas d'enluminure.

77. BnF 22, fol. 2va : Ci dit om.

78. BnF 22, fol. 3a : De la om.

79. BnF 22, fol. 4b : Grace Dieu et l'auteur qui parlent. Pas d'enluminure.

80. BnF 22, fol. 4vb : De l'ofice om.

81. BnF 22, fol. 5a : pas d'enluminure. $\mathrm{Au}$

fol. 5b, une rubrique intermédiaire suivie d'une enluminure, avant le v. 533 : Comment Raison parle a l'official, quiprestre de Dieu est. 82. Ms. de om. Corr. pour le sens. Cf. Bnf 22.

83. Ms. oindres.

84. BnF 22, fol. $7 \mathrm{~b}$ : pas d'enluminure.

85. Ms. ilz.

86. Ms. une.

87. $\mathrm{BnF} 22$, fol. $8 \mathrm{~b}$ : pas d'enluminure.

88. BnF 22, fol. $8 \mathrm{~b}$ : faisoit son office om.

89. $\mathrm{BnF} 22$, fol. $8 \mathrm{~b}$ : aidoit a son office.

90. Ms. ilz.

91. Ms. consancra. Corr. pour le sens.

92. BnF 22, fol. 9a : pas d'enluminure.

93. BnF 22, fol. 10vb : pas d'enluminure.

94. BnF 22, fol. 12a : pas d'enluminure; une seule UR ayant été réservée, le début et la fin sont écrits à la suite des v. 1430 à 1433.

95. Cette forme de participe passé n'a pas été corrigée en tant que graphie inverse liée à l'amuïssement généralisé des consonnes finales au $\mathrm{Xv}^{\mathrm{e}}$ siècle.

96. BnF 22, fol. 12a : pas d'enluminure; fol. $12 \mathrm{~b}$ : esbahie de ce priet [sic]. Une seule UR ayant été réservée pour la rubrique, le dernier mot est copié à la suite du v. 1465.

97. Ms. priet.

98. Ms. veue.

99. Exceptionnellement, la réserve prévue pour cette rubrique ( 8 UR) était excessive. Aussi le copiste écrit-il des lignes de deux ou trois mots seulement, plus brèves que les octosyllabes.

100. BnF 22, fol. 12va : une seule UR ayant été réservée pour la rubrique, le premier mot est copié à la suite du v. 1518.

101. BnF 13 : dans la marge de couture, titre d'attente, d'une encre très pâle et d'un calibre d'écriture très inférieur au reste de la copie.

102. BnF 22, fol. 16a : pas d'enluminure.

103. BnF 22, fol. $16 \mathrm{~b}$ : pas d'enluminure.

104. Ms. l'une.

105. Ms. chanceliere de relief.

106. Contrairement aux précédentes, la rubrique est en grande partie en marge, une seule UR lui ayant été réservée. À partir de là, le phénomène est courant, et la coordination entre la copie du texte et celle des rubriques pose régulièrement problème.

107. L'enluminure, la Passion du Christ, est peinte dans la marge de gouttière, faute de réserve.

108. Une seule UR ayant été prévue, cette rubrique déborde dans la marge.

109. BnF 22, fol. 20b : pas d'enluminure.

110. Rubrique de trois lignes débordant sur la marge de tête, une seule UR ayant été réservée.

111. Rubrique écrite à la suite des v. 2787 et 2788 , faute de réserve.

112. Rubrique écrite dans la marge de queue avec signe d'insertion (croix et piedde-mouche), faute de réserve.

113. Rubrique d'une écriture réduite, serrée sur deux lignes dans la hauteur d'une UR et débordant dans la marge de gouttière, faute de réserve suffisante.

114. BnF 13 : dans la marge de couture, titre d'attente, d'une encre très pâle et d'une écriture très réduite.

115. Rubrique écrite dans l'entrecolonne, faute d'une réserve suffisante. 
116. Rubrique débordant dans l'entrecolonne, une seule UR ayant été réservée.

117. Rubrique écrite dans la marge de gouttière, faute de réserve.

118. BnF 22, fol. 26va : De Grace Dieu qui.

119. BnF 22, fol. 26va : eschape [sic].

120. Rubrique écrite après les v. 3381 et 3382, juste à l'intérieur de la justification, faute de réserve.

121. Rubrique écrite à la suite des v. 3431 et 3432 , à cheval sur la marge de couture, faute de réserve.

122. Rubrique d'une écriture réduite, sur 5 lignes : 3 dans la marge de tête et 2 dans une seule UR de réserve.

123. BnF 22, fol. 30a : Comment G. D. moustre a.

124. Rubrique d'une écriture réduite, serrée sur deux lignes et débordant dans l'entrecolonne, sur la hauteur d'une seule UR de réserve.

125. Rubrique d'une écriture réduite, serrée sur trois lignes débordant un peu de la justification, sur la hauteur de 2 UR de réserve. Le dernier mot est sur une quatrième ligne, hors justification, à droite du v. 4001.

126. Dans la marge de gouttière, titre d'attente, d'une encre très pâle et d'une écriture très réduite.

127. BnF 22, fol. 31vb : et leur non [sic].

128. BnF 22, fol. 34a : enluminure; fol. $35 \mathrm{~b}$, titre intermédiaire avant le v. 4515 : Comment l'aucteur se demente a Grace Dieu de ses armes.

129. BnF 22, fol. 34a : de om.

130. Ms. en répété.

131. Rubrique d'une écriture réduite, serrée sur deux lignes et débordant dans la marge de couture, sur la hauteur d'une seule UR de réserve.

132. Rubrique écrite en partie à droite du v. 4736 , en partie à droite des v. 4739 et 4740 , dans des espaces libres à l'intérieur de la justification, une seule UR ayant été réservée.

133. $\mathrm{BnF} 22$, fol. 37a : pas d'enluminure.

134. BnF 13 : dans la marge de gouttière, titre d'attente (en partie rogné), d'une encre très pâle et d'une écriture très réduite.

135. $\mathrm{BnF} 13$ : dans la marge de gouttière, titre d'attente (en partie rogné), d'une encre très pâle et d'une écriture très réduite. BnF 22, fol. 37va : pas d'enluminure.

136. Rubrique en grande partie écrite à la suite des cinq vers précédents, débordant sur l'entrecolonne, une seule UR ayant été réservée.

137. Rubrique d'une écriture réduite, serrée sur trois lignes, dont la première dans la marge de tête, une seule UR ayant été réservée.

138. BnF 13 : dans la marge de gouttière, à gauche, deux titres d'attente, d'une encre pâle et d'une écriture très réduite. $\mathrm{BnF} 22$, fol. 38vb : pas d'enluminure.

139. Ms. relie. Corr. pour le sens.

140. BnF 13 : dans la marge de gouttière, à gauche, titre d'attente, d'une encre pâle et d'une écriture très réduite. $\mathrm{BnF} 22$, fol. 38vb : pas d'enluminure.

141. Rubrique d'une écriture fine, pour partie à la suite du v. 5030, pour partie serrée sur deux lignes dans une seule UR de réserve.

142. BnF 13 : une ur de blanc; titre à l'encre noire souligné en rouge, de la même main que le texte, suivi d'une autre UR en blanc. $\mathrm{BnF} 22$, fol. 39va : titre à l'encre rouge, non souligné, suivi d'une enluminure.

143. Ms. et le répété.

144. BnF 22, fol. 39vb : Deça est om.

145. BnF 22, fol. 39vb : gros om.

146. BnF 22, fol. 39vb : pas d'enluminure.

147. Ms. du humaine.

148. BnF 22, fol. $40 \mathrm{~b}$ et $40 \mathrm{va}$ : pas d'enluminure.

149. $\mathrm{BnF} 22$, fol. $40 \mathrm{vb}: R$. fist $l$.

150. BnF 13 : dans la marge de couture, à gauche, titre d'attente pour toute cette rubrique, d'une encre pâle et d'une écriture très réduite.

151. Ms. pisser.

152. Rubrique d'une écriture réduite placée dans la marge de gouttière, faute de réserve.

153. BnF 13 : dans la marge de gouttière, à gauche, titre d'attente partiel (en partie rogné), d'une encre pâle et d'une écriture réduite. $\mathrm{BnF} 22$, fol. $48 \mathrm{~b}$ : enluminure.

154. Réserve.

155. Rubrique d'une écriture réduite placée dans l'entrecolonne, faute de réserve.

156. $\mathrm{BnF} 13$ : dans la marge de gouttière, à gauche, titre d'attente partiel (en partie rogné), d'une encre pâle et d'une écriture réduite.

157. Réserve. 


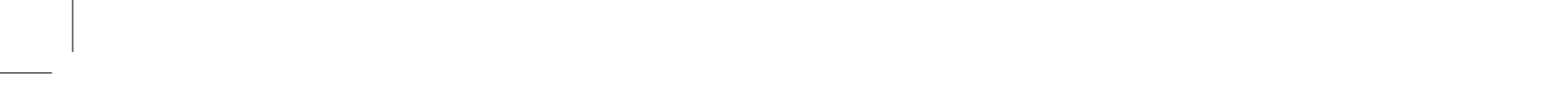

